editus $a b$

\title{
Embrik Strand
}

Pars 67:

August Busck

Stenomidae

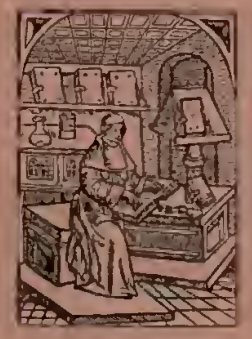

W. Junk

's-Gravenhage 15. I. 1935. 


\section{Lepidopterorum Catalogus}

Pars 1: Ch. Aurivillius, Chrysopolomidac. 1911. 4 p.

2: А. Pagenstecher, Callidulidae. 1911. $14 \mathrm{p}$.

3: A. Pagensteeher, Libytheidae. 1911. $12 \mathrm{p}$.

4: H. Wagner ef R. Plitzier, Hepialidae. 1911. 26 p.

5: E. Strond, Noctuidae: Agaristinae. 1912. 82 p.

6: E. Meyriek, Adeliclae, Micropterggidae, Gracilariadac. 1912. 68 p.

7: H. Zerny, Sintomidae. 1912. 179 p.

8: L. B. Pront, Geometridat: Brephinae, Oenoehrominae. 1912. 94 p.

9: P. Mubille, Hesperidae: Subf. Pyrrlopyginae. - MeDunnough, Megathynidae. 1912. $22 \mathrm{p}$.

10: E. Meyrick, Tortricidae. 1912. $86 \mathrm{p}$.

11: H. Eltringhan et K. Jordan, Nymphalidae: Subfam. Acraeinac. 1913. $65 \mathrm{p}$.

12, 18, 21, 23: H. Wagner, Sphingidae, $1913-1919.420$ p.

13: E. Meyricli, Carposinidae. Heliodinidae, Glyphipterygidac. 1913. $53 \mathrm{p}$.

34: L. B. Prout, Geometridae Subfum. Hemithemne. 1913. $192 \mathrm{p}$.

15: K. W. ron Dalla Torre, Castnidae: Subfam. Castuinac, Neoeastniinae, Pemphigostolinae. 1913. 28 p.

16: E. Straud, Bralmaeidne. - H. G. Wyar et E. Strand: Megalopygidae, Dalceridac, Epipyropidae. 1913. 35 p.

17: E. Meyriek, Pterophoridae, Orneodidae. 1913. 44 p.

19: E. Meyrick, Hyponomeutidae, Phtellidae, Amphitheridae. 1914. $64 \mathrm{p}$.

20: K. W. ron Dalla Torre, Thyrididae. 1914. 55 p.

22, 24, 26: E. Strand, Aretiidac [exel. Pericopinae]. 1919-1922. 900 p. - 45: F. Bryk, Perieopinae. 1931. 57 p.

25: K. W. von Dalla Torre, Cymatophoridae. 1921. 38 p.

27: F. Bryk, Baroniidae, Teinopalpidae, Parnassiidae. 1923. 247 p.

28: K. W. von Jalla Torre et E. Straud, Lepidarbelidae. - E. Strand, Heterogynididac. 1923. $14 \mathrm{p}$.

29: K. W. ron Halla 'Torre, Cossidac. 1923.63 p.

30: K. W. ron Walla 'Torre, Epiplemidae, Iranidac, 1924. 57 p.

31: K. W. von 1)alla 'Torre et E. Strand, Aegeridae. 1925. 282 p.

32: R. van Eeeke, Cochlidionidae (Limacodidae). 1925. 81 p.

33: H. Hurgefl, Zygaenidac I: Generis Zygaena palaearetica pars. 1926. $91 \mathrm{p}$.

34: K, W. von Dalla 'Torre et E. Strand, Psyehidae. 1929. 215 p. 


\section{Lenidopteroprum Calalogus}

editus $a b$

Embrik Strand

Pars 67:

August Busck

Stenomidae

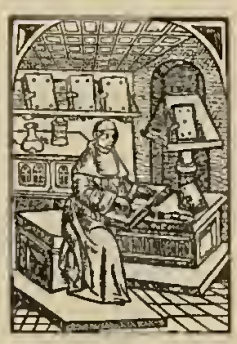

W. Junk

's-Gravenhage

1934. 


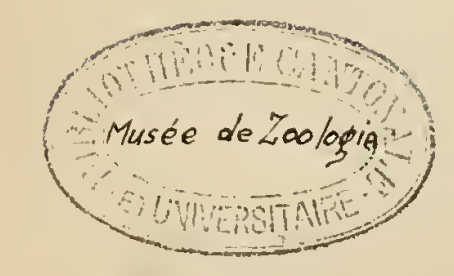




\section{Fam. Stenomidae}

\section{Auctore Augus! Busck}

Ste nomidae Meyrick (in part) Trans. Roy. Soc. S. Austral., 30 , p. 50 (1906); id., Trans. Ent. Soc. London, p. 28, (1909); id., Trans. Ent. Soc. London, p. 706 (1912); id., Anal. Museo. Nac. Hist. Nat. Buenos Aires, 36, p. 378, (1931).

S te no matidae Walsinghum, Proc. U. S. Nat. Mus., 33, p. 214 (1907).

Ste nomida e Walsingham, Bio. Centr.-Amer., 4, p. 153190 (1912-1913).

S te n o mida e Strand, (part.) Arch. f. Naturgesch., 97, A. 2, p. 94 (1913).

Ste nomidae Barnes and Busck, Contr. Nat. Hist. Lep. N. Amer., 4, p. 236 (1920).

Cryptolechiida e Meyrick, (part.) Trans. Ent. Soc. London, p. 124 (1883).

Xyloryctida e Heyrick, (part.) Exot. Micr., 1-4 (19251934).

$X y$ lorictidae Forbes, Cornell Agr. Exp. Sta. Mem., 68, p. 250 (1923).

C ryptophasida e Fletcher, (part.) Mem. Dept. Agr. India, 11 (1929).

Stenomides Meyrick, Ann. Nat. Mus. Wien, 44, p. 233 (1930).

Stenominae Janse, The Moths of South Africa, 1, p. 61 (1932).

\section{Genus Sefiostoma Zeller}

Zeller, Verh. Zool.-bot. Ges. Wien, 25, p. 324, t. 9, f. 42 (1875). Dyar, Can. Ent., 32, p. 37, 41 (1900). - Fernald, Can. En't., 32, p. 238, 244 (1900). - Meyrick, Lep. Cat., 13, p. 23 (1913). Busck, Can. Ent., 53, p. 279 (1921); id., Proc. Ent. Soc. Wash., 27, p. 48, t. 4, f. 1-4 (1925). - (Type: xanthobasis Zeller.)

callidora Meyrick, Trans. Ent. Soc. London, p. 36 Bolivia (1909).

chlorobasis Zeller, Verh. Zoo.-bot. Ges. Wien, 25, Brazil, 25, p. 325 (1875).

euscma Walsingham, Bio. Centr.-Amer., 4, p. 303, Guatemala t. 9, f. 12 (1914).

fernaldella Riley, Proc. Ent. Soc. Wash., 1, p. 155 California (1889).

flaviceps Felder, Reise Nov', t. 138; f. 1 (1875). Amazon 
hacmitheia Felder, Reise Nov., t. 140, f. 13 (1875). Colombia leuconympha Meyrick, Exot. Micr., 2, p. 477 (1921). Brazil xanthobasis Zeller, Verh. Zoo.-bot. Ges. Wien, 25, Eastern U. S. p. 324 (1875). - Busck, Proc. Ent. Soc. 8 Wash., 27 , p. 48 , t. 4 , f. $1-2$ (1925).

\section{Genus Pefasanthes Meyrick}

Meyrick, Exxot. Micr., 3, p. 158 (1925). - (Type: leucactis Meyrick.) leucactis Meyrick, Exot. Micr., 3, p. 158 (1925). Ecuador 1

\section{Genus Menesfomorpha Walsingham}

Walsingham, Proc. U. S. Nat. Mus., 33, p. 214 (1907). - Barnes and Busck, Contr. Lep. N. Amer., 4, p. 237 (1920). - (Type:oblongata Walsingham.)

oblongata Walsingham, Proc. U. S. Nat. Mus., 33, Arizona p. 215 (1907). - Barnes and Busck, Contr. 1 Lep. N. Amer., 4, p. 238 , t. 30 , f. 8 (1920).

\section{Genus Promenesfa Busck}

Busck, Proc. U. S. Nat. Mus., 47, p. 21 (1914). - Meyrick, Exot. Micr., 1, p. 411 (1915). - (Type: lithochroma Busck.)

autampyx Meyrick, Exot. Micr., 3, p. 161 (1925). Peru

callichlora Meyrick, Exot. Micr., 1, p. 411 (1915). B. Guiana

clrysampyx Meyrick, Exot. Micr., 1, p. 411 (1915); B. Guiana, id., Exot. Micr., 3, p. 161.(1925). Brazil,

citroscia Meyrick, Exot. Micr., 4, p. 46 (1931). Brazil

haplodoxa Meyrick, Exot. Micr., 3, p. 162 (1925). Brazil

isotrocha Meyrick, Exot. Micr., 2, p. 209 (1918). Argentina

leucomias Meyrick, Exot. Micr., 3, p. 162 (1925); Brazil id., Ann. Nat. Mus. Wien, 44, p. 237 (1930).

lithochroma Busck, Proc. U. S. Nat. Mus., 47, p. 22 Panama, (1914). - Meyrick, Ann. Nat. Mus. Wien, Brazil 44 , p. 237 (1930).

marginella Busck, Proc. U. S. Nat. Mus., 47, p. 22 Panama 9 (1914). 


\section{Genus Menesta Clemens}

Clemens, Proc. Acad. Nat. Sci. Phila., 12, p. 213 (1860). - Walsingham, Bio. Centr.-Amer., 4, p. 104 (1911). - Barnes and Busck, Contr. Lep. N. Amer., 4, p. 237 (1920). - (Type: tortriciformella Clemens.)

Hyale Chambers (type: tortriciformella Clemens), Cinn. Quart. Journ. Sci., 2, p. 242 (1880).

albacilincella Chambers, Can. Ent., 10, p. 77 (1878). N. America, - Busck, Proc. U. S. Nat. Mus., 25, p. 903 Mexico (1903).

albiciliella Walsingham, . Bio. Centr.Amer., 4, p. 104 (1911).

al baciliella Braun, Ent. News, 26, p. 160 (1915).

cinereocervina Walsingham, Proc. Zoo. Soc. London, W. Indies p. 519 (1891); id., Proc. Zool. Soc. London, p. 85 (1897).

mclanella Murtfeldt, Ins. Life, 2, p. 304 (1890). - Missouri - Busck, Proc. U. S. Nat. Mus., 25, p. 903 (1903).

tortriciformella Clemens, Proc. Acad. Nat. Sci. Eastern U.S. Phila., 12, p. 213 (1860). - Clemens, Stainton, Tin. N. Amer., p. 151 (1872). $\leftarrow$ Chambers, Bull. U. S. Geol. Surv., 4, p. 157 (1878). - Walsingham, Proc. Zoo. Soc. London, p. 319 (1881); id., Ins. Life, 2, p. 154 (1889). - Busck, Proc. U. S. Nat. Mus., 25, p. 903 (1903).

lit urella Walker, Cat. Lep. Het. Brit. Mus., 29, p. 591 (1864). - Walsingham, Proc. Zoo. Soc. London, p. 319 (1881); id., Ins. Life, 2, p. 154 (1889).

c oryliella Chambers, Cinn. Quart. Journ. Sci., 2, p. 242 (1875). - Walsingham, Ins. 4 Life, 2, p. 154 (1889).

\section{Genus Falculina Zeller}

Zeller, Hor. Soc. Ent. Ross., 13, p. 387, t. 5, f. 135 (1877):Meyrick, Exot. Micr., 1, p. 482 (1916). - (Type: ochricostata Zeller.)

antitypa Meyrick, Exot. Micr., 2, p. 58 (1916). $\quad$ F. Guiana caustopis Meyrick, Exot. Micr., 4, p. 288 (1932). Brazil Iepidota Meyrick, Exot. Micr., 1, p. 482 (1916). F. Guiana ochricostata Zeller, Hor. Soc. Ent. Rosis,, 13, p. S. America 387 (1877). - Meyrick, Exot. Micr., 1, p. 


\section{Genus Rhynchophyllis Meyrick}

Meyrick, Exot. Micr., 4, p. 289 (1932). - (Type: categorica Meyrick.)

categorica Meyrick, Exot. Micr., 4, p. 289 (1932). Brazil

\section{Genus Thioscelis Meyrick}

Meyrick, Trans. Ent. Soc. London, p. 29 (1909). - (Type: directrix Meyrick.)

directrix M e y i ck, Trans. Ent. Soc. London, p. Peru, 30 (1909). - Walsingham, Bio. Cent.-Amer., Costa Rica 4, p. 153 (1912).

geranomorpha Meyrick, Exot. Micr., 4, p. 287 Brazil 2 (1932).

\section{Genus Rhodanassa Meyrick}

Meyrick, Exot. Micr., 1, p. 480 (1915). - (Type: callimnestra Meyrick.)

callimnestra Meyrick, Exot. Micr., 1, p. 480 (1915). F. Guiana

io Busck, Proc. U. S. Nat. Mus., 40, p. 213 (1911). F. Guiana - Meyrick, Exot. Micr., 1, p. 480 (1915).

\section{Genus Anapafris Meyrick}

Meyrick, Exot. Micr., 4, p. 287 (1932). - (Type: chersopsamma Meyrick.)

chersopsamma Meyrick, Exot. Micr., 4, p. 287 Panama 1 (1932).

\section{Genus Mysaromima Meyrick}

Meyrick, Exot. Micr., 3, p. 227 (1926). - (Type: liquescens Meyrick.)

liquescens Meyrick, Exot. Micr., 3, p. 227 (1926). Colombia 1

\section{Genus Baeonoma Meyrick}

Meyrick, Exot. Micr., 1, p. 507 (1916). - (Type: mastodes Meyrick.) 
euphanes Meyrick, Exot. Micr., 1, p. 507 (1916). F. Guiana

helolypa Meyrick, Exot. Micr., 11, p. 508 (1916); Guianas, id., Ann. Nat. Mus. Wien, 44, p. 256 (1930). Brazil

holarga Meyrick, Exot. Micr., 1, p. 509 (1916); F. Guiana id., Exot. Micr., 3, p. 160 (1925).

holophaea Meyrick, Exot. Micr., 1, p. 541 (1916). F. Guiana

infamis Meyrick, Exot. Micr., 3, p. 160 (1925). Brazil

leucodelta Meyrick, Exot. Micr., 1, p. 184 (1914); B. Guiana id., Exot. Micr., 1, p. 507, (1916); id., Exot. Micr., 3, p. 160 (1925).

maslodes Meyrick, Exot. Micr., 1, p. 508 (1916); S. America id., Ann. Nat. Mus. Wien, 44, p. 256 (1930); id. Mitteil. Münch. Ent. Gésell., 21, p. 37 (1931).

orlhozoni Meyrick, Exot. Micr., 1, p. 508 (1916). F. Guiana

suavis Meyrick, Exot. Micr., 1, p. 541 (1916). F. Guiana 9

\section{Genus Psephomeres Meyrick}

Meyrick, Exot. Micr., 1, p. 505 (1916). - (Type: leptogramma Meyrick.)

Ieplogramma Meyrick, Exot. Micr., 1, p. 506 (1916). F. Guiana

\section{Genus Dinofropa Meyrick}

Meyrick, Exot. Micr., 1, p. 506 (1916). - (Type: ochrocrossa Meyrick.).

ochrocrossa Meyrick, Exot. Micr., 1, p. 506 (1916). F. Guiana 1

\section{Genus Hyalopseusfis Meyrick}

Meyrick, Exot. Micr., 3, p. 157 (1925). - (Type: vitrea Meyrick.)

vilrea Meyrick, Exot. Micr., 3, p. 158 (1925). Peru 1

\section{Genus Peleopoda Zeller}

Zeller, Hor. Soc. Ent. Ross., 13, p. 385, t. 5, f. 134 (1877). Meyrick, Trans. Ent. Soc. London, p. 124 (1883). - Busck, Proc. U. S. Nat. Mus., 40, p. 208 (1911). - Walsingham, Bio. Centr.Amer., 4, p. 131 (1912). - Meyrick, Exot. Micr., 3, p. 161, (1925). (Type: lobitarsis Zeller.) 
lobitarsis Zeller, Hor. Soc. Ent. Ross., 13, p. 386 Panama (1877). - Walsingham, Bio. Centr.-Amer., 4, p. 131 (1912). - Meyrick, Gen. Ins., 180 p. 188 (1922); id., Exot. Micr., 4, p. 14 (1930)

semonrossa Meyrick, Exot. Micr., 4, p. 13 (1930). Bolivia 2

\section{Genus Chlamydaslis Meyrick}

Meyrick, Exot. Micr., 1, p. 481 (1916). - (Type: lactis Busck.)

Agriophara Meyrick (nec Rosenstock), Trans. Ent. Soc. London, 1913, p. 182.

Ptilogenes Meyrick (type: acronitis Busck), Exot. Micr., 2 , p. 60 (1917).

acronilis Busck, Proc. U. S. Nat. Mus., 40, p. 213 F. Guiana (1911). - Meyrick, Trans. Ent. Soc. London, p. 182 (1913); id., Exot. Micr., 1, p. 485, (1916); id., Exot. Micr., 2, p. 60 (1917).

anamochln Meyrick, Trans. Ent. Soc. London, 76, Colombia p. $517(1929)$.

ancalota Meyrick, Exot. Micr., 1, p. 486 (1916). F. Guiana

apicalis Busck, Proc. U. S. Nat. Mus., 40, p. 215 F.Guiana (1911).

apoclina Meyrick, Trans. Ent. Soc. London, 76, p. Colombia 516 (1929).

argocymba Meyrick, Exot. Micr., 3, p. 232 (1926). Brazil

batrachopis Meyrick, Trans. Ent. Soc. London, p. Peru, 182 (1913); id., Ann. Nat. Mus. Wien, 44, Brazil p. $257(1930)$.

bifida Meyrick, Exot. Micr., 1, p. 541 (1916); id., Guianas, Ann. Nat. Mus. Wien, 44, p. 257 (1930). Brazil

byssophanes Meyrick, Exot. Micr., 3, p. 230 (1926). Peru,

Brazil

caccata Meyrick, Exot. Micr., 1, p. 487 (1916). F. Guiana

chionoptila Meyrick, Exot. Micr., 3, p. 229 (1926). Brazil

chionosphena Moyrick, Exot. Micr., 4, p. 45 (1931). F. Guiana

chloroloba Meyrick, Exot. Micr., 1, p. 439 (1915); Peru,

id., Ann. Nat. Mus. Wien, 44, p. 258 (1930). Guianas,

Brazil

chlorosticta Meyrick, Trans. Ent. Soc. London, p. Peru, 184 (1913); id., Ann. Nat. Mus. Wien, 44, Guianas, p. $257(1930)$.

Brazil

complexa Meyrick, Exot. Micr., 1, p. 542 (1916). F.Guiana

crateroptila Moyrick, Exot. Micr., 2, p. 211 (1918). F.Guiana 
curviliniella Busck, Proc. U. S. Nat. Mus., 47, p. Panama 37 (1914).

cysliodes Meyrick, Exot. Micr., 1, p. 489 (1916). F. Guiana

deflexa Meyrick, Exot. Micr., 1, p. 489 (1916); id., Guianas, Ann. Nat. Mus. Wien, 44, p. 258 (1930). Brazil

deflua Meyrick, Exot. Micr., 2, p. 210 (1918); id., Guianas, Ann. Nat. Mus. Wien, 44, p. 258 (1930). Brazil

diorista Meyrick, Trans. Ent. Soc. London, 76, p. Colombia 517 (1929).

discors Meyrick, Trans. Ent. Soc. London, p. 182 Peru (1913).

disticha Meyrick, Exot. Micr., 1, p. 488 (1916); id., F. Guiana, Trans. Ent. Soc. London, 76, p. 517 (1929). Colombia

dryosphaera Meyrick, Exot. Micr., 3, p. 231 (1926). Brazil

elaeostolaMeyrick, Ann. Nat. Mus. Wien, 44, p. Brazil 257 , t. 1 , f. 27 (1930).

epoplirysta Meyrick, Trans. Ent. Soc. London, p. 33 Peru (1909); id., Trans. Ent. Soc. London, p. 182 (1913).

forcipata Meyrick, Trans. Ent. Soc. London, p. 183 Colombia (1913).

fragmentella Dognin, Ann. Soc. Ent. Belg., 52, p. B. Guiana 417 (1913).

funicularis Meyrick, Exot. Micr., 3, p. 228 (1926). F.Guiana

galeomorpha Moyrick, Exot. Micr., 4, p. 44 (1931). Brazil

gemina Zeller, Linn. Entom., 10, p. 163, t. 1, f. 8 Colombia (1855). - Walker, Cat. Lep. Het. Brit. Mus., 29, p. 711 (1864). - Meyrick, Trans. Ent. Soc. London, p. 182 (1913).

hesmarcha Meyrick, Ann. Nat. Mus. Wien, 44, p. Brazil 258 , t. 2, f. 22 (1931).

ichthyodes Meyrick, Exot. Micr., 3, p. 231 (1926). Peru

illita Meyrick, Exot. Micr., 3, p. 232 (1926); id., Peru, Trans. Ent. Soc. London, 76, p. 518 (1929). Colombia

inscitum Busck, Proc. U. S. Nat. Mus., 40, p. 219 F. Guiana (1911).

inscita Meyrick, Trans. Ent. Soc. London, p. 182 (1913).

inspectrix Meyrick, Exot. Micr., 1, p. 542 (1916); id., Guianas, Ann. Nat. Mus. Wien, 44; p. 258 (1930). Brazil

lactis Busck, Proc. U. S. Nat. Mus., 40, p. 216 Guianas, (1911). - Moyrick, Exot. Micr., 1, p. 481 Brazil (1916); id., Aun. Nat. Mus. Wien, 44, p. $256(1930)$.

leplobelisea Meyrick, Trans. Ent. Soc. London, 76, Colombia p. $518(1929)$.

leucoplasta Meyrick, Exot. Micr., 3, p. 232 (1926). Brazil, 
Icucoptila Meyrick, Exot. Micr., 2, p. 210 (1918). F. Guiana

lichenias Meyrick, Exot. Micr., 1, p. 486 (1916); Guianas, id., Trans. Ent. Soc. London, 76, p. 516, Colombia, (1929); id., Ann. Nat. Mus. Wien, 44, p. Brazil 257 (1930).

lithograpta Meyrick, Trans. Ent. Soc. London, p. 184 Peru (1913).

melanometra Meyrick, Exot. Micr., 3, p. 229 (1926). Colombia

melanonea Meyrick, Exot. Micr., 1, p. 408 (1915); S. America id., Ann. Nat. Mus. Wien, 44, p. 258 (1930).

mendoron Busck, Proc. U. S. Nat. Mus., 40, p. 214 F. Guiana, (1911). - Walsingham, Bio. Centr.-Amer., Panama 4 , p. 171 , t. 6 , f. 16 (1913). - Meyrick,

Trans. Ent. Soc. London, p. 182 (1913).

metacymba Meyrick, Exot. Micr., 1, p. 489 (1916). F.Guiana

metacystis Meyrick, Exot. Micr., 2, p. 211 (1918). F. Guiana

metamochla Meyrick, Exot. Micr., 4, p. 45 (1931), Brazil

mochlopa Meyrick, Exot. Mier., 1, p. 409 (1915). B. Guiana

monastra Meyrick, Trans. Ent. Soc. London, p. 33 Peru (1909); id., Trans. Ent. Soc. London, p. 182 (1913).

morbida Zeller, Hor. Soc. Ent. Rnss., 13, p. 277, Poru t. 3, f. 77 (1877). - Meyrick, Trans. Ent. Soc. London, p. 182 (1913).

mysticopis Meyrick, Exot. Micr., 3, p. 233 (1926). Peru

nestes Busck, Proc. U. S. Nat. Mus., 40, p. 214 F. Guiana (1911). - Meyrick, Exot. Micr., ], p. 485 (1916).

niphochlacna Meyrick, Exot. Micr., 3, p. 233 (1926). Peru

noverea Meyrick, Exot. Micr., 1, p. 484 (1916). F.Guiana

obnupta Meyrick, Exot. Micr., 1, p. 483 (1916). F. Guiana

ommatopa Meyrick, Exot. Micr., 3, p. 230 (1926). Colombia,

Bolivia

ophiopa Meyrick, Exot. Micr., 1, p. 484 (1916). F. Guiana

orion Busck, Ins. Insc. Mens., 8, p. 90 (1920). Guatemala

oxyplaca Meyrick, Trans. Ent. Soc. London, 76, p. Colombia 518 (1929).

paradromis Meyrick, Exot. Micr., 1, p. 408 (1915). Colombia

perducta Meyrick, Exot. Micr., 1, p. 484 (1916). F. Guiana

phytoptera Busck, Proc. U. S. Nat. Mus., 47, p. Panama,

44 (1914).

platyspora Meyrick, Exot. Micr., 4, p. 305 (1932). Brazil 
plocogramma Meyrick, Exot. Micr., 1, p. 407 (1915); Guianas, id., Ann. Nat. Mus. Wien, 44, p. 258 (1930). Colombia, Brazil

poliopa Meyrick, Exot. Micr., 1, p. 485 (1916). Colombia

ponderata Meyrick, Exot. Micr., 1, p. 488, 543 Guianas, (1916); id., Ann. Nat. Mus. Wien, 44, p. Brazil 258 (1930).

praenubila Meyrick, Exot. Micr., 3, p. 231 (1926). Brazil

prasoleuea Meyrick, Exot. Micr., 1, p. 483 (1916). F. Guiana

prudentula Meyrick, Exot. Micr., 3, p. 232 (1926). Peru

ptilopa Meyrick, 'Trans. Ent. Soc. London, p. 183 Colombia (1913); id., Exot. Micr., 1, p. 485 (1916).

rhomaeopa Meyrick, Exot. Micr., 4, p. 43 (1931). Brazil,

rufispinis Meyrick, Exot. Micr., 4, p. 305 (1932). Colombia

seutellata Meyrick, Exot. Micr., 1, p. 487 (1916); S. America, id., Exot. Mier., 3, p. 230, (1926); id., Ann. Costa Rica Nat. Mus., Wien, 44, p. 257 (1930).

hemichlora Meyrick, Exot. Micr., 1, p. 487 (1916); id., Exot. Micr., 3, p. 230 (1926).

smodieopa Meyrick, Exot. Micr., 1, p. 409 (1915); Brazil id., Ann. Nat. Mus. Wien, 44, p. 257 (1930). Peru

stagnieolor Meyrick, Exot. Micr., 3, p. 229 (1926); Brazil id., Ann. Nat. Mus. Wien, 44, p. 257 (1930).

steloglypla Meyrick, Exot. Micr., 4, p. 44 (1931). F. Guiana

strabonla Meyrick, Ann. Nat. Mus. Wien, 44, p. Brazil 256 , t. 1 , f. 26 (1931).

synedra Meyrick, Exot. Micr., 1, p. 485 (1916). Paraguay

trastlees Busck, Proc. U. S. Nat. Mus., 40, p. 215 F.Guiana (1911). - Meyrick, Ann. Nat. Mus. Wien, 44 , p. $258(1930)$.

a phrogenes Meyrick, Exot. Micr., 1, p. 407 (1915); id., Ann. Nat. Mus. Wien, 44, p. $258(1930)$.

trltypa Meyrick, Trans. Ent. Soc. London, p. 32 Peru (1909); id., Trans. Ent. Soc. London, p. 182 (1913).

Irizeuela Meyrick, Ann. Nat. Mus. Wien, 44, p. Brazil 258 , t. 1 , f. 28 (1930).

truneatula Meyrick, Trans. Ent. Soc. London, p. 185 Venezuela (1913).

ungulifera Meyrick, Trans. Ent. Soc. London, 76, p. Colombia 517 (1929).

vividella Busck, Proc. U. .S Nat. Mus., 47, p. 43 Panama (1914).

xylinaspis Meyrick, Exot. Micr., 1, p. 407 (1915). Peru 86 


\section{Genus Cerconafa Meyrick}

Meyrick, Exot. Micr., 1, p. 385 (1915). - (Type: tridesma Meyrick.)

anonella Sepp, Surinam Vlinders, 3, p. 297, t. 137

S. America (1830). - Bondar, Bolet. Lab. Path. Veg. Bahia, p. 80 (1925). - Meyrick, Ann. Nat. Mus. Wien, 44, p. $249^{\prime}(1930)$.

ha mon Busck, Proc. U. S. Nat. Mus., 40, p. 223 (1911). - Meyrick, Ann. Nat. Mus. Wien, 44, p. 249 (1930).

brachyplaca Meyrick, Exot. Micr., 3, p. 228 (1926). Brazil,

F. Guiana

capnosphaera Meyrick, Exot. Micr., 1, p. 516 (1916). Tr. Guiana

carbonifer Busck, Proc. U. S. Nat. Mus., 47, p. 48 Panama, (1914). - Meyrick, Exot. Micr., 3, p. 228 Costa Rica (1926).

F. Guiana

palliat a Meyrick (nec Walsingham), Exot. Micr., 3, p. 228 (1926).

cora Busck, Proc. U. S. Nat. Mus., 47, p. 53 (1914). I'anama

cbenocista Meyrick, Exot. Micr., 3, p. 433 (1928). F. Guiana

Pusigera Meyrick, Exot. Micr., 1, p. 476 (1915); id., Guianas, Ann. Nat. Mus. Wien, 44, p. 243 (1930). Brazil

impressella Walker, Cat. Lep. Het. Brit. Mus., 29, Brazil, p. 720 (1864). - Meyrick, Ann. Nat. Mus. Peru, Wien, 44, p. 256 (1930).

pras o le uc a Meyrick, Exot. Micr., 1, p. 483 (1916); id., Ann. Nat. Mus. Wien, 44, p. $256(1930)$.

languescens Meyrick, Exot. Micr., 1, p. 458 (1915); Guianas, id., Ann. Nat. MIus. Wien, 44, p. 251 (1930). Brazil

minna Busck, Proc. U. S. Nat. Mus., 47, p. 52 Panama, (1914). - Mcyrick, Exot. Micr., 3, p. 192 Guianas, (1925); id., Ann. Nat. MLus. Wien, 44, p. Bolivia, 243 (1930).

orthridia Meyrick, Exot. Micr., 1, p. 520

Brazil

(1916); id., Exot. Micr., 3, p. 192 (1925);

id., Ann. Nat. Mus. Wien, 44, p. 213 (1930).

nimbosa Zeller, Hor. Soc. Ent. Ross., 13, p. 273 Peru, (1877). - Mcyrick, Exot. Mier., 3, p. 192 Guianas $(1925)$.

v a $n$ is Busck, Proc. U. S. Nat. Mus., 40, p. 221 (1911). - Meyrick, Exot., 1, p. 519 (1916); id., Exot. Micr., 3, p. 192 (1925).

bythochroa Meyrick, Exot. Micr., 1, p. 385 (1915); id., Exot. Micr., 1, p. 519, 1916;

Exot. Micr., 3, p. 192 (1925).

palliata Walsingham, Bio. Centr.-Amer., 4, p. 181, Guatemala t. 6, f. 24 (1913). - Meyrick, Exot. Micr., 3 , p. 228 (1926).

ptilosema Meyrick, Exot. Micr., 2, p. 201 (1918). F. Guiana 
recurvclla Walker, Cat. Lep. Hct. Brit. Mus., 29, p. Brazil, 712 (1864). - Meyrick, Exot. Micr., 3, p. Guianas, 192 (1925); id., Ann. Nat. Mus. Wien, 44, Colombia p. 241 (1930).

$p s e u d a c m a$ Meyrick, Exot. Micr., 2, p. 203 (1918); id., Exot. Micr., 3, p. 192 (1925); id., Ann. Nat. Mus. Wien, 44, p. 241 (1930). salutaris Butler, Cistula Entom., 2, p. 188 (1882). - Amazon, - Meyrick, Ann. Nat. Mus. Wien, 44, p. Brazil, 242 (1930).

Guianas

mar on $i$ Busck, Proc. U. S. Nat Mus., 40, p.

220 (1911). - Meyrick, Ann. Nat. Mus. Wien, 44, p. $242(1930)$.

tridesma Meyrick, Exot. Micr., 1, p. 386 (1915). 16

\section{Genus Paraspastis Meyrick}

Meyrick, Exot. Micr., 1, p. 479 (1915). - (Type: circographa Meyrick.).

circographa Meyrick, Exot. Micr., 1, p. 480 (1915); B.Guiana 1

id., Ann. Nat. Mus. Wien, 44, p. 237 (1930).

\section{Genus Gonioferma Walsingham}

Walsingham, Proc. Zoo. Soc. London, p. 101 (1897). - Busck, Proc: U. S. Nat. Mus., 40, p. 224 (1911). - Walsingham, Bio. Contr.Amer., 4, p. 187 (1913). - (Type: burmanniana Stoll.)

alsiosum Walsingham, Bio. Centr.-Amer., 4, p. 189, Panama t. 6 , f. $33(1913)$

anna Busck, Proc. U. S. Nat. Mus., 40, p. 224 Guianas, (1911). - Meyrick, Ann. Nat. Mus. Wien, Brazil 44, p. 245 (1930).

burmanniana Stoll, Cram., Pap. Exot., 4, p. 164, Brazil t. 372 , f. $H$ (1782). - Walsingham, Bio. Centr.-Amer., 4, p. 188 (1913).

tortricell $a$ Walker, Cat. Lep. Het. Brit. Mus., 29, p. 723 (1864). - Zeller, Hor. Soc. Ent. Ross., 13, p. 264 (1877). - Walsingham, Bio. Centr.-Amer., 4, p. 188 (1913).

collybista Meyrick, Exot. Micr., 1, p. 384 (1915); Peru id., Exot. Micr., 1, p. 520 (1916).

conchita Busck, Ins. Insc. Mens., 8, p. 93 (1920). Guatemala

descitum Walsingham, Bio. Centr.-Amer., 4, p. 188, Panama t. 6 , f. $31(1913)$.

emma Busck, Proc. U. S. Nat. Mus., 40, p. 226 F.Guiana (1911).

gerda Busck, Proc. U. S. Nat. Mus., 47, p. 52 Panama (1914).

hectorea Meyrick, Exot. Micr., 1, p. 384 (1915). Peru,

F. Guiana

Inga Busck, Proc. U. S. Nat. Mus., 40, p. 225 (1911). F. Guiana

lysalges Walsingham, Bio. Centr.-Amer., 4, p. 190, Panama t. 6 , f. 35 (1913). 
melema Walsingham, Bio. Centr.-Amer., 4, p. 189, Panama t. 6, f. 34 (1913).

paeatum Walsingham, Bio. Centr.-Amer., 4, p. 188 Guatemala (1913).

parvella Fabricius, Ent. Syst., 3, p. 343 (1794). - W. Indies Walsingham, Proc. Zoo. Soc. London, p. 101 (1897).

pauperatella Walker, Cat. Lep. Het. Brit. Mus., 29, F. Guiana p. 721 (1864). - Walsingham, Biol. Centr.Amer., 4, p. 170 , t. 6, f. 13 (1913). Meyrick, Exot. Micr., 3, p. 192 (1925); id., Ann. Nat. Mus. Wien, 44, p. 245 (1930).

diatriba Walsingham, Biol. Centr.-Amer., 4 , p. 171 , t. 6, f. 15 (1913). - Meyrick, Exot. Micr., 3, p. 192 (1925); id., Ann. Nat. Mus. Wien, 44, p. 245 (1930).

linte a ta Meyrick, Exot. Micr., 1, p. 525 (1916); id., Exot. Micr., 3, p. 192 (1925); id., Ann. Nat. Mus. Wien, 44, p. 245 (1930). advo c a ta Meyrick, Exot. Micr., 1, p. 525 (1916); id., Exot. Micr., 3, p. 192 (1925); id., Ann. Nat. Mus. Wien, 44, p. 245 (1930).

a $n$ it a Busck, Ins. Insc. Mens., 8, p. 93 (1920). - Meyrick, Exot. Micr., 3, p. 192 (1925); id., Ann. Nat. Mus. Wien, 44, p. 245 (1930).

stella Busck, Proc. U. S. Nat. Mus., 40, p. 225 F. Guiana 1911).

symposias Meyrick, Exot. Micr., 1, p. 385 (1915). 17

\section{Genus Phelofropa Meyrick}

Meyrick, Exot. Micr., 1, p. 411 (1915). - Type: oenodes Meyrick.) conversa Meyrick, Exot. Micr., 2, p. 614 (1922). F. Guiana oenodes Meyrick, Exot. Micr., 1, p. 411 (1915). B. Guiana 2

\section{Genus Energia Walsingham}

Walsingham, Biol. Centr.-Amer., 4, p. 113 (1912). - (Type: subversa Walsingham.)

inopina Walsingham, Bio. Centr.-Amer., 4, p. 114, Panama t. 4 , f. 3 (1912).

subversa Walsingham, Biol. Centr.-Amer., 4, p. 113 Mexico 2 (1912)

\section{Genus Pomphocrila Meyrick}

Meyrick, Ann. Nat. Mus. Wien, 44, p. 238 (1930). - (Type: obsordescens Meyrick.)

obsordescens Meyrick, Ann. Nat. Mus. Wien, 44, p. Brazil 1 238 , t. 1 , f. $8(1930)$. 


\section{Genus Mofhonica Walsingham}

Walsingham, Biol. Centr.-Amer., 4, p. 153 (1912). - Forbes, NewYork York Acad. Sci. Surv. Porto Rico, 12, p. 130 (1930). - Busck, Entom. Amer., 13, p. 163 (1934). - (Type: periapta Walsingham).

perlapta Walsingham, Bio. Centr.-Amer., 4, p. 153, Costa Rica t. 5, f. 20 (1912). - Forbcs, New York Acad. Sci. Surv. Porto Rico, 12, p. 130 1 (1930).

\section{Genus Cafarafa Walsingham}

Walsingham, Biol. Centr.-Amer., 4, p. 154 (1912). - Busck, Proc. U. S. Nat. Mus., 47, ps 35 (1914). - (Type: lepisma Walsingham.)

lapllella Busck, Proc. U. S. Nat. Mus., 47, p. 36 Panama (1914).

lepisma Walsingham, Biol. Centr.-Amer., 4, p. 154 Panama (1912).

obnubila Busck, Proc. U. S. Nat. Mus., 47, p. 36 Panama (1914).

ocellata Busck, Proc. U. S. Nat. Mus., 47, p. 37 Panama (1914).

stenota Walsingham, Biol. Centr.-Amer., 4, p. 155 Guatemala 5 (1912).

\section{Genus Zetesima Walsingham}

Walsingham, Biol. Centr.-Amer., 4, p. 157 (1912). - (Type: lasia Walsingham).

lasla Walsingham, Biol. Centr.-Amer., 4, p. 157, t. 5, Panama f. 25 (1912).

portentosa Busck, Proc. U. S. Nat. Mus., 47, p. Panama 39 (1914).

theobromae Busck, Ins. Insc. Mens., 8, p. 88 (1920). D. Guiana 3

\section{Genus Thyrsomnesfis Meyrick}

Meyrick, Trans. Ent. Soc. London, 76, p. 514 (1929). - Type: ceramoxantha Meyrick.)

ceramoxantha Meyrick, Trans. Ent. Soc. London, 76, Colombia 1 p. 514 (1929).

\section{Genus Eumiturga Meyrick}

Meyrick, Exot. Micr., 3, p. 177 (1925). - (Type: flocculosa Meyrick.) 
eommutata Meyrick, Exot. Micr., 3, p. 233 (1926). Brazil

floceulosa Meyrick, Exot. Micr., 3, p. 178 (1925); Brazil id., Ann. Nat. Mus. Wien, 44, p. 237 (1930).

promotella Zeller, Hor. Soc. Ent. Ross., 13, p. 296, Panama t. 3, f. 84 (1877). - Walsingham, Biol. Centr-Amer., 4, p. 170 (1913). - Mey3 rick, Exot. Micr., 3, p. 233 (1926).

\section{Genus Neophylarcha Meyrick}

Meyrick, Exot. Micr., 3, p. 240 (1926). - (Type: helicosema Meyrick.)

helieosema Meyrick, Exot. Micr., 3, p. 240 (1926). B. Guiana 1

F. Guiana

\section{Genus Timocratica Meyrick}

Meyrick, Trans. Ent. Soc. London, p. 706 (1912). - (Type: isographa Meyrick.)

Lychnocrates Meyrick (type: leucocapna Meyrick), Exot. Micr., 3, p. 226 (1926).

albella Zeller, Isis, 29, p. 196 (1839); id., Linn. Guianas Entom., 9, p. 377 (1854). - Walker, Cat.

Lep. Het. Brit. Mus., 29, p. 713 (1864).

anelaea Meyrick, Exot. Micr., 4, p. 305 (1932). 'Brazil

argonais Meyrick, Exot. Micr., 3, p. 224 (1925). Brazil

elaudescens Meyrick, Exot. Micr., 3, p. 177 (1925). Brazil

eompletclla Walker, Cat. Lep. Het. Brit. Mus., Brazil, 29, p. 718 (1864). - TValsingham, Biol. Panama, Centr.-Amer., 4, p. 184 , t. 6, f. 28 (1913). Colombia

crassa Meyrick, Exot. Micr., 3, p. 177 (1925). Brazil

effluxa Meyrick, Exot. Micr., 4, p. 19 (1930). Bolivia

fraternella Busck, Proc. Ent. Soc. Wash., 12, p. Costa Rica 80 (1910). - Walsingham, Biol. Centr.Amer., 4, p. 179 (1913).

grandaeva Zeller, Linn. Entom., 9, p. 381 (1854). - Brazil - Walker, Cat. Lop. Het. Brit. Mus., 29, p. 714 (1864).

grandis Perty, Delect. Anim. Art., p. 163, t. 32, f. Brazil 12 (1834). - Zeller, Linn. Entom., 9, p. 378 (1854). - Walker, Cat. Lep. Het. Brit. Mus., 29, p. 713 (1864). - Felder, Reise Nov., t. 139 , f. 56 (1875). - Strand, Entom. Rundsch., 28, p. 152 (1910); id., Lep. Niepelt. [I], p. 58 (1914). 
isarga Meyrick, Exot. Micr. 3, p. 224 (1925).

Bolivia

isographa Meyrick, Trans. Ent. Soc. London, p. 707 Venezuela (1912); id., Exot. Micr., 3, p. 176 (1925).

leucocapna Meyrick, Exot. Mier., 3, p. 227 (1926). Colombia

leucorcctis Meyrick, Exot. Micr., 3, p. 223 (1925). Brazil

Ioxotoma Busck, Proc. Ent. Soc. Wash., 11, p. 212 Mexico (1909). - Walsingham, Biol. Centr.-Amer., 4, p. 179 (1913).

macroleuca Meyrick, Exot. Micr., 4, p. 304 (1932). Bolivia

major Busck, Proc. U. S. Nat. Mus., 40, p. 212 Peru (1911). - Meyrick, Trans. Ent. Soc. London, p. 707 (1912).

malurescens Meyrick, Exot. Micr., 3, p. 223, (1925). F. Guiana

megaleuca Meyrick, Trans. Ent. Soc. London, p. 711 Colombia (1912); id., Exot. Micr., 3, p. 224 (1925).

monolonia Strand, Entom. Rundsch., 28, p. 151 Ecuador (1910); id., Lep. Niepelt. [I], p. 58, t. 11, f. 18 (1914).

palpalis Zeller, Hor. Soc. Ent. Ross., 13, p. 275 Brazil (1877). - Meyrick, Exot. Micr., 3, p. 239 (1926).

a u $x$ o le u c a Meyrick, Exot. Micr., 3, p. 223 (1925); id., Exot. Micr., 3, p. 239 (1926).

philomela Meyrick, Exot. Micr., 3, p. 224 (1925). Peru

pompeiana Meyrick, Exot. Micr., 3, p. 176 (1925). Peru

sexmaculata Dognin, Ann. Soc. Ent. Belg., 48, p. Ecuador 133 (1904).

staudingerana Maassen in Stübel, Reisen Südamer. Colombia Lep., p. 171 , t. 9 , f. 29 (1890).

stomatocosma Meyrick, 'Exot. Micr., 4, p. 304 Brazil (1932).

tristrigata Zeller, Linn. Entom., 9, p. 382, t. 3, f. Brazil, 21 (1854). - Walker, Cat. Lep. Het. Brit. Guianas Mus., 29, p. 714 (1864). - Meyrick, Trans. Ent. Soc. London, p. 707 (1912). - Strand, Entom. Rundschau, 28, p. 152 (1910); id., Lep. Niepelt., [I], p. 58 (1914).

a $p h$ a nodes $m$ a Meyrick, Exot. Micr., 11, p. 478 (1915); id., Exot. Micr., 1, p. 536 27 (1916).

\section{Genus Loxofoma Zeller}

Zeller, Linn. Entom., 9, pp. 354, 383 (1854). - Strand, Archiv f. Naturg., 1913, A. 2, p. 95 (part.). — (Type: elegans Zellcr.)

elegans Zeller, Linn. Entom., 9, p. 385, t. 3, f. S. America 22-23 (1854). - Walker, Cat. Lep. Het.

Brit. Mus., 29, p. 772 (1864). - Meyrick,

Exot. Micr., 1, p. 509 (1916); id., Ann.

Nat. Mus. Wien, 44, p. 237 (1930).

Lepidopterorum Catalogus 67. 
rhadanthes Meyrick, Exot. Micr., 1, p. 382 (1915); id., Exot. Micr., 1, p. 509 (1916).

liniella Busck, Proc. Ent. Soc. Wash., 12, p. 80 (1910). - Walsingham, Biol. Centr.-Amer., 4, p. 179 (1913).

seminigrescens Meyrick, Exot. Micr., 4, p. 288 Brazil 3 (1932).

\section{Genus Diastoma Möschler}

Möschler, Verh. Zool.-bot. Ges. Wicn, 31. p. 439 (1881); id., Verh. Zool.-bot. Ges. Wien, 32, p. 361 (1882). - Walsingham, Proc. Zool. Soc. London, 1892, p. 524; id., Proc. Zool. Soc. London, 1897, p. 100. - Strand, Archiv f. Naturg., 1913, A. 2, p. 95 (part.). (Type: nubilella Möschler.)

nubilella Möschler, Verh. Zool.-bot. Ges. Wien, 31, B. Guiana p. 440, t. 18 , f. 48 (1881); id., l. c., 32, p. 361 (1882).

squamosa Walsingham, Proc. Zool. Soc. London, p. W. Indies 524 (1892); id., Proc. Zool. Soc. London, p. 2 100 (1897).

\section{Genus Antaeofricha Zeller}

Zeller, Linn. Entom., 9, p. 390 (1854); id., Hor. Soc. Ent. Ross., 13, p. 258 (1877). - Walsingham, Trans. Ent. Soc. London, p. 254 (1881). - Walsingham and Durrant, Merton Rules, p. 12 (1896). - Walsingham, Proc. Zool. Soc. London, p. 98 (1897). - Meyrick, Trans. Ent. Soc. London, p. 30 (1909). - Walsingham, Bio. Centr.Amer., 4, p. 158 (1912). - Strand, Archiv f. Naturg., 1913, A. 2, p. 95. - (Type: [walchiana Zeller (nec Stoll)] = griseana Fabricius.)

Mesoptycha Zeller (type: nictitans Zeller), Linn. Entom., 9, pp. 355, 387 (1854); id., Hor. Soc. Ent. Ross., 13, p. 258 (1877). - Walsingham, Trans. Ent. Soc. London, p. 254 (1881); id., Biol. Centr.-Amer., 4, p. 158 (1912). Strand, Archiv f. Naturg., 1913, A., 2, p. 95.

Brachiloma Clemens (type: unipunctella Clemens), Proc. Ent. Soc. Phila., 2, p. 126 (1863). - Stainton, Tin. N. Amer., p. 232 (1872). - Chambers, Bull. U. S. Geol. Sury., 3, p. 122 (1877). - Busck, Proc. Ent. Soc. Wash., 5, p. 214 (1903); id., Proc. Ent. Soc. Wash., 10, p. 111 (1908). - Walsingham, Biol. Centr-Amer., 4, p. 158 (1912). - Strand, Archiv f. Naturg., 1913, A. 2, p. 95.

Harpalyce Chambers (type: tortricella Chambers = unipunctella Olemens), Can. Ent., 6, p. 234 (1874); id., Bull. U. S. Geol. Surv., 3, p. 122 (1877); id., Bull. U. S. Geol. Surv., 4, p. 150 (1878). - Walsingham, Biol. Centr.-Amer., 4, p. 158 (1912).

I de Chambers (type: tortricella Chambers = unipunctella Clemens), Journ. Oinn. Soc. Nat. Hist., 2, p. 180 (1880). Strand, Archiv f. Naturg., 1913, A. 2, p. 95. 
A edemoses Walsingham (typo: haesitans Walsingham), Biol. Centr.-Amer., 4, p. 154 (1912). - Heinrich, U. S. Journ. Agr. Res., 20, p. 816 (1921).

Athleta Walsingham (type: trisecta Walsingham), Biol. Centr.-Amer., 4, p. 155 (1912). - Busck, Proc. U. S. Nat. Mus., 47 , p. 38 (1914).

Prasolithitis Meyrick, (type: virens Meyrick), Trans.

Ent. Soc. London, p. 707 (1912).

Aphanoxena Meyrick, (type pellocoma Meyrick), Exot.

Micr., 1, p. 386, (1915); id., Exot. Micr., 3, p. 169 (1925).

acrobapta Meyrick, Exot. Micr., 4, p. 434 (1933). Argentina

acrograpta Meyrick, Exot. Micr., 1, p. 387 (1915); Brazil,

id., Ann. Nat. Mus. Wien, 44, p. 234 (1930). Guianas

acronephela Meyrick, Exot. Micr., 1, p. 392 (1915). B. Guiana

addon Busck, Proc. U. .S Nat. Mus, 40, p. 221 Guianas,

(1911). - Meyrick, Ann. Nat, Mus. Wien, Brazil

44, p. 237 (1930).

cicadella Sepp (praeoce.), Surinam Vlinlers, 3, p. 243, t. 110 (1830).

adjunctella Walker, Cat. Lep. Het. Brit. Mus., 29, Brazil,

p. 726 (1864). - Mevrick, Ann. Nat. Hist. Guianas Mus. Wion, 44, p. 235 (1930).

additella Walker, Cat. Lep. Het. Brit.

Mus., 29, p. 727 (1864). - Meyrick, Ann.

Nat. Mus. Wien, 44, p. 235 (1930).

abs conditella Walker, Cat. Lop. Het.

Brit. Mus., 29, p. 727 (1864). - Meyrick,

Ann. Nat. Mus. Wien, 44, p. 235 (1930).

aequabilis Meyrick, Exot. Micr., 1, p. 513 (1916). F. Guiana

aglypta Meyrick, Exot. Micr., 3, p. 174 (1925); id., Guianas, Ann. Nat. Mus. Wien, 44, p. 237 (1930). Brazil

albifrons Zeller, Hor. Soc. Ent. Ross., 13, p. 323, Brazil

t. 4, f. 100 (1877). - Meyrick, Exot. Micr., 3 , p. 557 (1930)

albovenosa Zeller, Hor. Soc. Ent. Ross., 13, p. 321, Peru t. 4 , f. 99 (187i).

amicula Zeller, Hor. Soc. Ent. Ross., 13, p. 317, Panama t. 4, f. 96 (1877). - Walsingham, Biol. Contr.-Amer., 4, p. 172 (1913).

ampherista Meyrick, Exot. Micr., 3, p. 163 (1925). Bolivia,

Brazil

amphilyta Meyrick, Exot. Mier., 1, p. 503 (1916); Guianas, id., Ann. Nat. Mus. Wien, 44, p. 237 (1930). Brazil

amphizyga Meyrick, Ann. Nat. Mus. Wicn, 44, p. Brazil 234 , t. 2 , f. $12(1930)$.

anaclintris Meyrick, Exot. Micr., 1, p. 499 (1916); id., Ann. Nat. Mus. Wien, 44, p. 234 (1930).

annixa Meyrick, Exot. Micr., 2, p. 198 (1918).

S. America

Brazil

aporodes Meyrick, Exot. Micr., 1, p. 400 (1915); S. America id., Ann. Nat. Mus. Wien, 44, p. 237 (1930); id., Mitteil. Münch. Ent. Gesell., 21, p. 37 (1931). 
arachniotis Meyrick, Ann. Nat. Mus. Wien, 44, p. Brazil 233 , t. 1 , f. 5 (1930).

arystis Meyrick, Exot. Micr., 1, p. 402 (1915). B. Guiana

assecta Zeller, Hor. Soc. Ent. Ross., 13, p. 313, t. 3, Peru f. 94 (1877).

astynoma Meyrick, Exot. Micr., 1, p. 388 (1915). B. Guiana

axena Meyrick, Exot. Micr., 1, p. 501 (1916). F. Guiana

balanocentra Meyrick, Exot. Micr., 1, p. 387 (1915). B. Guiana

ballista Meyrick, Exot. Micr., 1, p. 516 (1916). F. Guiana

basilaris Busck, Proc. U. S. Nat. Mus., 47, p. 45 Panama (1914).

basimacula Möschlcr, Verh. Zool.-bot. Ges. Wien, B. Guiana 31, p. 439 , t. 18 , f. 47 (1881).

biarcuata Meyrick, Exot. Micr., 3, p. 238 (1926). Colombia

bicolor Zeller, Isis, p. 195, 1839; Linn. Entom., 9, p. S. America 373 (1854). - Walker, Oat. Lep. Het. Brit. Mus., 29, p. 713 (1864).

basalis Zeller, Linn. Entom., 9, p. 398 (1854). - Walker, Cat. Lep. Het. Brit. Mus., 29, p. 773 (1864). - Meyrick, Exot. Micr., 1, p. 496 (1916); id., Ann. Nat. Mus. Wien, 44, p. 235 (1930).

herilis Felder, Reise Nov., 2, t. 138, f. 66 (1875). - Meyrick, Ann. Nat. Mus. Wien, 44 , p. 235 (1930).

binubila Zeller, Linn. Entom., 9, p. 396, t. 3, f. 31 Brazil $(1854)$. - Walker, Cat. Lep. Het. Brit. Mus., 29 , p. 773 (1864).

incisure lla Walker, Cat. Lep. Het. Brit. Mus., 29, p. 735 (1864).

bipupillata Meyrick, Exot. Micr., 4, p. 19 (1930). Brazil

brachysaris Meyrick, Exot. Micr., 1, p. 504 (1916). F. Guiana

brochota Meyrick, Exot. Mic1., 1, p. 396 (1915). Peru

camarina Meyrick, Exot. Micr., 1, p. 401 (1915). B. Guiana

campylodes Meyrick, Exot. Micr., 1, p. 494 (1916). F. Guiana

cantharitis Meyrick, Exot. Micr., 1, p. 490 (1916); S. America id., Ann. Nat. Mus. Wien, 44, p. 235 (1930).

caprimulga Walsingham, Biol. Centr.-Amer., 4, p. Mexico 165 , t. 5 , f. 33 (1912).

capsulta Meyrick, Exot. Micr., 2, p. 199 (1918). F. Guiana

carabophanes Meyrick, Exot. Micr., 4, p. 289 (1932). Colombia

carphitis Meyrick, Trans. Ent. Soc. London, p, 710 Brazil (1912).

cathagnista Meyrick, Exot. Micr., 3, p. 165 (1925. Brazil

catharactis Meyrick, Exot. Micr., 4, p. 22 (1930). Brazil 
cedroxyla Meyrick, Exot. Micr., 4, p. 23 (1930). Brazil celidotis Meyrick, Exot. Micr., 3, p. 169 (1925). Peru

cenotes Walsingham, Biol. Centr.-Amer., 4, p. 156, W. Indies, t. 5, f. 23 (1912). Guatemala

ceratistes Walsingham, Biol. Centr.-Amer., 4, p. Mexico 159 (1912).

chalastis Meyrick, Exot. Micr., 1, p. 413 (1915). B.Guiana

chelobathra Meyrick, Exot. MFicr., 1, p. 498 (1916); Guianas, id., Ann. Nat. Mus. Wien, 44, p. 236 (1930). Brazil,

Bolivia

christocoma Meyrick, Exot. Micr., 1, p. 398 (1915). Peru

cicadella Sepp, Surinam Vlinders, 2, p. 183, t. 80 Guianas (1830).

clcopatra Meyrick, Exot. Micr., 3, p. 166 (1925). Brazil

clivosa Meyrick, Exot. Micr., 2, p. 199 (1918). F. Guiana

compsographa Meyrick, Exot. Micr., 1, p. 491 F.Guiana (1916).

confixella Walker, Cat. Lep. Het. Brit. Mus., 29, Brazil p. 731 (1864).

congelala Meyrick, Exot. Micr., 3, p. 236 (1926). Peru

copromima Meyrick, Exot. Micr., 4, p. 22 (1930). F. Guiana

coriodes Meyrick, Exot. Micr., 1, p. 397 (1915). B. Guiana

corvigera Meyrick, Exot. Micr., 1, p. 390 (1915). B. Guiana

corvula Meyrick, Trans. Ent. Soc. London, p. 710 Colombia (1912).

cosmoterma IEyrick, Exot. Micr., 4, p. 19 (1930). Brazil

costatella Walker, Cat. Lep. Het. Brit. Mus., 29, Brazil p. 737 (1864). - Meyrick, Ann. Nat. Mus. Wien, 44 , p. 237 (1930).

cryreopis Meyrick, Exot. Micr., 3, p. 167 (1925). Mexico

cyclobasis Meyrick, Exot. Micr., 4, p. 23 (1930). Brazil

cyenomorpha Meyrick, Exot. Micr., 3, p. 169 (1925); Brazil

id., Ann. Nat. Mus. Wien, 44, p. 236 (1930).

cynopis Meyrick, Exot. Micr., 1, p. 434 (1915).

B. Guiana,

cyprodeta Meyrick, Exot. Micr., 3, p. 556 (1930). Brazil

decorosella Busck, Proc. Ent. Soc. Wash., 10, p. N. America 111 (1908).

decorase ila Barnes and Busck, Contr. Lep.

N. Amer., 4, p. 238, t. 29 , f. 5 (1920).

de co reli a Barnes and Busck, Contr. Lep.

N. Amer., 4, p. 256 (1920). 
dcltopis Meyrick, Exot. Micr., 1, p. 390 (1915); id., Guianas, Ann. Nat. Mus. Wien, 44, p. 236 (1930). Brazil

demotica Walsingham, Biol. Centr.-Amer., 4, p. 159 Mexico, (1912). Guatemala

deridens Meyrick, Exot. Micr., 3, p. 162 (1925). Bolivia

diffracta Meyrick, Exot. Micr., 1, p. 500 (1916). F. Guiana

diplarcha Meyrick, Exot. Micr., 1, p. 403 (1915). B. Guiana

diplophaen Meyrick, Exot. Micr., 1, p. 494 (1916). F. Guiana

discalis Busck, Proc. U. S. Nat. Mus., 47, p. 46 Panama (1914).

discolor Walsingham, Biol. Centr.-Amcr., 4, p. 164 Mexico, (1912).

Guatemala.

dissimilis Kearfott, Ent. News, 22, p. 126 (1911). Brazil

dynastis Meyrick, Exot. Micr., 1, p. 398 (1915). Peru

emollita Meyrick, Exot. Micr., 3, p. 234 (1926). Colombia

encyclia Meyrick, Exot. Micr., 1, p. 403 (1915). Colombia

enodata Meyrick, Exot. Micr., 1, p. 493 (1916). F. Guiana

epignampta Meyrick, Exot. Micr., 1, p. 395 (1915). Peru

episimbla Meyrick, Exot. Micr., 1, p. 389 (1915); S. America id., Ann. Nat. Mus. Wien, 44, p. 237 (1930).

crgates Walsingham, Biol. Centr.-Amer., 4, p. 185, Mexico t. $6, f .30$ (1913).

eucoma Meyrick, Exot. Micr., 3, p. 168 (1925). Brazil

euthrinca Meyrick, Exot. Micr., 1, p. 399 (1915). Colombia

excisa Meyrick, Exot. Micr., 1, p. 496, (1916); id., Guianas, Ann. Nat. Mus. Wien, 44, p. 235 (1930). Brazil

extenta Busck, Ins. Insc. Mens., 8, p. 90 (1920). Guatemala

exusta Meyrick, Exot. Micr., 1, p. 492 (1916); id., F. Guiana, Ann. Nat. Mus. Wien, 44, p. 233 (1930). Brazil

fasciatum Busck, Proc. U. S. Nat. Mus., 40, p. F. Guiana 217 (1911).

tascicularis Zeller, Iinn. Entom., 9, p. 393, t. 3, S. America, f. $32-33(1854)$. - Walsingham, Biol. C. America Centr.-Amer., 4, p. 172, t. 6, f. 12 (1913). - Meyrick, Exot. Micr., 1, p. 509 (1916); id., Ann. Nat. Mus. Wien, 44, p. 234 (1930).

gunni Busck, Proc. U. S. Nat. Mus., 40, p. 218 (1911).

leucogramma Meyrick, Exot. Micr., 1, p. 404 (1915); id., Exot. Micr., 1, p. 509 (1916). 
Iractilinea Walsingham, Biol. Centr.-Amer., 4, p. Mexico 166 (1912).

Irontalis Zeller, Linn. Entom., 10, p. 159, t. 1, f. 7 O. America, (1855). - Walker, Cat. Lcp. Het. Brit. Mus., Mexico 29, p. 710 (1864). - Walsingham, Biol. Centr.-Amer., 4, p. 163 (1912). - Meyrick, Exot. Micr., 4, p. 290 (1932).

fulla Meyrick, Exot. Mf́icr., 3, p. 234 (1926).

Colombia

Iumifica Walsingham, Biol. Centr.-Amcr., 4, p. 162, Mexico t. 5 , f. 31 (1912).

fumipennis Busck, Proc. U. S. Nat. Mus., 47, p. Panama, 45 (1914). - Meyrick, Exot. Micr., 4, p. Costa Rica, 292 (1932).

p y tho n a e a Meyrick, Exot. Micr., 1, p. 491 (1916); id., Exot. Micr., 4, p. 292 (1932).

furcala Walsingham, Ins. Life, 2, p. 153 (1889). - Arizona Barnes and Busck, Contr. Lep. N. Amer., 4, p. 238 , t. 30 , f. $3(1920)$.

generatrix Meyrick, Exot. Micr., 3, p. 239 (1926). Brazil

glaclata Meyrick, Trans. Ent. Soc. London, p. 30 Bolivia (1909).

glycerostoma Meyrick, Exot. Micr., 1, p. 399 (1915). Colombia

gravescens Meyrick, Exot. Micr., 3, p. 237 (1926). Colombia

griseana Fabricius, Ent. Syst., 3, p. 265 (1794). - S. America, Turton, Syst. Nat., 3, p. 352 (1802). - Zel- W.Indies ler, Isis, p. 195 (1839). - Walker, Cat. Lep. Het. Brit. Mus., 29, p. 773 (1864). Möschler, Verh. Zool.-bot. Ges. Wien, 31, p. 439 (1881). - Walsingham, Trans. Ent. Soc. London, p. 101 (1891); id., Merton Rules, p. 12 (1896); id., Proc. Zool. Soc. London, p. 98 (1897); id., Biol. Centr.Amer., 4, p. 164 (1912). - Busck, Ins. Insc. Mens., 1, p. 90 (1913). - Meyrick, Ann. Nat. Mrus. Wien, 44, p. 235 (1930). wa $l$ c h i a n a Zeller (nec Stoll), Linn. Entom., 9 , p. 391 , t. 3 , f. 29,30 (1854).

nec gris e a n a Zeller, Hor. Soc. Ent. Ross., 13 , p. 315 , t. 4 , f. 95 (1877) (zelleri Walsingham).

griscanomina Busck $\mathrm{n}$. $\mathrm{n}$.

$g r$ i s e a $n$ a Sepp (praeocc.), Surinam Vlinders, 3 , p. 273 , t. 125 (1830).

gubernatrlx Meyrick, Exot. Micr., 3, p. 173 (1925). Peru

gymnolopha Meyrick, E ot. Micr., 3, p. 174 (1925). Brazil

haesltans Walsingham, Biol. Centr.-Amer., 4, p. Mexico, 154, t. 5, f. 21 (1912). - Heinrich, Journ. Texas Agr. Res., 20, p. 816 (1921).

haplocentra Meyrick, Exot. Micr., 3, p. 170 (1925). Brazil

hapsicora Meyrick, Exot. Micr., 1, p. 399 (1915). Brazil 
harpobathra Meyrick, Exot. Micr., 1, p. 499 (1916). Argentina

heiicias Meyrick, Exot. Micr., 1, p. 502 (1916). $\quad$ F. Guiana

hemibatinra Meyrick, Exot. Micr., 4, p. 290 (1932). Mexico,

hemiscia Walsingham, Biol. Centr.-Amer., 4, p. 163 Guatemala (1912).

hemilephras Meyrick, Ann. Nat. Mus. Wien, 44, p. Brazil 236 , t. 1, f. 7 (1930).

himaea Meyrick, Exot. Micr., 1, p. 505 (1916). F. Guiana

homologa Meyrick, Exot. Micr., 1, p. 388 (1915). B. Guiana

humilis Zeller, Linn. Entom., 10, p. 156 (1855). - Dist. Walsingham, Ins. Life, 2, p. 154 (1889). - Columbia, Barnes and Busck, Contr. Lep. N. Amer., N. Carolina, 4 , p. 238 , t. 30 , f. 2 (1920). - Forbes, Texas Cornell Agr. Exp. Sta. Mem., 68, p. 253 (1923).

n и bеси losa Zeller, Linn. Entom., 10, p. 156 (1855). - Walsingham, Ins. Life, 2, p. 154 (1889).

canusella Chambers, Can. Ent., 6, p. 235 (1874). - Walsingham, Ins. Life, 2, p. 154 (1889).

hydrophora Meyrick, Exot. Micr., 3, p. 171 (1925). Peru

ianthina Walsingham, Biol. Centr.-Amer., 4, p. 178 Panama (1913). - Meyrick, Exot. Micr., 4, p. 295 (1932).

liiepida Meyrick, Exot. Micr., 1, p. 495 (1916). F.Guiana

immota Meyrick, Exot. Micr., 1, p. 502 (1961). F.Guiana

incompicta Meyrick, Exot. Micr., 4, p. 293 (1932). Mexico

incongrua Meyrick, Exot. Micr., 4, p. 291 (1932). Peru

incrassata Meyrick, Exot. Micr., 1, p. 504 (1916). F. Guiana

inquinuia Zeller, Linn. Entom., 9, p. 395 (1854). Brazil s u p p res s e l l a Walker, Cat. Lep. Het. Brit. Mus., 29, p. 717 (1864).

insimuiata Meyrick, Exot. Micr., 3, p. 237 (1926). Colombia

iopetra Meyrick, Exot. Micr., 4, p. 295 (1932). Guatemala

Iras Meyrick, Exot. Micr., 3, p. 237 (1926). Peru

irene Barnes and Busck, Contr. Lep. N. Amer., 4, Texas

isotona Meyrick, Exot. Micr., 4, p. 291 (1932). Panama,

Trinidad

ithytona Meyrick, Trans. Fnt. Soc. London, 76, p. Colombia $514(1929)$.

lathiptila Meyrick, Exot. Micr., 1, p. 425 (1915); B. Guiana id., Exot. Micr., 3, p. 190 (1925). 
laudala Meyrick, Exot. Micr., 1, p. 496 (1916); Guianas, id., Ann. Nat. Mus. Wien, 44, p. 235 (1930). Brazil,

Bolivia

lebelias Meyrick, Exot. Micr., 1, p. 433 (1915); Brazil, id., Exot. Micr., 1, p. 515 (1916); id., Ann. Guianas Nat. Mus. Wien, 44, p. 241 (1930).

lecithaula Meyrick, Exot. Micr., 1, p. 401 (1915); B.Guiana id., Exot. Micr., 1, p. 502 (1916).

Ieucillana Zeller, Lin. Entom., 9, p. 370 (1854). - Georgia, Walsingham, Ins. Life, 2, p. 153 (1889). Nova Scotia

a lgidell a Walker, Cat. Lep. Het. Brit. Mus., 29, p. 710 (1864). - Walsingham, Ins. Life, 2, p. 153 (1889). - Barnes and Busck, Contr. Lep. N. Amer., 4, p. 238, t. 29 , f. 4 (1920).

lignicolor Zeller, Hor. Soc. Ent. Ross., 13, p. 320, Peru t. 4 , f. 98 (1877).

Lindseyi Barnes and Busck, Contr. Lep. N. Amer., A rizona, 4, p .239, t. 29, f. 2 (1920). New Mexico

lunimaculata Dognin, Ann. Soc. Ent. Bolg., 57, p. Colombia 417 (1913).

lyslmeris Meyrick, Exot. Micr., 1, p. 391 (1915). Peru

machetes Walsingham, Biol. Centr.-Amer., 4, p. Mexico 162 (1912).

malachita Meyrick, Exot. Micr., 1, p. 404 (1915); B. Guiana, id., Exot. Micr., -1,1 p. 491 (1916); id., Brazil Ann. Nat. Mus. Wien, 44, p. 234 (1930).

marmorca Felder, Reise Now.b 2, t. 138, f. 60 (1875). Amazon

melanarma Meyrick, Exot. Micr., 1, p. 500 (1916). F. Guiana

mentigera Meyrick, Exot. Micr., 3, p. 236 (1926). Bolivia

mesostrota Meyrick, Trans. Ent. Soc. Lond., p. Guianas, 708, 1911 (1912); id., Exot. Micr., 1, p. Brazil, 393 (1915); id., Ánn. Nat. Mus. Wien, 44, Venezuela p. $234(1930)$.

milictis Meyrick, Exot. Micr., 3, p. 163 (1925); Colombia, id., Ann. Nat. Mus. Wien, 44, p. 235 (1930). Brazil

mitratella Busck, Proc. U. S. Nat. Mus., 47, p. 46 Panama (1914).

monoclona Mey̧rick, Exot. Micr., 4, p. 293 (1932). Bolivia

nerteropa Meyrick, Exot. Micr., 1, p. 395 (1915). Peru

neurographa Meyrick, Exot. Micr., 2, p. 614 (1922). Brazil

neurotona Meyrick, Exot. Micr., 1, p. 382 (1915). B.Guiana

nictitans Zeller, Linn. Entom., 9, p. 389, t. 3, f. S. America 26 (1854). - Walker, Cat. Lep. Het. Brit. Mus., 29, p. 774 (1864). - Walsingham, Biol. Centr.-Amer., 4, p. 179 (1913). Meyrick, Exot. Micr., 3, p. 192 (1925). 
h e te r o p a Meyrick, Trans. Ent. Soc. London, p. 187 (1913); id., Exot. Micr., 3, p. 192 (1925).

nimbata Meyrick, Exot. Micr., 3, p. 175 (1925). Peru

nilescens Meyrick, Exot. Micr., 3, p. 171 (1925). Brazil

nitrota Meyrick, Exot. Micr., 1, p. 497 (1916). F. Guiana

nuelearis Meyrick, Trans. Ent. Sco. London, p. 181 Peru (1913).

oeellifer Walsingham, Biol. Centr.-Amcr., 4, p. 162 C. America, (1912).

Mexico

orthophaea Meyrick, Exot. Micr., 4, p. 20 (1930). Brazil

orthotona Meyrick, Exot. Micr., 1, p. 495 (1916). F. Guiana

orthriopa Meyrick, Exot. Micr., 3, p. 166 (1925). Brazil

osseella Walsingham, Ins. Lifo, 2, p. 155 (1889). California - Barnes and Busck, Contr. Lep. N. Amer., 4, p. 239 (1920).

ovatella Walker, Cat. Lep. Het. Brit. Mus., 29, Brazil, p. 742 (1864). - Meyrick, Trans. Ent. Soc. Colombia London, 76, p. 514 (1929).

oxycentra Meyrick, Exot. Micr., 1, p. 497 (1916). Guianas, Ann. Nat. Mus. Wien, 44, p. 235 (1930). Brazil

oxydeeta Meyrick, Exot. Mricr., 1, p. 426 (1915). B. Guiana

pactota Meyrick, Exot. Micr., 1, p. 391 (1915); id., B. Guiana Exot. Micr., 3, p. 164 (1925).

palaestrias Meyrick, Exot. Micr., 1, p. 502 (1916); id., Ann. Nat. Mus. Wien, 44, p. 237 (1930).

pallulella Busck, Proc. U. S. Nat. Mus., 47, p. 47 (1914).

l a c e r tos a Meyrick, Exot. Micr., 1, p. 404

(1915); id., Exot. Micr., 1, p. 493 (1916);

id., Ann. Nat. Mus. Wien, 44, p. 234 (1930).

paraerypta Meyrick, Exot. Micr., 1, p. 405 (1915).

S. America

Panama

Costa Rica

parastis Klunder Van Gyen, Bolet. Mus. Nac. Chile, Chile 5, p. 339 (1913).

pellocoma Meyrick, Exot. Micr., 1, p. 387 (1915); Guianas, id., Ann. Nat. Mus. WVien, 44, p. 234 (1930). Brazil,

Bolivia

perenogona Meyrick, Exot. Micr., 3, p. 170 (1925). Peru

perfusa Meyrick, Exot. Micr., 1, p. 504 (1916). F. Guiana

phaeosaris Meyrick, Exot. Micr., 1, p. 394 (1915); S. America, id., Exot. Micr., 1, p. 492 (1916); id., Ann. W. Indies Nat. Mus. Wien, 44, p. 234 (1930).

phryactis Meyrick, Exot. Micr., 3, p. 167 (1925); Peru, id., Ann. Nat. Mus. Wien, 44, p. 236 (1930). Brazil

plagosa Zeller, Hor. Soc. Ent. Ross., 13, p. 311; t. 3, Brazil f. $92(1877)$. 
platydesma Meyrick, Exot. Micr., 1, p. 405 (1915). B. Guiana plerotis Meyrick, Exot. Micr., 3, p. 165 (1925). Peru plumosa Busck, Proc. U. S. Nat. Mus., 47, p. 47 Panama (1914).

praecisa Meyrick, Trans. Ent. Soc. London, p. 709 Brazil (1912).

pracrupta Meyrick, Exot. Micr., 1, p. 394 (1915). B. Guiana

protosaris Meyrick, Exot. Micr., 1, p. 406 (1915); B. Guiana, id., Exot. Mlicr., 3, p. 176 (1925). Brazil

pseudochyta Meyrick, Exot. Micr., 1, p. 393 (1915). B. Guiana

ptilocrates Meyrick, Exot. Micr., 4, p. 289 (1932). Panama

ptycta Walsingham, Biol. Centr.-Amer., 4, p. 156, t. S. America, 5 , f. 22 (1912). - Meyrick, Ann. Nat. Mus. O. America, Wien, 44, p. 239 (1930). W. Indies

pumilis Busck, Proc. U. S. Nat. Mus., 47, p. 36 Panama (1914).

purulenta Zeller, Hor. Soc. Ent. Ros., 13, p. 318, t. Guianas, 4, f. 97 (1877). - Meyrick, Ann. Nat. Mus. Brazil Wien, 44, p. 235 (1930).

quatiens Meyrick, Ann. Nat. Mus. Wien, 44, p. Brazil 235, t. 1, f. 6 (1930).

querciella Busck, Proc. Ent. Soc. Wash., 10, p. New Jersey 111 (1908). - Barnes and Busck, Contr. Lep. N. Amer., 4, p. 238, t. 29, f. 5 (1920). - Forbes, Cornell Agr. Exp. Sta. Mem., 68, p. 253 (1923). - Busck, Proc. Ent. Soc. Wash., 27, p. 48 , t. 4, p. 3, 4 (1925).

radlcalis Zeller, Hor. Soc. Ent. Ross., 13, p. 286 Panama, (1877). - Walsingham, Biol. Centr.-Amer., 4, p. 164 (1912).

radicicola Meyrick, Exot. Micr., 4, p. 292 (1932). Peru

raricilia Meyrick, Exot. Micr., 4, p. 20 (1930). Brazil

reciprocella Walkcr, Cat. Lep. Het. Brit. Mus., 29, Guianas, p. 731 (1864). - Meyrick, Ann. Nat. Mus. Brazil Wंien, 44, p. 236 (1930).

reductella Walker, Cat. Lep. Het. Brit. Mus., 29, p. Brazil, 721 (1864). - Meyrick, Ann. Nat. Mus. F. Guiana Wicn, 44, p. 241 (1930).

pho ebe Busck, Proc. U. S. Nat. Mus., 40, p. 222 (1911). - Meyrick, Ann. Nat. Mus. Wien, 44, p. 241 (1930).

refractrix Meyrick, Exot. Micr., 4, p. 21 (1930). Brazil

renselariana Stoll, Cram. Pap. Exot., 4, p. 114, t. S. America 348, f. H (1781). - Zeller, Linn. Entom., 9, p. 365 , t. 3, f. 16 (1854). - Sepp, Surinam Vlinders, 3, p. 301 , t. 139 (1855). - Walker, Cat. Lep. Het. Brit. Mus., 28, p. 409, 
439 (1863); id., 1. c., 29, p. 712 (1864). Zeller, Hor. Soc. Ent. Ross., 13, p. 260, 288 (1877). - Möschler, Verh. Zool.-bot. Ges. Wien, 31, p. 438 (1881). - Butler, Trans. Ent. Soc. London, p. 51 (1883). - Walsingham, Biol. Centr.-Amer., 4, p. 184 (1913). Meyrick, Ann. Nat. Mus. Wien, 44, p. 241 (1930).

bahiensis Perty, Delect. Anim. Art. Brazil, p. 163 , t. 32 , f. 13 (1834). - Zeller, Linn. Entom., 9, p. 365 (1854). - Walker, Cat. Lep. Het. Brit. Mus., 29, p. 712 (1864). Zeller, Hor. Soc. Ent. Ross., 13, p. 260 (1877).

reprehensa Meyrick, Exot. Micr., 3, p. 238 (1926). Brazil

resilliens Meyrick, Exot. Micr., 3, p. 173 (1925). Brazil

Ribbei Reller, Hor. Soc. Ent. Ross., 13, p. 309, t. Panama 3, f. 91 (1877). - Walsingham, Biol. Centr.- Mexico, Amer., 4, p. 165 (1912).

Bolivia

sana Meyrick, Exot. Micr., 3, p. 235 (1926).

Colombia

sareinata Meyrick, Exot. Micr., 2, p. 200 (1918). F. Guiana

sardania Meyrick, Exot. Micr., 3, p. 168 (1925); Brazil id., Ann. Nat. Mus. Wien, 44, p. 236 (1930).

Sehlaegeri Zeller, Linn. Entom., 9, p. 372 (1854); N. America id., Linn. Entom., 10, p. 158 (1855); id., Verh. Zool.-bot. Ges. Wion, 23, p. 246 (1873).

- Walsingham, Ins. Life, 2, p. 152 (1889).

- Barnes and Busck, Contr. Lep. N. Amer., 4, p. 238, t. 29, f. 1 (1920). - Forbes, Cornell Agr. Exp. Sta. Mem., 68, p. 252 (1923).

sellifera Meyrick, Exot. Micr., 3, p. 163 (1925). Brazil

semicinerea Zeller, Hor. Soc. Ent. Ross., 13, p. Panama. 312 (1877). - Walsingham, Biol. Centr.- Guatemala Amer., 4, p. 163 (1912).

semiovata Meyrick, Exot. Micr., 3, p. 234 (1926). Colombia

serangodes Meyrick, Exot. Micr., 1, p. 400 (1915). Panama

serarcha Meyrick, Exot. Micr., 3, p. 556 (1930). Brazil

similis Busck, Proc. U. S. Nat. Mus., 40, p. 222 Guianas, (1911). - Meyrick, Ann. Nat. Mus. Wien, Brazil 44 , p. 240 (1930).

smileula Meyrick, Exot. Micr., 1, p. 397 (1915). B. Guiana

sortifera Meyrick, Exot. Micr., 3, p. 557 (1930). Bolivia

sparganola Meyrick, Exot. Micr., 1, p. 389 (1915). B. Guiana

spermolitha Meyrick, Exot. Mier., 1, p. 432 (1915); B. Guiana id., Exot. Micr., 4, p. 23 (1930). 
spurca Zeller, Linn. Entom., 10, p. 155, t. 1, f. 5 (1855). - Walker, Cat. Lep. Het. Brit. Mus., 29, p. 711 (1864). - Meyrick, Ann. Nat. Mus. Wien, 44, p. 239 (1930).

$h u m e r i f e r e l l a$ Walker, Cat. Lep. Het.

Brit. Mus., 29, p. 735 (1864). - Meyrick,

Ann. Nat. Mus. Wien, 44, p. 239 (1930).

$E$ E s ch offi $i$ Zeller, Hor. Soc. Ent. Ross., 13 , p. 300 , t. 3 , f. 87 (1877). - Meyrick, Ann. Nat. Mus. Wien, 44, p. 239 (1930).

staurota Meyrick, Exot. Mier., 1, p. 493 (1916).

S. America,

C. America

stenobathra Meyrick, Exot. Micr., 4, p. 289 (1932). Panama.

stringens Meyrick, Exot. Micr., 3, p. 164 (1925). Brazil

substricta Meyrick, Exot. Micr., 2, p. 200 (1918). F. Guiana

superciliosa Meyrick, Exot. Micr., 2, p. 198 (1918); F. Guiana, id., Ann. Nat. Mus. Wien, 44, p. 236 (1930). Brazil

synercta Meyrick, Exot. Micr., 3, p. 173 (1925). Brazil

tanysta Meyrick, Exot. Micr., 1, p. 402 (1915); Guianas, id., Exot. Micr., 3, p. 189 (1925); id., Ann. Brazil Nat. Mus. Wien, 44, p. 239 (1930).

anticharis Meyrick, Exot. Micr., 1, p. 512

(1916); id., Exot. Mier., 3, p. 189 (1925);

id., Ann. Nat. Nfus. Wien, 44, p. 239 (1930).

teleosema Meyrick, Exot. Micr., 3, p. 165 (1925). Brazil

thalamobathra Meyrick, Exot. Micr., 4, p. 290 Bolivia (1932).

Thammii Zoller, Hor. Soc. Ent. Ross., 13, p. 306, Peru t. 3 , f. $89(1877)$.

tlapsinopa Meyrick, Exot. Micr., 1, p. 498 (1916). F. Guiana

thcorelica Meyrick, Exot. Micr., 4, p. 292 (1932). Panama

thesmophora Meyrick, Exot. Micr., 1, p. 392 (1915). B. Guiana

Thomasi Barnes and Busck, Contr. Lep. N. Amer., Arizona, 4 , p. 240, t. 30 , f. 5 (1920). New Mexico

tibialis Zeller, Hor. Soc. Ent. Ross., 13, p. 307, t. Brazil, 3, f. 90 (1877). - Walsingham, Proc. Zool. Trinidad Soc. London, p. 98 (1897).

tornogramma Meyrick, Exot. Micr., 3, p. 171 (1925). Brazil

tractrix Meyrick, Exot. Micr., 3, p. 172 (1925). Brazil

trichonota Meyrick, Exot. Micr., 3, p. 235 (1926). Brazil, Paraguay

triplintha Meyrick, Exot. Micr., 1, p. 490 (1916). F. Guiana

trisccla Walsingham, Biol. Centr.-Amer., 4, p. 155, Guatemala t. 5 , f. 24 (1912).

trisinuata Meyrick, Exot. Micr., 4, p. 21 (1930). Brazil 
tritogramma Meyrick, Exot. Micr., 3, p. 176 (1925). Brazil

trivallata Meyrick, Exot. Micr., 4, p. 465 (1934). Costa Rica

trochoscia Meyrick, Exot. Micr., 1, p. 396 (1915).

B. Guiana

umbratella Walker, Cat. Lep. Het. Brit. Mus., 29, Brazil p. 773 (1864).

unipunctclla Clemens, Proc. Ent. Soc. Phila.; 2, p. N. America 126 (1863). - Clemens, Stainton, Tin. N. Amer., p. 232 (1872). - Busck, Proc. Ent. Soc. Wash., 5, p. 214 (1903). - Barnes and Busck, Contr. Lep. N. $\Lambda$ mer., 4, p. 238, t. 29, f. 3 (1920). - Forbes, Cornell Agr. Exp. Sta. Mem., 68, p. 253 (1923).

lithosina Zeller, Verh. Zool.-bot. Ges. Wien, 23, p. 244 (1873). - Walsingham, Ins. Life, 2, p. 155 (1889).

tortricella Chambers, Can. Ent., 6, p. 235 (1874); id., Bull. Geol. Surv., 3, p. 122, 141 (1877). - Walsingham, Ins. Life, 2, p. $155(1889)$.

vacata Meyrick, Exot. Micr., 3, p. 170 (1925).

W. Indies

vestalis Zeller, Verh. Zool.-bot. Ges. Wien, 23, p. 247 (1873). - Walsingham, Ins. Life, 2, p. 155 (1889). - Barnes and Busck, Contr. Lep. N. Amer., 4, p. 238, t. 30, f. 4 (1920). Meyrick, Gen. Ins., 180, p. 82 (1922).

a l b e ll a Chambers, Can. Ent., 6, p. 235 (1874). - Walsingham, Ins. Life, 2, p. 155 (1889).

virens Meyrick, Trans. Ent. Soc. London, p. 707 (1912); id., Exot. Micr., 1, p. 477 (1915). viridis Busck, Proc. U. S. Nat. Mus., 47, p. 42 (1914).

Walchiana Stoll, Cram. Pap. Exot., 4, p. 191, t. 384 , f. F (1781). - Herbst, Einl. Kenntz. Ins., 2, p. 128 , t. 46 , f. $\mathrm{E}-4$, (1785). Walker, Cat. Lep. Het. Brit. Mus., 28, p. 325 (1863). - Walsingham, Proc. Zool. Soc. London, p. 99 (1897); id., Biol. Centr.Amer., 4, p. 164 (1912). - Meyrick, Ann. Nat. Mus. Wien, 44, p. 235 (1930).

nec W a lchian a Zcller, Linn. Entom., 9, p. 391, t. 3, f. 29,30 (1854) (griseana Fab.).

lativittella Walker, Cat. Lep. Het. Brit. Mus., 29, p. 720 (1864). - Walsingham, Proc. Zool. Soc. London, p. 99 (1897). Meyrick, Ann. Nat. Mus. Wien, 44, p. 235 (1930).

xanthoptila Meyrick, Trans. Ent. Soc. London, p. D. Guiana 709 (1912).

xuthosaris Meyrick, Exot. Micr., 3, p. 175 (1925). Brazil

xylocosma Meyrick, Exot. Mier., 1, p. 491 (1916). F. Guiana

Zelleri Walsingham and Durrant, Merton Rules, C. America, p. 12 (1896); id., Proc. Zool. Soc. London, S. America p. 99 (1897); id., Biol. Centr.-Amer., 4, p. 173 (1913). - Meyrick, Exot. Micr., 1, p. 491 (1916). 
gris e a n a Zeller (nec Fabricius), Hor. Soc.

Ent. Ross., 13, p. 315, t. 4, f. 95 (1877).

zelotes Walsingham, Biol. Centr.-Amer., 4, p. 159 Mexico (1912).

244

\section{Genus Stenoma Zeller}

Zeller, Isis, 32, p. 195 (1839); id., Linn. Entom., 9, p. 354 (1854); id., Hor. Soc. Ent. Ross., 13, p. 258 (1877). - Walsingham, Trans. Ent. Soc. London, 1891, p. 101. - Strand, Archiv f. Naturgesch., 1913, A. 2, p. 94 (part.). - Barnes and Busck, Contr. Lep. N. Amer., 4, p. 236 (1920). - (Typo: litura Zellor.)

A uxocross a Zeller, (type: Hopfferi Zeller), Linn. Entom., 9, p. 385, t. 3, f. 24, 25 (1854); id., Hor. Soc. Ent. Ross., 13, p. 258 (1877). - Strand, Archiv f. Naturgesch., 1913, A. 2, p. 95.

A ux o c rass a Walsingham, Trans. Ent. Soc. London, 1881, p. 254.

Orphnolechia Meyrick (type: crypsiphragma Meyrick), Trans. Ent. Soc. London, 1913, p. 28.

accurata Meyrick, Exot. Micr., 1, p. 526 (1916). F. Guiana

acontielia Walker, Cat. Lep. Het. Brit. Mus., 29, Brazil p. 733 (1864).

acratodes Meyrick, Exot. Micr., 1, p. 536 (1916); Guianas, id., Ann. Nat. Mus. Wien, 44, p. 255 (1930). Brazil

acribota Meyrick, Ann. Nat. Mus. Wien, 44, p. Brazil, 247 t. 1, f. 19 (1930). Guianas,

Peru

acridula Meyrick, Exot. Micr., 2, p. 201 (1918). F. Guiana

actista Meyrick, Trans. Ent. Soc. London, 1913, p. Venezuela, 186.

B. Guiana

adduetella Walker, Cat. Lep. Het. Brit. Mus., 29, Brazil p. 740 (1864).

adminiculata Meyrick, Exot. Micr,, 1, p. 472 (1915); Guianas, id., Ann. Nat. Mus. Wien, 44, p. 244 (1930). Brazil

admixta Walsingham, Biol. Centr.-Amer., 4, p. 170, Mexico t. 6, f. 3 (1913).

adoratrix Meyrick, Exot. Micr,, 3, p. 200 (1925). Bolivia

adornata Meyrick, Exot. Micr., 1, p. 443 (1915). Peru

adulans Meyrick, Exot. Micr., 3, p. 220 (1925). Peru

adustella Walker, Cat. Lep. Het. Brit. Mus., 29, p. Venezuela 726 (1864). - Meyrick, Exot. Micr., 1, p. 532 (1916).

adytodes Meyrick, Exot. Micr., 3, p. 196 (1925). Peru

acrinotata Butler, Cistula Entom., 2, p. 190 (1882). S. America

- Meyrick, Exot. Micr., 3, p. 192 (1925);

id., Ann. Nat. Mus. Wien, 44, p. 255 (1930). 
sperata Busck, Proc. U. S. Nat. Mus., 40, p. 219 (1911); id., Ins. Insc. Mens., 1, p. 90 (1913). - Meyrick, Exot. Micr., 3, p. 192 (1925).

aeslocopia Walsingham, Biol. Centr.-Amer., 4, p. 179, Mexico t. 6, f. $17(1913)$.

aflinis Felder, Reise Nov., t. 138, f. 34 (1875). Amazon

affirmatella Busck, Proc. U. S. Nat. Mus., 47, p. Panama 51 (1914).

agathelpis Meyrick, Exot. Micr., 4, p. 303 (1932). Brazil

aggravata Meyrick, Exot. Micr., 1, p. 514 (1916). F.Guiana

aggregata Meyrick, Exot. Micr., 1, p. 527 (1916). F. Guiana

agraria Meyrick, Exot. Micr., 3, p. 210 (1925); id., S. America Ann. Nat. Mus. WVien, 44, p. 243 (1930).

agrloschista Meyrick, Exot. Micr., 3, p. 365 (1927). Texas

albIcella Zeller, Linn. Entom., 9, p. 371 (1854). Venezuela

alblda Walker, Cat. Lep. Het. Brit. Mus., 29, p. Brazil 712 (1864).

albitincta Meyrick, Exot. Micr., 4, p. 28 (1930). Brazil

algosa Meyrick, Exot. Micr., 1, p. 537 (1916); id., S. America Ann. Nat. Mus. Wien, 44, p. 255 (1930).

alligans Butler, Cistula Entom., 2, p. 191 (1882). - S. America Meyrick, Exot. Micr., 3, p. 192 (1925); id., Ann. Nat. Mus. Wien, 44, p. 254 (1930).

o belode 8 Meyrick, Exot. Micr., 1, p. 456 (1915); id., Exot. Micr., 3, p. 192 (1925).

alluvialis Meyrick, Exot. Micr., 3, p. 204 (1925). Peru

amblens Meyrick, Exot. Micr., 2, p. 615 (1922). F.Guiana

ammodes Walsingham, Biol. Centr.-Amer., 4, p. 176, Mexico t. 6, f. 18 (1913).

amphiptera Meyrick, Trans. Ent. Soc. London, 1913, Peru p. 185 .

anaphanta Meyrick, Exot. Micr., 3, p. 180 (1925). Brazil

anaxcsta Meyrick, Exot. Micr., 1, p. 452 (1915); Guianas, id., Ann. Nat. Mus. Wien, 44, p. $247(1930)$. Brazil

anceps Butler, Cistula Entom., 2, p. 163 (1882). - Amazon, Meyrick, Exot. Micr., 3, p. 192 (1925). F. Guiana

pra e e p s Meyrick, Exot. Micr., 1, p. 453

(1915); id., Exot. Micr., 3, p. 192 (1925).

ancillaris Meyrick, Exot. Mlicr., 1, p. 530 (1916); Guianas, id., Ann. Nat. Mus. Wien, 44, p. 250 (1930). Brazil

anconitis Meyrick, Exot. Micr., 1, p. 414 (1915). B. Guiana ancylacma Meyrick, Exot. Micr., 3, p. 205 (1925). Peru anetodes Meyrick, Exot. Micr., 1, p. 438 (1915). B. Guiana 
annosa Butler, Cistula Entom., 2, p. 189 (1882). Amazon anophthalma Meyrick, Exot. Micr., 4, p. 36 (1931). Paraguay antilyra Meyrick, Exot. Micr., 3, p. 215 (1925). S. America antitacta Meyrick, Exot. Micr., 3, p. 219 (1925). Peru aphrogramma Meyrick, Trans. Ent. Soc. London, Panama 76 , p. 515 (1929). aphrophanes Meyrick, Exot. Micr., 2, p. 208 (1918). F. Guiana aplytopis Meyrick, Ann. Nat. Mus. Wien, 44, p. Brazil 253 , t. 2, f. 19 (1930). apsorrhoa Meyrick, Exot. Micr., 1, p. 413 (1915). B. Guiana, Peru

aptila Meyrick, Exot. Micr., 1, p. 467 (1915); id., S. America Ann. Nat. Mus. Wien, 44, p. 245 (1930).

arachnia Meyrick, Exot. Micr., 1, p. 429 (1915). B. Guiana

aratella Walker, Cat. Lep. Het. Brit. Mus., 29 (1864). Brazil

arenaria Walsingham, Biol. Centr.-Amer., 4, p. 176 Panama, (1913). Brazil

arenosa Meyrick, Exot. Micr., 1, p. 519 (1916). F. Guiana argiccrauna Meyrick, Exot. Micr., 3, p. 221 (1925). Colombia argocorys Meyrick, Exot. Micr., 4, p. 34 (1931). Brazil argotoma Meyrick, Exot. Micr., 1, p. 412 (1915). B. Guiana armata Zeller, Hor. Soc. Ent. Ross., 13, p. 282 Brazil (1877).

armiferella Walker, Cat. Lep. Het. Brit. Mus., 29, Brazil p. 725 (1864).

aromatica Meyrick, Exot. Micr., 1, p. 449 (1915); Brazil, id., Ann. Nat. Mus. Wien, 44, p. 255 (1930). Colombia

arridens Meyrick, Exot. Micr., 4, p. 36 (1931). T. Guiana ascodes Meyrick, Exot. Micr., 1, p. 441 (1915). B. Guiana asphalopis Meyrick, Exot. Micr., 3, p. 188 (1925). F. Guiana assignata Meyrick, Exot. Micr., 2, p. 208 (1918). F. Guiana associata Meyrick, Exot. Micr., 3, p. 214 (1925). Brazil astacopis Meyrick, Ann. Nat. Wien, 44, p. 242, t. F. Guiana, 1, f. 11 (1930). Brazil

asthenopa Meyrick, Exot. Micr., 1, p. 517 (1916); F. Guiana, id., Ann. Nat. Mus. Wien, 44, p. 243 (1930). Brazil

astronoma Meyrick, Trans. Ent. Soc. London, p. 34 Bolivia (1909).

Lepidopterorum Catalogus 67. 
alerpes Walsingham, Biol. Centr.-Amer., 4, p. 180, Mexico t. 6 , f. 23 (1913).

atmodes Meyrick, Exot. Micr., 1, p. 451 (1915). Peru

almospora Meyrick, Exot. Micr., 3, p. 209 (1925). Colombia

atricenssis Meyrick, Exot. Micr., 1, p. 530 (1916). F. Guiana

augeseens Meyrick, Exot. Micr., 3, p. 206 (1925). Peru

aurieoma Meyrick, Exot. Micr., 4, p. 32 (1930). Brazil

aztecana Walsingham, Biol. Cent.-Amer., 4, p. 175, Mexico t. 6 , f. 7 (1913).

balanoplis Meyrick, Exot. Micr., 4, p. 293 (1932). Peru

baliandra Meyrick, Exot. Micr., 1, p. 442 (1915). B. Guiana

basiferella Walker, Cat. Lep. Het. Brit. Mus., 29, Brazil p. 744 (1864).

basirubrclla Walker, Cat. Lep. Het. Brit. Mus., 29, Brazil p. 719 (1864).

bathrocentra Meyrick, Exot. Micr., 1, p. 462 (1915). B. Guiana

bathrogramma Meyrick, Trans. Ent. Soc. London, Venezuela 1912 , p. 711.

bathroloma Meyrick, Exot. Micr., 3, p. 189 (1925); Brazil id., Ann. Nat. Mus. Wien, 44, p. 239 (1930).

bathyntis Meyrick, Exot. Micr., 4, p. 39 (1931). Brazil

bathyphnen Meyrick, Exot. Micr., 4, p. 297 (1932). Panama

benigna Meyrick, Exot. Micr., 1, p. 540 (1916). T. Guiana

biannulata Meyrick, Ann. Nat. Mus. Wien, 44, p. Brazil 248 , t. 2 , f. 15 (1930).

bieensa Meyrick, Exot. Micr., 1, p. 464 (1915); id., Brazil, Trans. Ent. Soc. London, 76, p. 515 (1929). Panama

bilinguis Meyr, Exot. Micr., 2, p. 202 (1918). F. Guiana

binodis Meyrick, Exot. Micr., 1, p. 472 (1915). T. Guiana

biseriata Zeller, Hor. Soc. Ent. Ross., 13, p. 269 S. America, (1877). - Walsingham, Biol. Centr.-Amer., C. America 4 , p. $182(1913)$.

bisignala Meyrick, Exot. Micr., 1, p. 523 (1916). F. Guiana

blandula Meyrick, Exot. Micr., 1, p. 456 (1915). Venezuela

bolislis Meyrick, Exot. Micr., 3, p. 203 (1925). Brazil

bovinella Busck, Proc. U. S. Nat. Mus., 47, p. 50 Panama (1914).

brevisella Walker, Cat. Lep. Het. Brit. Mus., 29, p. Brazil 730 (1864).

bryoeosma Meyrick, Exot. Micr., 1, p. 535 (1916); F. Guiana, id., Ann. Nat. Mus Wien, 44, p. $253(1930)$. Brazil 
bryophanes Meyrick, Exot. Micr., 1, p. 477 (1915); F: Guiana id., Exot. Micr., 1, p. 537 (1916).

bryoxyla Meyrick, Exot. Micr., 1, p. 437 (1915). Peru

butyrota Meyrick, Trans. Ent. Soc. London, 76, p. Colombia $516(1929)$.

byrsinites Meyrick, Trans. Ent. Soc. London, p. Colombia 713 (1912).

byssina Zeller, Linn. Entom., 10, p. 165 (1855). - C.America, Walker, Cat. Lep. Het. Brit. Mus., 29, p. S. America, 711 (1864). - Meyrick, Exot. Micr., 3, p. W. Indies 192 (1925); id., Trans. Ent. Soc. London, 76 , p. 515 (1929); id., Ann. Nat. Mus. Wien, 44, p. 244 (1930).

te trago ne ll a Walker, Cat. Lep. Het. Brit. Mus., 29, p. 723 (1864). - Walsingham, Biol. Centr.-Amer., 4, p. 187 (1913). Meyrick, Exot. Micr., 3, p. 192 (1925).

is a b e ll a Felder, Reise Nov., 2, t. 139, f. 24 (1875). - Möschler, Verh. Zool.-bot. Ges. Wien, p. 439 (1881). - Walsingham, Proc. Zool. Soc. London, p. 101 (1897); id., Biol. Centr.-Amer., 4, p. 187 (1913). - Meyrick, Exot. Micr., 3, p. 192 (1925).

bythitis Meyrick, Exot. Micr., 1, p. 443 (1915); id., Guianas, Ann. Nat. Mus. Wien, 44, p. 255 (1930). Brazil

argo \& pora Meyrick, Exot. Micr., 1, p. 443 (1915); id., Ann. Nat. Mus. Wien, 44, p. $255(1930)$.

caenochytis Meyrick, Exot. Micr., 1, p. 415 (1915); id., Exot. Micr., 3, p. 187 (1925).

caesarea Meyrick, Exot. Micr., 1, p. 450 (1915); Guianas, id., Ann. Nat. Mus. Wien, 44, p. 250 (1930). Brazil

caesia Meyrick, Exot. Micr., 1, p. 449 (1915). I. Guiana

caliginea Meyrick, Exot. Micr., 4, p. 30 (1930). IBrazil

callicoma Meyrick, Exot. Micr., 1, p. 528 (1916). F.Guiana

camarodes Meyrick, Exot. Micr., 1, p. 478 (1915). F. Guiana

camptospila Meyrick, Exot. Micr., 3, p. 202 (1925). Brazil

cana Felder, Reise Nov., 2, t. 138, f. 37 (1875). Amazon

canonias Meyrick, Trans. Ent. Soc. London, 1913, F. Guiana p. 187.

cantatrix Meyrick, Exot. Micr., 3, p. ${ }^{\prime 221 ~(1925) . ~ B o l i v i a ~}$

capnobola Meyrick, Trans. Ent. Soc. London, 1913, Dutch p. 186.

capnocoma Meyrick, Exot. Micr., 4, p. 37 (1931). Brazil

capnocrossa Meyrick, Exot. Micr., 3, p. 197 (1925). Brazil

capsilormis Meyrick, Exot. Micr., 4, p. 25 (1930). Brazil 
carabodes Meyrick, Exot. Micr., 1, p. 435 (1915). B. Guiana carbasea Méyrick, Exot. Micr., 1, p. 426 (1915). Brazil caryodesma Meyrick, Exot. Micr., 3, p. 184 (1925). Peru caryograpta Meyrick, Exot. Micr., 4, p. 26 (1930). Brazil cassigcra Meyrick, Exot. Micr., 1, p. 479 (1915). F. Guiana castellana Meyrick, Exot. Micr., 1, p. 516 (1916). F.Guiana catapsecta Meyrick, Exot. Micr., 1, p. 452 (1915); S. America, id., Ann. Nat. Mus. Wien, 44, p. 247 (1930). C. America

catenifer Walsingham, Biol. Centr.-Amer., 4, p. 168 Guatemala, (1912).

Panama

catharmosta Meyrick, Exot. Micr., 1, p. 445 (1015). Guianas

cathosiota Meyrick, Exot. Micr., 3, p. 200 (1925). Brazil

cceropia Meyrick, Exot. Micr., 1, p. 509 (1916). Panama i mpresse ll a Busck, (praeocc.) Proc. U. S. Nat. M[us., 47, p. 51 (1914). - Meyrick, Exot. Micr., 1. p. 509 (1916).

centrodina Meyrick, Exot. Micr., 1, p. 531 (1916). F.Guiana

certiorata Meyrick, Exot. Micr., 4, p. 296 (1932). Bolivia

chalepa Walsingham, Biol. Centr.-Amer., 4, p. 173, Panama t. 6, f. 4 (1913).

chalinophanes Meyrick, Exot. Micr., 4, p. 42 (1931). Bolivia

chalybaeella Walker, Cat. Lep. Het. Brit. Mus., 29, Brazil p. 719 (1864).

chiloscma Meyrick, Exot. Micr., 2, p. 208 (1918); F. Guiana id., Exot. Micr., 3, p. 219 (1925).

chionodora Meyrick, Exot. Micr., 1, p. 464 (1915); Guianas, id., Exot. Micr., 3, p. 192 (1925); id., Ann. Brazil Nat. Mus. Wien, 44, p. 246 (1930).

r it a Busck, Ins. Insc. Mens., 8, p. 92 (1920). - Meyrick, Ann. Nat. Mus. Wien, 44, p. $246(1930)$.

vita Meyrick (nec Busck), Exot. Micr., 3, p. 192 (1925).

chionogramma Meyrick, Trans. Ent. Soc. London, Bolivia p. 29 (1909).

chlorina Kearfott, Proc. U. S. Nat. Mus., 22, p. 126 Brazil, (1911). - Busck, Proc. U. S. Nat. Mus., 47, Panama p. 41 (1914).

chloromis Meyrick, Exot. Micr., 1, p. 433 (1915); B. Guiana id., Exot. Ḿicr., 3, p. 195 (1925).

chloroplaca Meyrick, Exot. Micr., 1, p. 383 (1915); B. Guiana, id., Trans. Ent. Soc. London, 76, p. 515 Panama (1929).

chlorotrota Meyrick, Exot. Micr., 4, p. 296 (1932). Bolivia

chloroxantha Meyrick, Exot. Micr., 3, p. 216 (1925). Brazil 
cholcrocrossa Meyrick, Exot. Micr., 4, p. 32 (1930). Brazil choleroptila Meyrick, Exot. Micr., 1, p. 467 (1915). B. Guiana chromalopa Meyrick, Exot. Micr., 4, p. 29 (1930). Brazil chromolitha Meyrick, Exot. Micr., 3, p. 203 (1925). Bolivia chromolechna Meyrick, Exot. Micr., 3, p. 212 Brazil (1925); id., Ann. Nat. Mus. Wien, 44, p. 252 (1930).

chrysogastra Meyrick, Exot. Micr., 1, p. 476 (1915). F. Guiana cirrhogramma Meyrick, Exot. Micr., 4, p. 27 (1930). Brazil cirrhoxantha Meyrick, Exot. Micr., 1, p. 477 (1915). F. Guiana citrophaea Meyrick, Exot. Micr., 4, p. 42 (1931). Brazil citroxantha Meyrick, Exot. Micr., 1, p. 515 (1916). F. Guiana claripennis Busck, Proc. U. S. Nat. Mus., 47, p. Panama 39 (1914).

clysmographa Meyrick, Exot. Micr., 3, p. 197 (1925). Peru cnemosaris Meyrick, Exot. Micr., 3, p. 181 (1925). Brazil codicala Meyrick, Exot. Micr., 1, p. 530 (1916); Guianas, id., Ann. Nat. Mus. Wien, 44, p. 251 (1930). Brazil

colligata Meyrick, Exot. Micr., 1, p. 461 (1915). B. Guiana colposaris Meyrick, Exot. Micr., 3, p. 185 (1925). Brazil columbaris Meyrick, Trans. Ent. Soc. London, p. Peru 31 (1909).

comma Busck, Proc. U. S. National Mus., 40, p. 218 Guianas, (1911). - Meyrick, Exot. Micr., 1, p. 509 Cuba (1916); id., Exot. Micr., 1, p. 535 (1916). Busck, Entom. Amer., 13, p. 162, t. 41, f. 5 a, 5,7 (1934).

mel a no cry $p$ ta Meyrick, Exot. Micr., 1, p. 455 (1915); id., Exot. Micr., 1, p. 509

(1916). - Busck, Entom. Amer., 13, p. 162, t. 31 , f. 5,7 (1934).

comosa Walsingham, Biol. Centr.-Amer., 4, p. 161, Mexico t. 5 , f. 30 (1912).

compressa Walsingham, Biol. Centr.-Amer., p. 171, Mexico t. 6 , f. $14(1913)$.

compsocharis Meyrick, Exot. Micr., 3, p. 218 (1925). Bolivia compsocoma Meyrick, Ann. Nat. Mus. Wien, 44, p. Brazil 249 , t. 2, f. 16 (1930).

compsoneura Meyrick, Exot. Micr., 3, p. 217 (1925). Brazil, F. Guiana

condemnatrix Meyrick, Exot. Micr., 4, p. 31 (1930). Colombia 
congressella Walker, Cat. Lep. Het. Brit. Mus., 29, p. 736 (1864). - Meyrick, Exot. Micr., 3, p. $192(1925)$

me le $m a$ Walsingham, Biol. Centr.-Amer., 4, p. 189, t. 6, f. 34 (1913). - Meyrick, Exot. Micr., 3, p. 192 (1925).

c or a Busck, Proc. U. S. Nat. Mus., 47, p. 53 (1914). - Meyrick, Exot. Micr., 3, p. 192 (1925).

cens or i a Meyrick, Exot. Mficr., 1, p. 460

(1915); id., Exot. Micr., 3, p. 192 (1925). congrua Meyrick, Exot. Micr., 3, p. 213 (1925).

Peru

coniopa Meyrick, Exot. Micr., 3, p. 184 (1925). Brazil

coniophaea Meyrick, Ann. Nat. Mus. Wien, 44, p. Brazil 246 , t. 1, f. 17 (1930).

consobrina Meyrick, Exot. Micr., 1, p. 460 (1915). B. Guiana

consociella Walker, Cat. Lep. Het. Brit. Mus., 29, S. America p. 730 (1864). - Meyrick, Ann. Nat. Mus. Wien, 44, p. 254 (1930).

s u r in a me ll a Möschler, Verh. Zool.-bot. Ges. Wien, p. 60, t. 18 , f. 46 (1882). - Meyrick, Ann. Nat. Mrus. Wien, 44, p. 254 (1930).

petrina Walsingham, Biol. Centr.-Amer., 4, p. 168 , t. 6 , f. 9 (1912). - Meyrick, Ann. Nat. Mus: Wien, 44, p. 254 (1930).

consonella Busck n. n.

Brazil

consociella Walker (praeocc.), Cat. Lep.

Het. Brit. Mus., 29, p. 741 (1864).

constituta Meyrick, Exot. Micr., 3, p. 191 (1925). F. Guiana

constricta Meyrick, Exot. Micr., 3, p. 225 (1926). Colombia

conlophora Meyrick, Exot. Micr., 1, p. 472 (1915); S: America id., Ann. Nat. Mus. Wien, 44, p. 244 (1930).

contortella Walker, Cat. Lep. Het. Brit. Mus., 29, p. 829 (1864). - Meyrick, Gen. Insect., 180, p. 185 (1922).

conturbatella Walker, Cat. Lep. Het. Brit. Mus., 29, p. 738 (1864). - Meyrick, Exot. Micr., 3, p. 192 (1925).

i $i$ l u c ide li a Walker, Cat. Lep. Brit. Mus., 29, p. 739 (1864). - Meyrick, Exot. Micr., 3, p. $192(1925)$.

trochistis Meyrick, Exot. Micr., 1, p. 518 (1916); id., Exot. Mficr., 3, p. 192 (1925).

conveniens Meyrick, Exot. Micr., 3, p. 217 (1925). Brazil

crambina Busck, Ins. Insc. Mens., 8, p. 89 (1920). Mexico - Busck and Dampf, Estud. Ofic. Fed. Def. Agr. Mexico, 2, p. 5-51, f. 1-24 (1929).

crambitella Walsingham, Ins. Insc., 2, p. 154 (1889). Arizona - Barnes and Busck, Contr. Lep. N. Amer., 4 , p. 238 , t. 30 , f. 7 (1920).

cremastis Meyrick, Exot. Micr., 3, p. 194 (1925). Peru 
crepitana Meyrick, Exot. Micr., 2, p. 204 (1918). F. Guiana

cretifera Felder, Reise Nov., 2, t. 138, f. 38 (1875). Colombia

crocoptila Meyrick, Exot. Micr., 1, p. 466 (1915). B. Guiana

crocosticta Meyrick, Exot. Micr., 3, p. 219 (1925). Peru

crocuta Felder, Reise Nov., 2, t. 138, f. 38 (1875). Amazon

crypsangcla Meyrick, Exot. Micr., 4, p. 294 (1932). Peru

erypsastra Meyrick, Exot. Micr., 1, p. 414 (1915); B. Guiana, id., Ann. Nat. Mus. Wien, 44, p. 238 (1930). Brazil

crypsetacra Meyrick, Exot. Micr., 3, p. 183 (1925). Brazil crypsiphaca Meyrick, Exot. Micr., 3, p. 190 (1925). Brazil crypsiphragma Meyrick, Trasn. Ent. Soc. London, p. Bolivia 28 (1909).

erypsithias Meyrick, Exot. Micr., 3, p. 558 (1930). Brazil

curiata Meyrick, Trans. Ent. Soc. Lond., 76, p. 515 Panama (1929).

eurtipennis Butler, Cistula Entom., 2, p. 189 (1882). Amazon

cyanarcha Meyrick, Fxot. Micr., 1, p. 414 (1915). B. Guiana

cycloptila Meyrick, Exot. Micr., 1, p. 446 (1915). B. Guiana

cycnographa Meyrick, Ann. Nat. Mus. Wien, 44, Brazil p. 254, t. 1, f. 32 (1930).

cycnolopha Meyrick, Exot. Micr., 3, p. 186 (1925). Peru

cymbalista Meyrick, Exot. Micr., 2, p. 204 (1918). F. Guiana

eymogramma Meyrick, Exot. Micr,, 3, p. 193 (1925); Peru, id., Ann. Nat. Mus. Wien, 44, p. 240 (1930). Guianas,

Brazil

cyphoxantha Meyrick, Exot. Micr., 4, p. 36 (1931). Brazil

dasyncura Meyrick, Exot. Micr., 2, p. 614 (1922). F. Guiana

decora Zeller, Linn. Entom., 9, p. 375 (1854). - Brazil

Walker, Cat. Lep. Het. Brit. Mus., 29, p. 735 (1864). - Meyrick, Exot. Micr., 4, p. 29 (1930).

delcnita Meyrick, Exot. Micr., 1, p. 473 (1915).

F. Guiana

dcIphinodes Meyrick, Exot. Micr., 3, p. 222 (1925); Peru, id., Exot. Micr., 4, p. 303 (1932). Colombia,

Panama

deItomis Meyrick, Exot. Micr., 3, p. 206 (1925). Brazil

demas Busck, Proc. U. S. Nat. Mus., 40, p. 223 F, Guiana (1911). 
desceta Meyrick, Exot. Micr., 2, p. 203 (1918). F. Guiana

desidiosa Meyrick, Exot. Micr., 3, p. 201 (1925). Colombia

destillata Zeller, Hor. Soc. Ent. Ross., 13, p. 283 Panama,

(1877). - Walsingham, Biol. Centr.-Amer. Colombia 4, p. 178 (1913).

deuteropa Meyrick, Linn. Soc. Journ. Zool., 37, Paraguay p. 281 (1931).

dlacta Meyrick, Exot. Micr., 1, p. 513 (1916). F. Guiana

diametrica Meyrick, Exot. Micr., 3, p. 239 (1926). Colombia

dlciyogramma Meyrick, Exot. Micr., 4, p. 301 (1932). Brazil

diffinis Felder, Reise Nov., 2, t. 138, f. 65 (1875). ChL̉e - Calvert, Cat. Lep. Ohile, Anales Univ. Chile, 69, p. 39 (1886).

dilinopa Meyrick, Exot. Micr., 3, p. 198 (1925). Brazil

dimctropis Meyrick, Exot. Micr., 4, p. 297 (1932). Mexico

diplosaris Meyrick, Exot. Micr., 1, p. 418 (1915). B. Guiana

dircmpta Zeller, Linn. Entom., 10, p. 154, t. 1, f. Brazil 4 (1855). - Walker, Cat. Lep. Het. Brit. Mus., 29, p. 711 (1864).

discrepana Meyrick, Exot. Micr., 3, p. 199 (1925). Peru

disjecta Zeller, Linn. Entom., 9, p. 368 (1854). - Guianas, Walker, Cat. Lep. Het. Brit. Mus., 29, p. Bolivia, 712 (1864). - Meyrick, Exot. Micr., 1, p. Brazil 515 (1916); id., Exot. Micr., 3, p. 192 (1925); id., Ann. Nat. Mus. Wien, 44, p. 241 (1930).

intersect a Meyrick, Exot. Micr., 1, p. 515

(1916); id., Exot. Micr., 3, p. 192 (1925).

dissona Mevrick, Exot. Micr., 3, p. 191 (1925). Brazil

doleropls Meyrick, Exot. Micr., 1, p. 421 (1915), B. Guiana

dorcadopa Meyrick, Exot. Micr., 1, p. 532 (1916). F.Guiana

dromica Meyrick, Exot. Micr., 3, p. 185 (1925). Brazil

dryaula Meyrick, Linn. Soc. Journ. Zool., 37, p. 281 Paraguay, (1931).

Amazon,
Brazil

dryoconis Meyrick, Exot. Micr., 4, p. 31 (1930). Bolivia

dryocosma Meyrick, Exot. Micr., 2, p. 206 (1918); Guianas, id., Ann. Nat. Mus. Wien, 44, p. 252 (1930). Brazil

dryoscia Meyrick, Exot. Micr., 4, p. 301 (1932). Mexico

dryotechna Meyrick, Exot. Micr., 1, p. 421 (1915). B.Guiana

ebria Meyrick, Exot. Micr., 1, p. 441 (1915); id., Tenezuela, Ann. Nat. Mus. Wien, 44, p. 252 (1930). Brazil 
claeodes Walsingham, Biol. Centr.-Amer., 4, p. 178, Mexico t. 6 , f. 22 (1913).

elaeurga Meyrick, Exot. Micr., 3, p. 226 (1926). Bolivia

elatior Felder, Reise Nov., 2, t. 138, f. 67 (1875). Amazon

embythia Meyrick, Exot. Micr., 1, p. 529 (1916). F. Guiana

cminens Meyrick, Exot. Micr., 2, p. 206 (1918). F. Fuiana

emphatica Moyrick, Exot. Micr., 1, p. 539 (1916). F. Guiana

endochra Meyrick, Exot. Micr., 3, p. 198 (1925). Brazil

entephras Meyrick, Exot. Micr., 1, p. 453 (1915); B. Guiana, id., Ann. Nat. Mus. Wien, 44, p. 248 (1930). Brazil

enumerala Meyrick, Exot. Micr., 4, p. 299 (1932). Brazil

epicnesta Meyrick, Exot. Micr., 1, p. 461 (1915). B.Guiana

epicrossa Mcyrick, Exot. Micr., 4, p. 294 (1932). Peru

epicta Walsingham, Biol. Centr.-Amer., 4, p. 160, t. Mexico 5, f. 28 (1912).

epipacta Meyrick, Exot. Micr., 1, p. 444 (1915); Guianas, id., Ann. Nat. Mus. Wien, 44, p. 252 (1930). Brazil

eriacma Meyrick, Exot. Micr., 1, p. 456 (1915). B. Guiana

erotarcha Meyrick, Exot. Micr., 1, p. 171 (1915). F. Guiana

erotica Meyrick, Exot. Micr., 1, p. 534 (1916). F. Guiana

eusticta Meyrick, Exot. Micr., 1, p. 521 (1916); Guianas, id., Ann. Nat. Mus. Wien, 44, p. $253(1930)$. Brazil

eva Meyrick, Exot. Micr., 1, p. 447 (1915). B. Guiana

evanescens Butler, Cistula Entom., 2, p. 189 (1882). Amazon

exarala Zellor, Linn. Entom., 9, p. 378, t. 3, f. 19 C. America, (1854). - Walker, Cat. Lep. Het. Brit. S. America Mus., 29, p. 713 (1864). - Walsingham, Biol. Centr.-Amer., 4, p. 178 (1913). - Meyrick, Trans. Ent. Soc. London, 76, p. 516 (1929); id., Ann. Nat. Mus. TVien, 44, p. 255 (1930). exasperata Meyrick, Exot. Micr., 1, p. 533 (1916). F. Guiana exempta Moyrick, Exot. Micr., 3, p. 179 (1925). Brazil exhalata Meyrick, Exot. Micr., 1, p. 474 (1915). F. Guiana expansa Meyrick, Exot. Micr., 1, p. 464 (1915). Brazil expilata Meyrick, Exot. Micr., 1, p. 469 (1915); id., Guianas, Ann. Nat. Mus. Wien, 44, p. 246 (1930). Brazil explicita Meyrick, Ann. Nat. Mus. Wien, 44, p. Brazil 247 , t. 1 , f. 18 (1930). 
externella Walker, Cat. Lep. Het. Brit. Mus., 29, Brazil, p. 732 (1864). - Meyrick, Exot. Micr., 3, B. Guiana p. $192(1925)$.

megaspil e li a Walker, Cat. Lep. Het. Brit. Mus., 29, p. 734 (1864). - Meyrick, Exot. Micr., 3, p. 192 (1925).

a g gerata. Meyrick, Exot. Micr., 1, p. 428 (1915); id., Exot. Micr., 3, p. 192 (1925).

faecosa Felder, Reise Nov., t. 138, f. 64 (1875). Amazon

fallax Butler, Cistula Entom., 2, p. 163 (1882). Amazon

Palsidiea Meyrick, Exot. Micr., 1, p. 426 (1915). D. Guiana

farraria Meyrick, Exot. Micr., 1, p. 462 (1915). Brazil

fastigata Meyrick, Exot. Micr., 1, p. 430 (1915). B. Guiana

favillata Meyrick, Exot. Micr., 1, p. 430 (1915) Peru

fenestra Busck, Proc. U. S. Nat. Mus., 47, p. 44 Punama (1914).

fereulata Meyrick, Exot. Micr., 2, p. 615 (1922). F. Guiana

fermentata Meyrick, Exot. Micr., 1, p. 539 (1916). F. Guiana

ferroeanella Walker, Cat. Lep. Het. Brit. Mus., 29, C. America, p. 716 (1864), - Walsingham, Biol. Centr.- S. America Amer., 4, p. 175, t. 6, f. 10 (1913). Meyrick, Ann. Nat. Mrus. Wien, 44, p. 246 (1930).

figularis Meyrick, Exot. Micr., 2, p. 204 (1918); id., F. Guiana, Trans. Ent. Soc. London, 76, p. 515 (1929). Colombia

filiferella Walker, Cat. Lep. Het. Brit. Mus., 29, Brazil finilrix Peyrick, Fxot. Micr., 3, p. 208 (1925). Colombia, Bolivia

flavieosta Felder, Reise Nov!, 2, t. 138, f. 47 (1875). Amazon

flexibilis Meyrick, Exot. Micr., 1, p. 538 (1916). F. Guiana

fluminala Meyrick, Trans. Ent. Soc. London, p. C. America, 716 (1912); id., Ann. Nat. Mus. Wien, 44, S. America p. 253 (1930). - Busck, Entom. Amer., 13, p. $162(1934)$.

Forreri Walsingham, Biol. Centr.-Amer., 4, p. 172, Mexico, t. 6, f. 2 (1913).

fractinubes Walsingham, Biol. Centr.-Amer., 4, p. Panama 165 , t. 5 , f. 32 (1912).

fraterna Felder, Reise Nov., 2, t. 138, f. 51 (1875). Amazon

Prondifer Busck, Proc. U. S. Nat. Mus., 47, p. 42 Panama (1914).

fulcrata Meyrick, Exot. Micr., 1, p. 471 (1915). F. Guiana

fulminala Meyrick, Exot. Micr., 1, p. 539 (1916). F. Guiana 
funerana Sepp, Surinam Vlinders, 2, p. 205, t. 91 Guianas (1830)

fusistrigella Walker, Cat. Lep. Het. Brit. Mus., 29, Brazil p. 725 (1864).

futura Meyrick, Trans. Ent. Soc. London, p. 188 Peru (1913).

gemenata Meyrick, Exot. Micr., 1, p. 524 (1916). F. Guiana

genetta Foldor, Reise Novl., 2, t. 138, f. 35 (1875). Anrazon

germinans Meyrick, Exot. Micr., 3, p. 211 (1925). Colombia

glaphyrodes Moyrick, Trans. Ent. Soc. London, F.Guiana, p. 186 (1913). Brazil

glaucescens Meyrick, Exot. Micr., 1, p. 537 (1916). F. Guiana

glaucopa Mcyrick, Trans. Ent. Soc. London, p. 712 Colombia (1912).

graphica Busck, Ins. Inse. Mens, 8, p. 91 (1920). Costa Rica

graphopterella Walker, Cat. Lep. Het. Brit. Mus., Brazil 29 , p. 739 (1864).

gubernata Meyrick, Exot. Micr., 1, p. 465 (1915); Guianas, id., Ann. Nat. Mus. Wien, 44, p. 245 (1930). Brazil

gymnastis Meyrick, Exot. Micr., 1, p. 453 (1915); Guianas, id., Ann. Nat. Mus. Wien, 44, p. 247 (1930). Brazil

gypsolitha Meyrick, Exot. Micr., 4, p. 38 (1931). Paraguay

gypsoterma Moyrick, Exot. Micr., 1, p. 424 (1915). B. Guiana

habilis Meyrick, Exot. Micr., 1, p. 427 (1915). B. Guiana

halmas Meyrick, Exot. Micr., 3, p. 200 (1925). Peru

haploxyla Meyrick, Exot. Micr., 1, p. 420 (1915). D. Guiana

harpoceros Meyrick, Ann. Nat. Mus. Wien, 44, p. Brazil 255 , t. 1 , f. 25 (1930).

hebes Dognin, Ann. Soc. Ent. Belg., 49, p. 89 Colombia (1905). - Walsingham, Biol. Centr--Amer., 4, p. 189 (1913). - Meyrick, Exot. Micr., 3, $192(1925)$. $q u a d r a t e l l a$ Walsingham (nec Walker), Biol. Centr.-Amer., 4, p. 189 (1913).

hemilampra Meyrick, Exot. Micr., 1, p. 470 (1915). F. Guiana

hemiphanta Meyrick, Exot. Micr., 3, p. 198 (1925). Brazil

herbacea Meyrick, Exot. Micr., 4, p. 38 (1931). Brazil

herifuga Meyrick, Exot. Micr., 4, p. 298 (1932). Peru

heterosaris Meyrick, Exot. Micr., 1, p. 418 (1915). Guianas

heterosema Meyrick, Ann. Nat. Mus. Wien, 44, p. F. Guiana, 244 (1930). 
heteroxantha Moyrick, Exot. Micr., 4, p. 37 (1931). Paraguay

hexascia Meyrick, Exot. Micr., 3, p. 215 (1925). Brazil

himerodes Meyrick, Exot. Micr., 1, p. 535 (1916). F. Guiana

holeadiea Meyrick, Exot. Micr., 1, p. 531 (1916). F. Guiana

homala Walsingham, Biol. Centr.-Amer., 4, p. 167, Mexico t. 6, f. 8 (1912).

Hopfferi Ziller, Linn. Entom., 9, p. 386, t. 3, f. 24 Brazil 25 (1854). - Walker, Cat. Lep. Het. Brit. Mus., 29, p. 772 (1864).

hoplitiea Meyrick, Exot. Micr., 3, p. 216 (1925); id., Brazil Ann. Nat. Mus. Wien, 44, p. 253 (1930).

horizontias Meyrick, Exot. Micr., 3, p. 188 (1925). Brazil

horocharis Meyrick, Ann. Nat. Mus. Wien, 44, p. Brazil 251 , t. 1, f. 21 (1930).

horocyma Meyrick, Exot. Micr., 3, p. 209 (1925). Brazil

horometra Meyrick, Exot. Micr., 3, p. 222 (1925). Peru

hospitalis Meyrick, Exot. Micr., 1, p. 463 (1915). Brazil

humerella Walker, Cat. Lep. Het. Brit. Mus., 29, Brazil p. 716 (1864).

hyacinlhitis Meyrick, Exot. Micr., 3, p. 559 (1930). B. Guiana

hyalocryptis Meyrick, Ann. Nat. Mus. Wien, 44, p. Brazil 250 , t. 2, f. 17 (1930).

hyalophanta Meyrick, Exot. Micr., 4, p. 294(1932). Peru

hydraena Meyrick, Exot. Micr., 1, p. 536 (1916). T.Guiana

hydrelasas Meyrick, Exot. Micr., 4, p. 33 (1931). F. Guiana

hypocirrha Meyrick, Exot. Micr., 4, p. 30 (1930). Brazil

iatma Meyrick, Exot. Micr., 1, p. 474 (1915). F. Guiana

ieteropis Moyrick, Exot. Micr., 3, p. 209 (1925). Brazil

ignobilis Zeller, Linn. Entom., 9, p. 361 (1854). - Brazil Walker, Cat. Lep. Het. Brit. Mus., 29, p. 712 (1864).

immersa Walsingham, Biol. Centr.-Amer., 4, p. 177, Mexico t. 6, f. 20 (1913).

inuminens Meyrick, Exot. Micr., 1, p. 431 (1915). D. Guiana

immunda Zoller, Linn. Entom., 9, p. 360 (1854). - Brazil, Walker, Cat. Lep. Het. Brit. Mus., 20, p. Guianas 711 (1864). - Zeller, Hor. Soc. Ent. Ross., 13, p. 259 (1877). - Walsingham, Proc. Zool. Soc. London, p. 100 (1897); id., Biol. Centr.-Amer., 4, p. 182 (1913). - Meyrick, Exot. Micr., 1, p. 468 (1915). 
te c $t$ e l l $a$ Walker, Cat. Lep. Het. Brit. Mus. 29, p. 714 (1864). - Meyrick, Exot. Micr., 1, p. 468 (1915); id., Ann. Nat. Mus. Wien, 44, p. 246 (1930).

sub notate l la Walker, Cat. Lep. Het. Brit. Mus., 29, p. 724 (1864).

th y la candra Meyrick, Exot. Micr., 1, p. 468 (1915); id., Ann. Nat. Mus. Wien, 44, p. 246 (1930).

impactella Walker, Cat. Lep. Het. Brit. Mus., 29, Brazil p. 742 (1864).

impedila Meyrick, Exot. Micr., 1, p. 422 (1915). Peru

impurata Meyrick, Exot. Micr., 1, p. 468 (1915). D. Guiana

inardescens Meyrick, Exot. Micr., 3, p. 202 (1925). Brazil

Incitatrix Meyrick, Exot. Micr., 3, p. 207 (1925); Argentina, id.; Ann. Nat. Mns. Wien, 44, p. 246 (1930). Brazil

indccora Zeller, Linn. Entom., 9, p. 376 (1854). - Brazil - Walker, Cat. Lep. Het. Brit. Mus., 29, p. 713 (1864). - Meyrick, Exot. Micr., 4, p. 41 (1931).

indlcatella Walker, Cat. Lep. Het. Brit. Mus., 29, Brazil p. 732 (1864).

infecta Meyrick, Ann. Nat. Mus. Wien, 44, p. 254, Brazil t. 2, f. 20 (1930).

inflata Butler, Cistula Entom., 2, p. 187 (1882). Amazon

infrenata Meyrick, Exot. Micr., 2, p. 202 (1918). F. Guiana

infusa Meyrick, Exot. Micr., 1, p. 522 (1916). F. Guiana

injucunda Meyrick, Exot. Micr., 3, p. 219 (1925). Peru

innexa Meyrick, Exot. Micr., 3, p. 190 (1925). Poru

insldiata Meyrick, Exot. Micr., 1, p. 512 (1916). F. Guiana

inturbatella Walker, Cat. Lep. Het. Brit. Mus., 29, Brazil p. 737 (1864).

invigilans Meyrick, Exot. Micr., 1, p. 476 (1915); Guianas, id., Ann. Nat. Mus. Wien, 44, p. 244 (1930). Brazil

involucralls Meyrick, Exot. Micr., 4, p. 40 (1931). Brazil

invulgata Meyrick, Exot. Micr., 1, p. 458 (1915); S. America id., Ann. Nat. Mus. Wien, 44, p. 248 (1930).

iocoma Meyrick, Exot. Micr., 1, p. 450 (1915); id., Guianas, Exot. Micr., 1, p. 528 (1916); id., Ann. Brazil Nat. Mus. Wien, 44 , p. 250 (1930).

ioperena Meyrick, Exot. Micr., 4, p. 300 (1932). Peru

ioptila Meyrick, Exot. Micr., 1, p. 433 (1915). B. Guiana

iostalacta Meyrick, Exot. Micr., 3, p. 212 (1925). Peru 
iraseens Meyrick, Ann. Nat. Mus. Wien, 44, p. 252, Brazil t. 1, f. $22(1930)$.

irenias Meyrick, Exot. Micr., 1, p. 537 (1916). F. Guiana

ischioptiia Meyrick, Exot. Micr., 3, p. 211 (1925); Colombia, id., Exot. Micr., 4, p. 301 (1932). Panama

isehnoseia Meyrick, Exot. Micr., 4, p. 298 (1932). Brazil

isoehyta Meyrick, Exot. Micr., 1, p. 420 (1915). B. Guiana

isomeris Meyrick, Trans. Ent. Soc. London, p. 711 Brazil (1912).

isoplintha Meyrick, Exot. Micr., 3, p. 193 (1925); Brazil id., Ann. Nat. Mus. Wien, 44, p. 241 (1930).

isostiela Meyrick, Exot. Micr., 4, p. 299 (1932). Mexico

javariea Butler, Cistula Entom., 2, p. 192 (1882). Amazon, - Meyrick, Exot. Micr., 3, p. 192 (1925). F، Guiana

paramochla Meyrick, Exot. Micr., 2, p. 207 (1918); id., Exot. Micr., 3, p. 192 (1925).

jueunda Meyrick, Exot. Micr., 1, p. 429 (1915); Peru id., Exot. Micr., 1, p. 536 (1916).

juvenaiis Meyrick, Ann. Nat. Mus. Wien, 44, p. Brazil 240 , t. 2 , f. 13 (1930).

kiemaniana Stoll, Cram. Pap. Exot., 4, p. 192, t. Guianas 384, f. i (1782). - Walker, Cat. Lep. Het. Brit. Mus., 28, p. 414 (1863).

iaeera Zellor, Hor. Soc. Ent. Ross., 13, p. 328, t. 4, S. America f. 103 (1877).

iaetifiea Busck, Ins. Insc. Mens., 8, p. 91 (1920). Guatemala

iampyrideila Busck, Proc. U. S. Nat. Mus., 47, p. Panama 41 (1914).

Iatipennis Zeller, Hor. Soc. Ent. Ross., 13, p. 279, Colombia t. 3, f. 79 (1877).

latitans Dognin, Ann. Soc. Ent. Belg., 49, p. 89 Brazil (1905).

iavata Walsingham, Biol. Centr.-Amer., 4, p. 174, Mexico t. 6 , f. $6(1913)$.

iaxa Mfeyrick, Exot. Micr., 1, p. 428 (1915). Venezuela

iembifera Meyrick, Exot. Micr., 1, p. 440 (1915). Guianas

iepidoearpa Meyrick, Ann. Nat. Mus. Wien, 44, p. Brazil 239 , t. 1 , f. 9 (1930).

ieprosa Felder, Reise Nov., 2, t. 138, f. 65 (1875). Amazon

ieptogma Meyrick, Exot. Micr., 3, p. 217 (1925); Colombia, id., Exot. Micr., 3, p. 559 (1930). Brazil

leueana Sepp, Surinam Vlinders, 2, p. 127, t. 60 O.America, (1850). - Walker, Cat. Lep. Het. Brit. Mus., 28, p. 360 (1863). - Walsingham, Biol. Centr.-Amer., 4, p. 186 (1913). Meyrick, Exot. Micr., 3, p. 192 (1925); id., Trans. Ent. Soc. London, 76, p. $515(1929)$; id., Ann. Nat. Mus. Wien, 44, p. 246 (1930). 
t e n e r a Zeller, Linn. Entom., 9, p. 364 (1854); id., Linn. Entom., 10, p. 153 (1855). Walker, Cat. Lep. Het. Brit. Mus., 29, p. 712 (1864). - Zeller, Hor. Soc. Ent. Ross., 13, p. 263 (1877). - Walsingham, Proc. Zool. Soc. London, p. 100 (1897). - Meyrick, Exot. Micr., 3, p. 192 (1925).

virginalis Butler, Cistula Intom., 2, p. 192 (1882). - Meyrick, Exot. Mlicr., 3, p. 192 (1925); id., Ann. Nat. Mus. Wien, 44, p. $246(1930)$.

a lb a nus Walsingham (nec Fabricius), Proc. Zool. Soc. London, 1897, p. 100; id., Biol. Centr.-Amer., 4, p. 186 (1913).

ne a nic a Walsingham, Biol. Centr.-Amer., 4, p. 186 (1913). - Meyrick, Exot. Micr., 3, p. 192 (1925).

Ieucaniella Walker, Cat. Lep. Het. Brit. Mus., Venezuela 29 , p. 715 (1864).

leucocryptis Meyrick, Exot. Micr., 4, p. 295 (1932). Colombia

lcucophaeella Walker, Cat. Lep. Het. Brit. Mus., Brazil 29 , p. 724 (1864).

lencosaris Meyrick, Exot. Micr., 3, p. 196 (1925). Peru

leucothea Busck, Proc. U. S. Nat. MLus., 47, p. 50 Panama (1914).

lianthes Meyrick, Exot. Micr., 4, p. 301 (1932). Brazil

libertina Meyrick, Exot. Micr., 1, p. 526 (1916). F. Guiana

licmaea Meyrick, Exot. Micr., 1, p. 462 (1915). B. Guiana

lithogypsa Meyrick, Exot. Micr., 4, p. 299 (1932). Brazil

litura Zeller, Isis, 3, p. 195 (1839); id., Linn. En- S. America tom., 9, p. 369 (1854). - Walker, Cat. Lep. Het. Brit. Mus., 29, p. 713 (1864).

Iophoptycha Meyrick, Exot. Micr., 3, p. 188 (1925). Brazil

Iophosaris Meyrick, Exot. Micr., 3, p. 186 (1925). Brazil

loxogrammos Zellcr, Linn. Entom., 9, p. 367, t. 3, Brazil f. 17 (1854). - Walker, Cat. Lep. Het. Brit. Mus., 29, p. 712 (1864).

Incidiorella Walker, Cat. Lep. Het. Brit. Mus., 29, Brazil p. 728 (1864).

Iucrosa Meyrick, Exot. Micr., 3, p. 184 (1925). Brazil

Iuctifica Zeller, Hor. Soc. Int. Ross., 13, p. 301 Panama (1877). - Walsingham, Biol. Centr.-Amer., I. Guiana, 4, p. 174 (1913).

Peru

Iuscina Zeller, Hor. Soc. Ent. Ross., 13, p. 288 Panama (1877). - Walsingham, Biol. Centr.-Amer., 4, p. 169 (1913).

Iutulenta Zeller, Hor. Soc. Ent. Ross., 13, p. 270 S. America, (1877). - Walsingham, Biol. Centr.-Amer., C. America 4, p. 182 (1913). 
machinatrix Meyrick, Exot. Micr., 3, p. 208 (1925). Colombia macraulax Meyrick, Exot. Micr., 3, p. 559 (1930). Brazil maeronota Meyrick, Trans. Ent. Soc. London, p. 716 Colombia, (1912). D. Guiana

maeroptyeha Meyrick, Exot. Micr., 4, p. 28 (1930). Panama

malacoxesta Meyrick, Ann. Nat. Mus. Wien, 44, p. Brazil 252 , t. 1 , f. $23(1930)$.

manceps Meyrick, Exot. Micr., 3, p. 172 (1925). Peru

mareida Butler, Cistula Entom., 2, p. 190 (1882). Amazon

melanesia Meyrick, Trans. Ent. Soc. London, p. 712 Colombia (1912).

melanixa Meyrick, Trans. Ent. oSc. London, p. Colombia, 715 (1912); id., Exot. Micr., 1, p. 540 Guatemala, (1916); id., Exot. Micr., 3, p. 192 (1925). Brazil acrosticta Walsingham, Biol. Centr.-Amer., 4 , p. 183 , t. 6, f. 27 (1913). - Meyrick, Exot. Micr., 3, p. 192 (1925).

melanopis Meyrick, Trans. Ent. Soc. London, 1909, Peru p. 31 ; id., Exot. Vicr., 1, p. 492 (1916).

meligrapla Meyrick, Exot. Micr., 3, p. 183 (1925). Brazil

melinopa Meyrick, Exot. Micr., 3, p. 222 (1925). Brazil

melixesta Meyrick, Exot. Micr., 3, p. 210 (1925). Colombia

mendax Zeller, Linn. Entom., 10, p. 161 (1855). - Brazil, Walkor, Cat. Lep. Het. Brit. Mus., 29, p. Panama 711 (1864). - Zeller, Hor. Soc. Ent. Ross., 13, p. 286 (1877). - Walsigham, Biol. Centr.-Amer., 4, p. 163 (1912).

menesiella Walsingham, Biol. Centr.-Amer., 4, p. Panama 174 , t. 6 , f. 5 (1913).

meridiana Meyrick, Exot. Micr., 1, p. 435 (1915); Guianas, id., Ann. Nat. Mus. Wien, 44, p. 255 (1930). Brazil

meridogramma Meyrick, Ann. Nat. Mus. Wien, 44, Brazil p. 242 , t. 1 , f. $12(1930)$.

mesosarís Meyrick, Exot. Micr., 3, p. 178 (1925). F. Guiana

methystica Meyrick, Ann. Nat. Mus. Wien, 44, p. Brazil 251, t. 2 , f. 18 (1930).

metroleuca Meyrick, Ann. Nat. Mus. Wien, 44, p. Brazil 256 , t. 2, f. 21 (1930).

meyeriana Cramer, Pap. Exot., 4, p. 138, t. 360 , f. Guianas $\mathrm{K}$ (1782). - Walker, Cat. Lep. Het. Brit. Mus., 28, p. 360 (1863).

mierotypa Meyrick, Exot. Micr., 1, p. 422 (1915). B. Guiana

miliehodes Meyrick, Exot. Micr., 1, p. 448 (1915). Colombia

minor Busck, Proc. U. S. Nat. Mus., 47, p. 49 Panama (1914). 
misefa Walsingham, Biol. Centr.-Amer., 4, p. 180 Costa Rica, 1913). $\quad$ F. Guiana

mistrella Busck, Proc. Ent. Soc. Wash., 8, p. 93 N.America, (1907). - Walsingham, Biol. Centr.-Amer., 4, Mexico p. 183 (1913). - Barnes and Busck, Contr. Lep. N. Amer., 4, p. 238 , t. 30 , f. 6 (1920). - Busck and Dampf, Estud. Ofic. Fed. Def. Agr. Mexico, 2, p. 13 (1929).

mniodora Meyrick, Exot. Micl., 3, p. 204 (1925). Colombia

modulata Meyrick, Exot. Micr., 1, p. 436 (1915); Guianas, id., Ann. Nat. Mus. Wien, 44, p. 252 (1930). Brazil

monosaris Meyrick, Exot. Micr., 1, p. 419 (1915); Guianas, id., Ann. Nat. Mus. Wien, 44, p. 238 (1930). Brazil

nundella Walker, Cat. Lep. Het. Brit. Mus., 29, Brazil p. 738 (1864).

mundula Meyrick, Exot. Micr., 1, p. 528 (1916). F. Guiana

murinella Walker, Cat. Lep. Het. Brit. Mus., 29, Brazil p. 743 (1864).

muscula Zeller, Hor. Soc. Ent. Ross., 13, p. 295 Panama (1877). - Walsingham, Biol. Centr.-Amer., 4, p. 169 (1913).

mustela Walsingham, Biol. Centr.-Amer., 4, p. 167, Panama t. 6, f. 1 (1912). - Meyrick, Exot. Micr., 4, p. 295 (1932).

nyopina Zeller, Hor. oSc. Ent. Ross., 13, p. 271 Brazil (1877).

myrochroa Mcyrick, Exot. Micr., 1, p. 448 (1915). Venezuela

myrodora Meyrick, Exot. Micr., 3, p. 197 (1925); Guianas, id., Ann. Nat. Mus. Wien, 44, p. 243 (1930). Brazil

nyyrrhinopa Meyrick, Exot. Micr., 4, p. 300 (1932). Brazil,

Guatemala

navicularis Mcyrick, Exot. Micr., 4, p. 24 (1930). Brazil

neastra Meyrick, Exot. Micr., 1, p. 412 (1915). B. Guiana

nebrila Walsingham, Biol. Centr.-Amer., 4, p. 176, C. America, t. 6, f. 11 (1913); id., Ann. Nat. Mus. Wien, S. America 44 , p. $256(1930)$.

lith ox e s t a Meyrick, Exot. Micr., 1, p. 432 (1915); id., Ann. Nat. Mus. Wien, 44, p. 256 (1930).

negotiosa Meyrick, Exot. Micr., 3, p. 201 (1925). Brazil

neocrossa Meyrick, Exot. Micr., 3, p. 193 (1925). Peru

neoperena Meyrick, Ann. Nat. Mus. Wien, 44, p. Brazil 245 (1930).

neoptila Meyrick, Exot. Micr., 3, p. 195 (1925). Brazil

nephelocyma Meyrick, Exot. Micr., 4, p. 27 (1930). Brazil

Lepidopterorum Catalogus 67. 
nepheloleuca Meyrick, Exot. Micr., 4, p. 298 (1932). Costa Rica neurocentra Meyrick, Exot. Micr., 3, p. 179 (1925). Peru

nigricans Busck, Proc. U. S. Nat. Mus., 47, p. 38 Panama (1914).

niphacma Meyrick, Exot. Micr., 1, p. 510 (1916). F. Guiana

nitens Butler, Cistula Entom., 2, p. 188 (1882). Amazon

nitidorella Walker, Cat. Lep. Het. Brit. Mus., 29, Brazil p. 729 (1864).

niviliturella Walker, Cat. Lep. Het. Brit. Mus., 30, Brazil

p. 1020 (1864). - Walsingham, Biol. Centr.-

Amer., 4, p. 174 (1913). - Meyrick, Ann.

Nat. Mus. Wien, 44, p. 249 (1930).

nonagriella Walker, Cat. Lep. Het. Brit. MCus., 29, C. America, p. 715 (1864). - Meyrick, Exot. Micr., 3, p. S.America 192 (1925); id., Ann. Nat. Mus. Wien, 44, p. $247(1930)$.

a rgill acea Zeller, Hor. Soc. Ent. Ross., 13 , p. 266 (1877). - Walsingham, Biol. Centr.-Amer., 4, p. 183 (1913). - Meyrick, Exot. Micr., 3, p. 192 (1925).

praeca u ta Meyrick, Exot. MIicr., 1, p. 527 (1916); id., Exot. Micr., 3, p. 192 (1925). notifera Meyrick, Exot. Mici., 1, p. 465 (1915). Paraguay

notogramma Meyrick, Ann. Nat. Mus. Wien, 44, p. Brazil 243, t. 1 , f. 13 (1930).

nolosaris Meyrick, Exot. Micr., 3, p. 181 (1925); Brazil id., Exot. Micr., 3, p. 240 (1926); id., Ann.

Nat. Mus. Wien, 44, p. 238 (1930).

notosemia Zeller, Hor. Soc. Ent. Ross., 13, p. 298, Colombia t. 3 , f. 86 (1877).

nuntia Meyrick, Exot. Micr., 3, p. 179 (1925). Peru

nycleropa Meyrick, Exot. Micr., 1, p. 422 (1915). B. Guiana

nymphas Meyrick, Exot. Nicr., 1, p. 534 (1916). F.Guiana

nymphotima Meyrick, Exot. Micr., 4, p. 41 (1931). Brazil

oblita Butler, Cistula Entom., 2, p. 163 (1882). $\quad$ Mmazon

obmutescens Meyrick, Exot. Micr., 1, p. 525 (1916). F.Guiana

obovata Meyrick, Exot. Micr., 4, p. 40 (1931). Brazil

oblusa Meyrick, Exot. Micr., 1, p. 513 (1916). F. Guiana

obydella Felder, Reise Nov., 2, t. 138, f. 29 (1875). Amazon

occanitis Meyrick, Exot. Micr., 1, p. 519 (1916). F. Guiana

ocellea Forbes, Sci. Surv. Porto Rico, 12, p. 131, Cuba

f. 3, 8 (1930). - Busck, Entom. Amer., 13, p. $162(1934)$. 
ochlodes Walsingham, Biol. Centr.-Amer., 4, p. 166, Panama t. 5 , f. 35 (1912).

ochricollis Zellcr, Hor. Soc. Ent. Ross., p. 294, t. C. America, 3, f. 83 (1877). - Walsingham, Biol. Centr.- S. America

Amer., 4, p. 169 (1913). - Meyrick, Exot.

Micr., 3, p. 192 (1925); id., Trans. Ent.

Soc. Loudon, 76, p. 515 (1929); id., Ann.

Nat. Mus. Wien, 44, p. 249 (1930).

marginata Busck, Proc. U. S. Nat. Mus., Panama 47, p. 49 (1914). - Meyrick, Exot. Micr., 3, p. 192 (1925).

th y miota Meyrick, Exot. Micr., 1, p. 451 B. Guiana (1915); id., Exot. Micr., 3, p. 192 (1925).

ochropa Walsingham, Biol. Centr.-Amer., 4, p. 173 Panama (1913).

ochrosaris Meyrick, Exot. Micr., 3, p. 199 (1925). Brazil

ochrothicata Meyrick, Exot. Micr., 3, p. 180 (1925). Brazil

octacentra Meyrick, Exot. Micr., 1, p. 459 (1915). Peru

ogmoloplaa Meyrick, Exot. Micr., 3, p. 557 (1930). Brazil

ogmosaris Meyrick, Exot. Micr., 1, p. 415 (1915). B.Guiana

omphacopa Meyrick, Exot. Micr., 4, p. 39 (1931). Bolivia

ophrysta Meyrick, Trans. Ent. Soc. London, 1912, D. Guiana p. '708.

orgadopa Meyrick, Exot. Micr., 3, p. 182 (1925). Brazil

orncopis Meyrick, Exot. Mic1., 3, p. 221 (1925). Brazil

orthocapna Meyrick, Trans. Ent. Soc. London, 1912; Guianas,

p. 717 ; id., Ann. Nat. Mus. Wien, 44 , p. Brazil 241 (1930).

orthographa Meyrick, Exot. Micr., 3, p. 205 (1925). Brazil

ortholampra Meyrick, Exot. Micr., 4, p. 29 (1930). Brazil

orthopa Meyrick, Exot. Micr., 4, p. 297 (1932). Panama

ostodes Walsinghain, Biol. Centr.-Amer., 4, p. 174 Guatemala (1913).

ovulifera Meyrick, Exot. Micr., 3, p. 182 (1925). Peru

oxyschista Meyrick, Exot. Micr., 3, p. 187 (1925). Brazil

oxyscia Meyrick, Exot. Micr., 2, p. 615 (1922). T. Guiana

pallicosta Felder, Reise Nov., 2, t. 138, f. 41 (1875). Amazon

pantogenes Meyrick, Exot. Micr., 4, p. 30 (1930). Brazil

paracapna Meyrick, Exot. Micr., 1, p. 444 (1915). B. Guiana

paracta Meyrick, Exot. Micr., 1, p. 425 (1915). Peru

paraplecta Meyrick, Exot. Micr., 3, p. 214 (1925). Brazil 
pardalodes Meyrick, Exot. Micr., 2, p. 207 (1918). F. Guiana paropta Meyrick, Exot. Micr., 1, p. 536 (1916). F. Guiana parlicularis Zeller, Hor. Soc. Ent. Ross., 13, p. 293, Panama t. 3 , f. 82 (1877). - Walsingham, Biol. Centr.-Amer., 4, p. 169 (1913).

patellifera Meyrick, Exot. Micr., 4, p. 34 (1931). Brazil

palens Meyrick, Trans. Ent. Soc. London, p. 189 Peru (1913).

patula Meyrick, Exot. Micr., 1, p. 526 (1916). F. Guiana

paurocentra Meyrick, Trans. Ent. Soc. London, Colombia 1912, p. 713.

pauroconis Meyrick, Exot. Micr., 4, p. 303 (1932). Brazil

peccans Butler, Cistula Entom., 3, p. 191 (1882). Amazon

pelinilis Meyrick, Trans. Ent. Soc. London, 1912, Colombia p. 714 .

pcrcnocarpa Meyrick, Exot. Micr., 3, p. 181 (1925). Brazil

periaula Meyrick, Exot. Micr., 1, p. 510 (1916). T. Guiana

perldesma Meyrick, Exot. Micr., 3, p. 220 (1925). Brazil

pcriphrictis Meyrick, Exot. Micr., 1, p. 451 (1915). B. Guiana

perirrhoa Meyrick, Exot. Micr., 4, p. 28 (1930). F. Guiana

periscelta Meyrick, Exot. Micr., 1, p. 457 (1915). Pern

perjecta Meyrick, Exot. Micr., 4, p. 36 (1931). Brazil

perjura Moyrick, Exot. Micr., 3, p. 207 (1925). Brazil

peronia Busck, Ins. nIsc. Mens., 1, p. 90 (1913). B. Guiana

perophora Meyrick, Exot. Micr., 1, p. 469 (1915). Peru

persita Meyrick, Exot. Micr., 1, p. 463 (1915). Peru

pertinax Meyrick, Exot. Micr., 1, p. 459 (1915). Peru

phaeomistis Meyrick, Exot. Micr., 3, p. 197 (1925). Peru

phaeoneura Meyrick, Trans. Ent. Soc. London, 1913, B. Guiana p. 187.

phaeophanes Meyrick, Trans. Ent. Soc. London, Colombia 1912 , p. 714.

phaeoplintha Meyrick, Exot. Micr., 1, p. 424 (1915); Guianas, id., Ann. Nat. Mus. Wien, 44, p. 239 (1930). Brazil

phalacropa Meyrick, Exot. Micr., 4, p. 303 (1932). Panama

phaseolodes Meyrick, Exot. Micr., 4, p. 39 (1931). Brazil 
phaula Walsingham, Biol. Centr.-Amer., 4, p. 160, Guatemala t. 5 , f. 26 (1912).

phocnissa Butler, Trans. Ent. Soc. London, 1883, p. Chile 81, t. 11, f. 12,12 a. - Calvert, Cat. Lep.

Chile, Anales Univ. Chile, 69, p. 39 (1886).

phollicodes Meyrick, Exot. Micr., 1, p. 533 (1916). F. Guiana

phorlax Meyrick, Exot. Micr., 1, p. 383 (1915); W. Indies, id., Ann. Nat. Mus. Wien, 44, p. 244 (1930). S. America

phyllocosma Meyrick, Exot. Micr., 1, p. 520 (1916); Guianas, id., Ann. Nat. Mus. Wien, 44, p. 244 (1930). Brazil

phylloxantha Meyrick, Exot. Micr., 4, p. 435 (1933). Argentina physotricha Meyrick, Exot. Micr., 1, p. 455 (1915). Venezuela picrantris Meyrick, Ann. Nat. Mus. Wien, 44, p. Brazil 253 , t. 1, f. 24 (1930).

picta Zeller, Linn. Entom., 9, p. 362, t. 3, 位. 15 Brazil (1854). - Walker, Cat. Lep. Het. Brit. Mus., 29, p. 712 (1864). - Meyrick, Exot. Mier., 4, p. 28 (1930).

planicoma Meyrick, Exot. Micr., 3, p. 189 (1925). Brazil platycolpa Meyrick, Exot. Micr., 1, p. 465 (1915). F. Guiana platyphylla Meyrick, Exot. Micr., 1, p. 540 (1916). F.Guiana platylerma Meyrick, Exot. Micr., 1, p. 436 (1915). B.Guiana plebicola Meyrick, Exot. Micr., 2, p. 205 (1918); Guianas, id., Ann. Nat. Mus. Wien, 44, p. 248 (1930). Brazil

pleonastes Meyrick, Exot. Micr., 1, p. 475 (1915). F. Guiana plesistia Meyrick, Exot. Micr., 4, p. 24 (1930). Brazil pleurotricha Neyrick, Exot. Micr., 3, p. 206 (1925); Brazil id., Ann. Nat. Mus. Wien, 44, p. 246 (1930). pleximorpha Moyrick, Exot. Micr., 4, p. 32 (1930). Bolivia plurima Walsingham, Biol. Centr.-Amer., 4, p. 160, Guatemala t. 5, f. 27 (1912). polyglypta Meyrick, Exot. Micr., 1, p. 427 (1915). B. Guiana porinodes Meyrick. Exot. Micr., 1, p. 454 (1915); Guianas, id., Ann. Nat. Mus. Wien, 44, p. 248 (1930). Peru, Brazil

porplyyrastis Meyrick, Exot. Micr., 1, p. 499 (1915); Guianas, id., Exot. Micr., 1, p. 529 (1916); id., Ann. Brazil Nat. Mus. Wien, 44, p. 250 (1930).

pratifera Meyrick, Exot. Micr., 3, p. 222 (1925). Costa Rica procritica Meyrick, Exot. Micr., 3, p. 217 (1925). Brazil projecta Meyrick, Exot. Micr., 1, p. 466 (1915). F.'Guiana 
promolclla Zeller, Hor. Soc. Ent. Ross., 13, p. 296, Panama t. 3, f. 84 (1877). - Walsingham, Biol. Centr-Amer., 4, p. 170 (1913). - Meyrick, Exot. Micr., 3, p. 233 (1926).

prosora Walsingham, Biol. Centr.-Amer., 4, p. 161, Panama t. 5 , f. 29 (1912).

psalmographa Meyrick, Exot. Micr., 4, p. 35 (1931). Brazil

psilomorpha Meyrick, Exot. Micr., 1, p. 470 (1915). Peru

ptilallactis Mevrick, Exot. Micr., 4, p. 24 (1930). Brazil

ptychobathra Meyrick, Ann. Nat. Mus. Wien, 44, Brazil p. 245 , t. 1 , f. $16(1930)$.

ptychocentra Meyrick, Exot. Micr., 1, p. 510 (1916). F. Guiana

ptychophthalma Meyıick, Exot. Micr., 4, p. 31 Bolivia (1930).

punicea Meyrick, Exot. Micr., 1, p. 518 (1916). F. Guiana

pustulatella Walker, Cat. Lep. Het. Brit. Mus., 29, Brazil p. 729 (1864).

pyramidea Walsingham, Biol. Centr.-Amer., 4, p. Guatenala $172(1913)$

pyrenodes Meyrick, Exot. Micr., 1, p. 448 (1915). Argentina

pyrgota Meyrick, Exot. Micr., 4, p. 25 (1930). Brazil

pyrobathra Meyrick, Exot. Micr., 4, p. 33 (1931). Brazil

pyrrhias Meyrick, Exot. Micr., 1, p. 455 (1915). B.Guiana

pyrrhonota Meyrick, Exot. Micr., 1, p. 446 (1915). B. Guiana

quadratclla Walker, Cat. Lep. Het. Brit. Mus., 29, C. America, p. 715 (1861). - Walsingham, Biol. Centr.- S. America Amer., 4, p. 189, t. 6, f. 32 (1913). - Meyrick, Exot. Micr., 1, p. 384 (1915); id., Exot. Micr., 3, p. 192 (1925).

le ont ode s Meyrick, Exot. Micr., 1, p. 384 (1915); id., Exot. Micr., 3, p. 192 (1925).

quieseens Meyrick, Exot. Micr., 1, p. 514 (1916). F.Guiana receptella Walker, Cat. Lep. Het. Brit. Mus., 29, p. Brazil 734 (1864).

recondila Meyrick, Exot. Micr., 1, p. 439 (1915). B. Guiana

rectificata Meyrick, Exot. Micr., 3, p. 180 (1925). Brazil

recurrens Meyrick, Exot. Micr., 3, p. 210 (1925). Bolivia

redintegrata Meyrick, Exot. Micr., 3, p. 218 (1925). Bolivia

regesla Meyrick, Exot. Micr., 3, p. 225 (1926). Peru,

Colombia

relata Meyrick, Exot. Micr., 3, p. 207 (1925). $\quad \begin{gathered}\text { Brazil, } \\ \text { Peru }\end{gathered}$ 
remorsa Meyrick, Exot. Micr., 3, p. 195 (1925). Bolivia

residuclla Zeller, Hor. Soc. Ent. Ross., 13, p. 297, Brazil f. 85 (1877). - Meyrick, Exot. Micr., 3, p. 558 (1930).

rhipidaula Meyrick, Exot. Micr., 1, p. 431 (1915). B. Guiana

rhodocolpa Meyrick, Exot. Micr., 1, p. 517 (1916). F. Guiana

rhothiodes Meyrick, Exot. Micr., 1, p. 437 (1915). Brazil

robiginosa Meyrick, Exot. Micr., 3, p. 215 (1925). Brazil

rosa Busck, Proc. U. S. Nat. Mus., 40, p. 224 Guianas, (1911). - Meyrick, Ann. Nat. Mus. Wien, Brazil 44 , p. 244 (1930).

rosacca Butler, Cistula Entom., 2, p. 192 (1882). Amazon

rostriformis Meyrick, Exot. Micr., 1, p. 532 (1916). F.Guiana

rubiginosella Walker, Cat. Lep. Het. Brit. Mus., Brazil 29, p. 745 (1864). - Meyrick, Exot. Micr., 2, p. 626 (1922).

sagax Busck, Proc. U. S. Nat. Mus., 47, p. 40 Panama (1914).

salome Busck, Proc. U. S. Nat. Mus., 40, p. 219 Brazil (1911). - Meyrick, Exot. Micr., 3, p. 192 (1925).

clavifera Meyrick, Trans. Eut. Soc. Lon- Brazil don, 1912, p. 715; id., Exot. Micr., 3, p. 192 (1925).

salubris Meyrick, Exot. Micr., 3, p. 208 (1925). Brazil

satelles Meyrick, Exot. Micr., 3, p. 202 (1925); id., Brazil Ann. Nat. Mus. Wien, 44, p. 245 (1930).

satyropa Meyrick, Exot. Micr., 1, p. 478 (1915); Guianas, id., Ann. Nat. Mus. Wien, 44, p. 255 (1930). Brazil

seapularis Meyrick, Exot. Micr., 2, p. 208 (1918). F. Guiana sceptrifera Meyrick, Exot. Micr., 1, p. 524 (1916). F. Guiana

seiaphilina Zeller, Hor. Soc. Ent. Ross., 13, p. 291, Mexico, t. 3, f. 81 (1877). - Walsingham, Biol, Panama, Centr.-Amer., 4, p. 169 (1913). - Mey- B. Guiana rick, Exot. Micr., 3, p. 192 (1925); id., Ann. Nat. Mus. TVien, 44, p. 249 (1930).

a $p h$ a ne s Walsinglam, Biol. Centr.-Amer., 4, p. 167 (1912). - Meyrick, Ann. Nat. Mus. Wicn, 44, p. 249 (1930).

torophragma Meyrick, Exot. Micr., 1, p. 439 (1915); id., Exot. Micr., 3, p. 192 (1925); id., Ann. Nat. Mus. Wien, 44, p. 249 (1930).

seiocnesta Meyrick, Exot. Micr., 3, p. 213 (1925). Brazil

seiogama Meyrick, Exot. Micr., 3, p. 558 (1930). Brazil 
seiophthaIma Meyrick, Exot. Micr., 4, p. 34 (1931). Brazil

seiospila Meyrick, Exot. Micr., 4, p. 27 (1930).

Brazil

scitiorella Walker, Cat. Lep. Het. Brit. Mus., 29, p. 743 (1861). - Meyrick, Exot. Micr., 3, p. 192 (1925); id., Ann. Nat. Mus. Wien, 44, p. $249(1930)$

la e vi u s c u l a Zeller, Hor. Soc. Ent. Ross., 13 , p. 290 , t. 3 , f. 80 (1S77). - Meyrick, Exot. Miel., 3, p. 192 (1925).

felix Busck, Proc. U. S. Nat. Mus., 47, p. 40 (1914). - Meyrick, Exot. Micr,, 3, p. 192 (1925).

scoliandra Merrick, Exot. Mier., 1, p. 441 (1915); Guianas, id., Ann. Nat. Mus., 44, p. 252 (1930). Brazil

scolopacina Walsingham, Biol. Centr.-Amer., 4, p. Panama 181, t. 6 , f. 25 (1913).

scoriodes Meyrick, Exot. Micr., 1, p. 382 (1915); Guianas id., Exot. Micr., 1, p. 509 (1916).

a vid a Meyrick, Exot. Micr., 1, p. 435 (1915); id., Exot. Micr., 1, p. 509 (1916).

seorlea Meyrick, Exot. Micr., 1, p. 459 (1915). B. Guiana, Brazil

secundata Meyrick, Exot. Micr., 3, p. 214 (1925). Peru

sedueta Meyrick, Exot. Mier., 2, p. 206 (1918). F. Guiana

segmentata Meyrick, Exot. Micr., 1, p. 423 (1915). B. Guiana

sematopa Meyrick, Exot. Micr., 1, p. 450 (1915). B. Guiana

semisiquella Walker, Cat. Lep. Het. Brit. Mus., Brazil 29, p. 741 (1864).

seppiana Cramer, Pap. Exot., 4, p. 135, t. 359, f. Guianas H (1782). - Walker, Cat. Lep. Het. Brit. Mus., 28, p. 360 (1863).

sequestra Meyrick, Exot. Micr., 2, p. 205 (1918); Guianas, id., Ann. Nat. Mus. Wien, 44, p. 245 (1930). Brazil

serieata Butler, Cistula Entom., 2, p. 163 (1877); S. America id., Ann. Nat. Mus. Wien, 44, p. 245 (1930). e minula Meyrick, Exot. Micr., 1, p. 473 (1915); id., Ann. Nat. Mus. Wien, 44, p. 245 (1930).

sesquitertia Zeller, Linn. Entom., 9, p. 379, t. 3, Peru, f. 20 (1854). - Walker, Cat. Lep. Het. Guianas, Brit. Mus., 29, p. 714 (1864). - Meyrick, Brazil Ann. Nat. Mus. Wien, 44, p. 255 (1930).

graphiphorella Walker, Cat. Lep. Het. Brit. Mus., 29, p. 770 (1864). - Zeller, Hor. Soc. Ent. Ross., 13, p. 281 (1877). Meyrick, Ann. Nat. Mus. Wien, 44, p. 255 (1930).

lapide a Meyrick, Exot. Micr., 1, p. 540 (1916); id., Ann. Nat. Mus. Wien, 44, p. $255(1930)$.

simplex Busck, Proc. U. S. Nat. Mus., 47, p. 49 Panama (1914). 
sinuata Fabricius, Sppl. Ent. Syst., p. 509 (1798). W. Indies (1798). - Turton, Syst. Nat., 3, p. 383 (1806). - Walsingham, Proc. Zool. Soc. London. p. 99 (1897).

dentella Fabricius (praeoce.), Ent. Syst., 3, p. 343 (1794). - Turton. Syst. Nat., 3, 383 (1806). - Walsingham, Proc. Zool. Soc. London, p. 99 (1897).

siraphora Mcyrick, Exot. Micr., 1, p. 475 (1915); Guianas, id., Ann. Nat. Mus. Wien, 44, p. 241 (1930). Brazil

sommerella Zeller, Hor. Soc. Ent. Ross., 13, p. 278, C. America? t. 3, f. 78 (1877). - Walsingham, Biol. S. America Centr.-Amer., 4, p. 169 (1913).

speetrophthalma Meyrick, Exot. Micr., 4, p. 302 Bolivia (1932).

spermidias Meyrick, Exot. Mic1., 4, p. 295 (1932). Panama

sphragidopis Meyrick, Exot. Micr., 1, p. 431 (1915); Guianas, id., Aun. Nat. Mus. Wicn, 44, p. 256 (1930). Brazil

spodinopis Meyrick, Exot. Micr., 4, p. 35 (1931). Brazil

stabilis Butler, Cistula Entom., 2, p. 164 (1882). Amazon

stephanodes Meyrick, Exot. Micr., 4, p. 42 (1931). F.Guiana

sterrhomitra Meyrick, Exot. Micr., 3, p. 178 (1925). Brazil

stigmatias Walsingham, Biol. Centr.-Amer., 4, p. Guatemala 184 , t. 6, f. 29 (1913).

straminella Walker, Cat. Lep. Het. Brit. Mus., 29, Brazil p. 722 (1864).

strenuella Walker, Cat. Lep. Het. Brit. Mus., 29, Brazil, p. 736 (1864). - Meyrick, Ann. Nat. Mus. Guianas, Wien, 44, p. 251 (1930). Bolivia

striatella Busck, Proc. U. S. Nat. Mus., 47, p. 47 Panama (1914).

strigivenata Butler, Cistula Eutom., 2, p. 180 (1882). Amazon

Striolata Meyrick, Exot. Micr., 4, p. 302 (1932). Brazil

strophalodes Meyrick, Exot. Micr., 1, p. 454 (1915). Peru

slupefacta Meyrick, Exot. Micr., 1, p. 523 (1916). F. Guiana

slygeropa Meyrick, Exot. Micr., 3, p. 187 (1925). Brazil

stylonola Meyrick, Exot. Micr., 1, p. 447 (1915). B. Guiana

subduleis Meyrick, Exot. Micr., 3, p. 195 (1925). Brazil

subita Meyrick, Exot. Micr., 3, p. 224 (1925). Bolivia

sublimbata Zeller, Hor. Soc. Ent. Ross., 13, p. 325, Panama, t. 4, f. 101 (1877). - Walsingham, Biol. Colombia, Centr.-Amer., 4, p. 172 (1913). - Mey- Bolivia rick, Exot. Micr., 3, p. 205 (1925). 
sublunaris Meyrick, Ann. Nat. Mus. Wien, 44, p. Brazil 248 , t. 1 , f. 29 (1930).

submersa Meyrick, Exot. Micr., 1, p. 429 (1915).

B. Guiana

subovalis Meyrick, Exot. Micr., 4, p. 304 (1932). Brazil

suffumigata Walsingham, Proc. Zool. Soc. London, W. Indies 1897 , p. 98.

sustentata Meyrick, Exot. Micr., 3, p. 325 (1926); Colombia id., Trans. Ent. Soc. London, 76, p. 515 (1929).

symmicta Walsingham, Biol. Centr.-Amer., 4, p. C. America, 183, t. 6, f. 26 (1913). - Meyrick, Exot. S. America Micr., 4, p. 303 (1932).

charitarcha Meyrick, Exot. Micr., 1, p. 438 (1915); id., Ann. Nat. Mus. Wien, 44, p. 253 (1930); id., Exot. Micr., 4, p. 303 (1932).

symphonica Meyrick, Exot. Micr., 1, p. 522 (1916); F. Guiana, id., Trans. Ent. Soc. London, 76, p. 515 Panama (1929).

syndicastis Meyrick, Trans. Ent. Soc. London, 76, p. Colombia 516 (1929).

syngraphopis Meyrick, Ann. Nat. Mus. Wien, 44, Brazil p. 240 , t. 1 , f. $10(1930)$.

tabida Butler, Cistula Entom., 2, p. 164 (1882). Amazon

tectoria Meyrick, Exot. Micr., 1, p. 429 (1915); id., Guianas, Ann. Nat. Mus. Wien, 44, p. 241 (1930). Brazil

tempcstiva Meyrick, Exot. Micr., 1, p. 529 (1916). F. Guiana

Iephrodesma Mcyrick, Exot. Micr., 1, p. 511, 513 Brazil, (1916); id., Ann. Nat. Mus. Wien, 44, p. Guianas 239 (1930).

tetrabola Meyrick, Trans. Ent. Soc. London, 1913, p. Peru 189.

tetrapctra Meyrick, Exot. Micr., 3, p. 194 (1925). Brazil

thalcropa Meyrick, Exot. Micr., 1, p. 529 (1916). F. Guiana

thespia Meyrick, Exot. Micr., 1, p. 474 (1915). F. Guiana

tholodes Meyrick, Exot. Micr., 1, p. 457 (1915). B. Guiana

thologramma Meyrick, Exot. Micr., 4, p. 300 (1932). Peru

thoristes Busck, Proc. U. S. Nat. Mus., 40, p. 220 F. Guiana (1911). - Meyrick, Exot. Micr., 3, p. 192 (1925).

contumax Mcyrick, Exot. Micr., 1, p. 522 (1916); id., Exot. Micr., 3, p. 192 (1925).

thylacosaris Meyrick, Exot. Micr., 1, p. 419 (1915); Grinanas, id., Ann. Nat. Mus. Wicn, 44, p. 238 (1930). Brazil

thysanodes Mcyrick, Exot. Micr., 1, p. 434 (1915); Guianas, id., Ann. Nat. Mus. Wien, 44, p. 241 (1930). Brazil

tinactis Meyrick, Exot. Micr., 1, p. 414 (1915). B. Guiana 
linctipennis Butler, Cistula Entom., 2, p. 187 (1882). Amazon, - Meyrick, Ann. Nat. Mus. Wien, 44, p. 243 Brazil $(1930)$.

tolmeta Walsingham, Biol. Centr.-Amer., 4, p. 166, Panama t. 5, f. 34 (1912).

trcmulella Walker, Cat. Lep. Het. Brit. Mus., 30, Brazil p. 1035 (1864).

triacmopa Meyrick, Exot. Micr., 4, p. 37 (1931). Paraguay

tribomias Meyrick, Exot. Micr., 1, p. 4177 (1915). B. Guiana

tricapsis Meyrick, Exot. Micr., 4, p. 26 (1930). Brazil

tricharacta Meyrick, Exot. Micr., 3, p. 199 (1925). Brazil,

F. Guiana

trichocolpa Meyrick, Exot. Micr., 1, p. 445 (1915). F. Guiana

Irichoneura.Meyrick, Trans. Ent. Soc. London, 1913, Venezuela p. 189.

trichorda Meyrick, Trans. Ent. Soc. London, 1912, Colombia p. 713.

trilineata Butler, Cistula Entom., 2, p. 192 (1882). Amazon

triplectra Meyrick, Exot. Micr., 1, p. 423 (1915). B. Guiana

tripustulata Zeller, Linn. Entom., 9, p. 358, t. 3, f. Venezuela 14 (1854). - Walker, Cat. Lep. Het. Brit. Mus., 29, p. 711 (1864).

tripustulella Walker, Cat. Lep. Het. Brit. Mus., 29, Brazil p. 733 (1864).

trirecla Meyrick, Exot. Micr., 4, p. 38 (1931). Brazil

trochilosticta Walsingham, Biol. Centr.-Amer., 4, p. Panana 17 , t. 6 , f. 19 (1913).

Irymalopa Meyrick, Exot. Micr., 3, p. 211 (1925). Colombia

tryphon Busck, Ins. Insc. Jfens., 8, p. 89 (1920). Guatemala

tumens Meyrick, Exot. Micr., 1, p. 511 (1916). F. Guiana

lumulata Meyrick, Exot. Micr., 1, p. 538 (1916). F. Guiana

tyrocrossa Meyrick, Exot. Micr., 3, p. 183 (1925). Brazil

tyroxesta Meyrick, Exot. Micr., 3, p. 213 (1925). Brazil

ulosema Meyrick, Exot. Micr., 3, p. 559 (1930). Brazil

umbriferella Walker, Cat. Lep. Het. Brit. Mus., 29, Brazil p. 740 (1864).

umbrincrvis Meyrick, Ann. Nat. Mus. Wien, 44, Brazil p. $211(1930)$.

unclicoma Meyrick, Exot. Micr., 1, p. 528 (1916); Guianas, id., Ann. Nat. MLus. Wien, 44, p. 249 (1930)' Brazil

unguentata Meyrick, Ann. Nat. Mus. Wien, 44, Brazil p. 250 , t. 1 , f. 20 (1930).

unisccta Meyrick, Exot. Micr., 4, p. 26 (1930). Brazil 
unisignis Meyrick, Exot. Micr., 4, p. 296 (1932). Bolivia uranophanes Meyrick, Exot. Micr., 4, p. 41 (1931). Colombia urbana Butler, Cistula Entom., 2, p. 190 (1882). Amazon uruguayensis Berg, Anal. Soc. Cient. Argentina, 19, Uruguay p. 280 (1885).

vacaus Meyrick, Exot. Micr., 1, p. 519 (1916); id., F. Guiana Exot. Micr., 4, p. 29 (1930).

vaccula Walsingham, Biol. Centr.-Amer., 4, p. 177, Mexico t. 6, f. 21 (1913).

vaga Butler, Cistula Entom., 2, p. 187 (1882). Amazon

vannifera Meyrick, Exot. Micr., 1, p. 416 (1915). Peru

vapida Butler, Cistula Entom., 2, p. 188 (1882). Amazon

vasifera Meyrick, Exot. Micr., 3, p. 204 (1925). Colombia

vellalum Busck, Proc. U. S. Nat. Mus., 40, p. 217 Guianas, (1911). - Meyrick, Ann. Nat. Mus. Wien, Bolivia, 44, p. 241 (1930).

venosella Walker, Cat. Tep. Het. Brit. Mus., 29, p. Brazil $718(1864)$

venlilalrix Meyrick, Exot. Mic1., 1, p. 327 (1916). F. Guiana

vexata Meyrick, Exot. Mic.r., 1, p. 444 (1915). B. Guiana

vinifera Meyrick, Exot. Micr., 1, p. 521 (1916); id., Guianas, Ann. Nat. Mus. Wien, 44, p. 253 (1930). Brazil

vila Busck, Proc. U. S. Nat. MLus., 40, p. 226 (1911). Brazil, - Meyrick, Exot. Micr., 3, p. 192 (1925); Guianas id., Ann. Nat. Mus. Wien, 44, p. 245 (1930).

vilreola Meyrick, Exot. Micr., 3, p. 209 (1925). Brazil

vivax Busck, Proc. U. S. Nat. Mus., 47, p. 40 Panama (1914).

volilans Meyrick, Exot. Micr., 3, p. 220 (1925). Peru

xanlhobyrsa Meyrick, Exot. Micr., 1, p. 447 (1915); Guianas, id., Ann. Nat. Mus. Wien, 44, p. 251 (1930). Brazil

xanthopelala Meyrick, Exot. Micr., 4, p. 41 (1931). Brazil

xanthophaeella Walker, Cat. Lep. Het. Brit. Mus., Brazil

xanlhophacella Walker, Cat. Lep. Het. Brit. Mus., Brazil 29, p. 830 (1864). - Meyrick, Gen. Insect., 180 , p. $185(1922)$.

xanlhosoma Dognin, Ann. Soc. Ent. Belg., 57, p. 416 (1913). - Meyrick, Exot. Micr., 3, p. 192 $(1925)$.

s a c r a Meyrick, Exot. Micr., 2, p, 209 (1918); id., Exot. Micr., 3, p. 192 (1925).

xylinopa Meyrick, Exot. Nicr., 3, p. 203 (1925). Bolivia

xylograpta Meyrick, Exot. Micr., 4, p. 40 (1931). Brazil 
xylurga Meyrick, Trans. Fnt. Soc. London, 1913, p. Peru 188.
zanclogramma Mejrick, Exot. Micr., 1, p. 417 B. Guiana zephyritis Meyrick, Exot. Micr., 3, p. 218 (1925). Brazil zobeida Meyrick, Exot. Micr., 4, p. 33 (1931). Mexico 705

\section{Genus Anadasmus Walsingham}

Walsingham, Proc. Zool. Soc. London, 1897, p. 100; id., Biol. Centr.-Amer., 4, p. 158 (1912). - Strand, Archiv f. Naturg., 1913, A. 2, p. 95 . - (Type: sororia Zeller.)

pelodes Walsingham, Biol. Centr.-Amer., 4, p. 180 Mexico, (1913).

Panama

sororia Zeller, Hor. Soc. Ent. Ross., 13, p. 267, t. 3, Mexico, f. 76 (1877). - Walsingham, Proc. Zool. C. America Soc. London, p. 100 (1897); id., Biol. Centr.-

2 Amer., 4, p. 182 (1913).

35 Genera

1170 Species 


\section{Index.}

Scripsit Embrik Strand

\section{Familia, Genera.}

Aedemoses Walshm. 19

Agriophara Meyr. 8

Anadasmus Walshm. 61

Anapatris Meyr. 6

Antaeotricha Zell. 18

Aphanoxena Meyr. 19

Athleta Walshm. 19

Auxocrossa Zell. 31

Auxocrassa Walshm. 31

Baeonoma Meyr. 6

Brachiloma Olem. 18

Catarata Walsghm. 15

Cerconata Meyr. 12

Chlamydastis Meyr. 8

Oryptolechiidae Meyr. 3

Cryptophasidae Fletch. 3

Diastoma Möschl. 18

Dinotropa Meyr. 7

Energia Walsghm. 14

Eumiturga Meyr. 15

Falculina Zell. 5

Gonioterma Tralsghm. 13

Harpalyce Ohamb. 18

Hyale Chamb. 5

Hyalopseustis Meyr. 7

Ide Chamb. 18

Loxotoma Zell. 17

Lychnocrates Meyr. 16

Menesta Clem. 5

Menesthomorpha Walsghm. 4

Mesoptycha Zell. 18

Mothonica Walsghm. 15

Mysaromima Meyr. 6

Neophylarcha Meyr. 16

Orphnolechia Meyr. 31

Paraspastis Meyr. 13

Peleopoda Zell. 7

Petasanthes Meyr. 4

Phelotropa Meyr. 14

Pomphocrita Meyr. 14

Prasolithitis Meyr. 19

Promenesta Busck 4

Psephomeres Meyr. 7

Ptilogenes Meyr. 8

Rhodanassa Meyr. 6

Rhynchophyllis Meyr. 6

Setiostoma Zell. 3

Stenoma Zell. 31

Stenomidae Meyr. 3

Stenomatidae Walsghm. 3

Stenomidae Walsghm. 3

Stenomidae Strand 3

Stenomidae Barn. \& Busck 3

Stenomides Meyr. 3

Stenominac Janse 3

Thioscelis Meyr. 6

Thyrsomnestis Meyr. 15

Timocratica Meyr. 16

Xylorictidae Forb. 3

Xyloryctidae Mey.r. 3

Zetesima Walsghm. 15 


\section{Species.}

absconditella Walk. 19 accurata Meyr. 31 acontiella Meyr. 31 acratodes Meyr. 31 acribota Meyr. 31 acridula Meyr. 31 acrobapta MLeyr. 19 acrograpta Meyr. 19 acronephela Meyr. 19 acronitis Busck 8 acrosticta Wlshm. 48 actista Meyr. 31 additella Walk. 19 addon Busck 19 adductella Moyr. 31 adjunctella Walk. 19 adminiculata Meyr. 31 admixta Walshm. 31 adoratrix Meyr. 31 adornata Meyr. 31 adulans Meyr. 31 adustella Walk. 31 advocata Meyr. 14 adytades Meyr. 31 acrinotata Butl. 31 aequabilis Meyr. 19 aerinotata Butl. 31 aesioscopia Walshm. 32 affinis Felderi 32 affirmatella Busck 32 agathelpis Meyr. 32 aggerata Meyr. 42 aglypta Meyr. 19 aggravata Meyr. 32 aggregata Meyr. 32 agraria Meyr. 32 agrioschista Meyr. 32 albaciliacella Chamb. 5 albaciliella Braun 5 albanus Walshm. 47 albella Chamb. 30 albella Zell. 16 albicella Zell. 32 albiciliella Walsh. 5 albida Walk. 32 albitincta Meyr. 32 albifrons Zell. 19 albovenosa Zell. 19 algidella Walk. 25 algosa Meyr. 32 alligans Butl. 32 alluvialis Meyr. 32 alsiosum Walsghm. 13 ambiens Meyr. 32 amicula Zell. 19 ammodes Meyr. 32 amplierista Meyr. 19 amphilyta Meyr. 19 amphiptera Meyr. 32 amphizyga Meyr. 19 anaclintris Meyr. 19 anamochla Meyr. 8 anaphanta Meyr. 32 anaxesta Meyr. 32 ancalota Meyr. 8 anceps Butl. 32 ancillaris Meyr. 32 anconitis Meyr. 32 ancylacma Meyr. 32 anelaea Meyr. 16 anetodes Meyr. 32 anita Busck 14

anna Busck 13 annixa Meyı. 19 annosa Meyr. 33 anonella Sepp 12 anophthalma Meyr. 33 anticharis Meyr. 29 intilyra Meyr. 33 antitacta Meyr. 33 antitypa Meyr. 5 aphanes Walsglim. 5i aphanodesma Meyr. 17 aphrogenes Meyr. 11 aphrogramma Meyr. 33 aphrophanes Meyr. 33 apicalis Busck 8 aplytopis Meyr. 33 apoclina Meyr. 8 aporodes Meyr. 19 apsorrhoa Meyr. 33 aptila Meyr. 33 arachnia Meyr. 33 arachniotis Meyr. 20 aratella Meyr. 33 arenaria Walsh. 33 arenosa Meyr. 33 argicerauna Meyr. 33 argillacea Zell. 50 argocorys Meyr. 33 argocymba Meys. 8 argonais Meyr. 16 argospora Meyr. 35 argotoma Meyr. 33 nrmata Zell. 33 armiferella Meyr. 33 aromatica Meyr. 33 arridens Meyr. 33 urystis Meyr. 20 ascodes Meyr. 33 asphalopis Meyr. 33 assecta Zell. 20 assignata Meyr. 33 associata Meyr. 33 
astacopis Meyr. 33 asthenopa Meyr. 33 astronoma Meyr. 33 astynoma Meyr. 20 aterpes Walshm. 34 atmodes Meyr. 34 atmospora Meyr. 34 atricassis Meyr. 34 augescens Mroyr. 34 auricoma Meyr. 34 autampyx Meyr. 4 auxoleuca Moy1. 17 avida Meyr. 56 axena Meyr. 20 aztecana Walshm. 34

bahiensis Pexty 28 balanocentra Meyr. 20 balanoptis Meyr. 34 baliandra Meyr. 34 ballista Meyr. 20 basalis Zell. 20 basiferella WValk. 34 basilaris Busck 20 basimacula Möschl. 20 basirubrella Walk. 34 bathrocentra Meyr. 34 bathrogramma Meyr. 34 bathrotoma Meyr. 34 bathyntis Meyr. 34 bathyphaea Meyr. 34 batrachopis Meyr. 8 benigna Meyr. 34 biannulata Meyr. 34 biarcuata Meyr. 20 bicensa Meyr. 34 bicolor Zell. 20 bifida Meyr. 8 bilinguis Meyr. 34 binodis Meyr. 34 binubila Zell. 20 bipupillata Meyr. 20 biseriata Zell. 34 bisignata Meyr. 34 blandula Meyr. 34 bolistis Meyr. 34 bovinella Busck 34 brachyplaca Meyr. 12 brachysaris Meyr. 20 brevisella Walk. 34 brochota Meyr. 20 bryocosma Meyr. 34 bryophanes Meyr. 35 bryoxyla Meyr. 35 burmanniana Stoll 13 butyrota Meyr. 35 byrsinitis Meyr. 35 byssina Zell. 35 byssophanes Meyr. 8 bythitis Meyr. 35 bythochroa Meyr. 12

caecata Meyr. 8 caenochytis Meyr. 35 caesarea Meyr. 35 caesia Meyr. 35 caliginea Meyr. 35 callichlora Meyr. 4 callicoma Meyr. 35 callidora Meyr. 3 callimnestra Meyr. 6 camarina Meyr. 20 camarodes Mleyr. 35 camptospila Meyr. 35 campylodes Meyr. 20 cana Feld. 35 canonias Meyr. 35 cantatrix Meyr. 35 cantharitis Meyr. 20 canusella Chamb. 24 capnobola Meyr. 35 capnocoma Meyr. 35 capnocrossa Meyr. 35 capnosphaera Meyr. 12 caprimulga Walshm. 20 capsiformis Meyr. 35 capsulta Meyr. 20 carabodes Meyr. 36 carabophanes Meyr. 20 carbasea Meyr. 36 carbonifer Busck 12 carphitis Mevr. 20 caryodesma Meyr. 36 caryograpta Meyr. 36 cassigera Meyr. 36 castellana Meyr. 36 catapsecta Meyr. 36 categorica Meyr. 6 catenifer Walshm. 36 cathagnista Meyr. 20 catharactis Meyr. 20 catharmosta Meyr. 36 cathosiota Meyz. 36 caustopis Meyr. 5 ceramoxantha Meyr. 15 cecropia Meyr. 36 cedroxyla Meyr. 21 celidotis Meyr. 21 cenotes Walshm. 21 censoria Meyr. 38 centrodina Meyr. 36 ceratistes Walshm. 21 certiolata Meyr. 36 chalastis Meyr. 21 chalepa Walshm. 36 chalinophanes Meyr. 36 chalybaeella Walk. 36 charitarcha Meyr. 58 
chelohathra Meyr. 21

chersopsamma Meyr. 6 chionogramma Meyr. 36 chionoptila Meyr. 8 chionosphena Meyr. 8 clilosena Meyr. 36 chionodora Meyr. 36 chlorina Kearf. 36 chlorobasis Zell. 3 chloroloba Meyr. 8 chloromis Meyr. 36 chloroplaca Meyr. 36 chlorosticta Moyr. 8 chlorotroti Meyr. 36 chloroxantha Meyr. 36 oholerocrossa Meyr. 37 choleroptila Meyr. 37 christocoma Meyr. 21 chromatopa Meyr. 37 chromolitha Meyr. 37 chromotochna Meyr. 37 chrysampyx Meyr. 4 chrysogastra Meyr. 37 cicadella Sepp 19 cicadella Sepp 21 cinereocervina Walsghm. 5 circographa Meyr. 13 cirrhogramma Meyr. 37 cirrhoxantha Meyr. 37 citrophaea Meyr. 37 citroscia Meyr. 4 citroxantlia Meyr. 37 claripennis Busck 37 claudescens Meyr. 16 clavifera Meyr. 55 cleopatra Meyr. 21 clivosa Meyr, 21 clysmograpla Meyr. 37 cnemosaris Meyr. 37 codicata Meyr: 37 colligats M Teyr. 37 collybista Meyr. 13 colposaris Meyr. 37 columharis Meyr. 37 comma Busck 37 commutata Meyr. 16 comosa Walshn. 37 completella Neyr. 16 complexa M Icyr. 8 compressa Walchm. 37 compsocharis Meyr. 37 compsocoma Meyr. 37 compsographa Meyr. 21 compsoneura Meyr. 37 conchita. Busck 13 confixella Walk. 21 congelata Meyr. 21 condemnatrix Meyr. 37 congressella Walk. 38

congrua Meyr. 38 coniopa Meyr. 38 couiophaea Meyr. 38 consobrina Meyr. 38 consociella Walk. 38 consociella Busck 38 consociella Walk. 38 constituta Meyr. 38 constricta Meyr. 38 contophora Meyr. 38 contortella Walk. 38 conturbatella Walk. 38 contumax Meyr. 58 conveniens Meyr. 38 conversa Meyr. 14 copromima Mey1. 21 cora Busck 12 cora Busck 38 coriodes Meyr'. 21 corvigera Meyr. 21 corvula Meyr. 21 coryliella Chamh. $\overline{5}$ cosmoterma Meyr. 21 costatella Walk. 21 crambina Busck 38 cramhitella Walshm. 38 crassa Meyr. 16 crateroptila Meyr. 8 cremastis Meyr. 38 crepitana Meyr. 39 cretifera Feld. 39 crocoptila Meyr. 39 crocosticta Meyr. 39 crocuta Feld. 39 cryreopis Meyr. 21 crypsangela Meyr. 39 crypsastra Meyr. 39 crypsetaera Meyr. 39 crypsiphaea Meyr. 39 crypsiphragma Meyr. 39 crypsithias Meyr. 39 curiata Meyr. 39 curtipeunis Butl. 39 curviliniella Busck 9 cyanarcha Meyr. 39 cyclobasis Meyr. 21 cycloptila Meyr. 39 cycnographa Meyr. 39 cycnolopha Meyr. 39 cycnomorpha Meyr. 21 cymbalista Meyr. 39 cymogramma Meyr. 39 cynopsis Meyr. 21 cyphoxantha Meyr. 39 cyprodeta Meyr. 21 cystiodes Meyr. 9

dasyneura Meyr. 39 decora. Zell. 39 
decorasella Barnes \& Busck 21 decorosella Busck 21 decorella Barnes \& Busck 21 deflexa Meyr. 9 deflua Meyr. 9 delenita Meyr. 39 delphinodes Meyr. 39 deltomis MLyr. 39 deltopis Meyr 22 demas Busck 39 demotica Walshm. 22 dentella F. 57 deridens Meyr. 22 descitum Walsghm. 13 desecta Meyr. 40 desidiosa Meyl: 40 deuteropa Meyr. 40 diacta Meyr. 40 diametrica Meyr. 40 diatriba Walsghm. 14 dictyogramma Meyl. 40 diffinis Feld. 40 diffracta Meyr. 22 dilinopa Meyr. 40 dimetropis Meyr. 40 diorista Meyr. 9 diplarcha Meyr. 22 diplophaea Meyr. 22 diplosaris Meyr. 40 directrix Meyr. 6 lirempta Zell. 40 discalis Busck 22 discolor Walshm. 22 discors Meyl. 9 discropana Meyr. 40 disjecta Zell. 40 dissimilis Kearf. 22 dissona Meyr. 40 disticha Meyr. 9 distillata Meyr. 40 doleropis Moyr. 40 lorcadopa Meyr. 40 dromica Meyr. 40 dryaula Meyr. 40 dryoconis Meyr. 40 dryocosma Meyr. 40 dryoscia Meyr. 40 dryosphaera MLуц. 9 dryotechna Meyl. 40 dynastis Meyr. 22

ebenocista Meyl. 12 ebria Meyr. 40 effluxa Meyr. 16 claeodes Walshm. 41 elaeostola Meyr. 9 elaeurga Meyr. 41 elasior Feld. 41 elegans Zell. 17 embythia Meyr. 41 eminens Meyr. 41 eminula Meyr. 56 emma Busck 13 emollita Meyr. 22 emphatica Meyr. 41 encyclia Meyr. 22 endochra Meyr. 41 enodata Meyr. 22 entephras Meyr. 41 enumerata Meyr. 41 epicnesta Meyl. 41 epicrossa Meyl. 41 epicta Walshm. 41 epignampta Meyr. 22 epipacta Meyr. 41 episimbla Meyr. 22 epophrysta Meyr. 9 ergates Walshm. 22 oriacma Meyr. 41 erotarcha Meyr. 41 erotica Meyr. 41 Erschoffi Zell. 29 eucoma Meyr. 22 euphanes Meyr. 7 eusema Walsghm. 3 eusticta Meyr. 41 euthrinca Meyr. 22 eva Meyr. 41 evamescens Meyr. 41 exarata Zell. 41 exasperata Meyr. 41 excisa Meyr. 22 exempta Meyr. 41 exhalata Meyr. 41 expansa Mcyr. 41 expilata Meyr. 41 explicita Meyr. 41 extenta Busck 22 extel'nella Walk. 42 exusta Mfeyr. 22

faecosa Feld. 42 fallax Butl. 42 falsidica Meyr. 42 farraria Meyr. 42 fascicularis Zell. 22 fasciatum Busck 22 fastigata Meyr. 42 favillata Meyr. 42 felix Busck 56 fenestra Busck 42 ferculata Meyr. 42 fermentata Meyr. 42 fernaldella Ril. 3 ferrocanella Walk. 42 figularis Meyr. 42 filiferella Walk. 12 finitrix Meyr. 42 
flaviceps Feld. 3

flavicosta Feld. 42

flexibilis Meyr. 42

flocculosa Meyr. 16

fluminata Meyr. 42

forcipata Meyr, 9

Forreri Walshm. 42

fractilinea Walshm. 23

fractinubes Walshm. 42

fragmentella Dogn. 9

fraterna Feld. 42

fraternella Busck 16

frondifer Busck 42

frontalis Zell. 23

fulcrata Meyr. 42

fulminata Meyr. 42

fulta Meyr. 23

funifion Wulshm. 23

fumipennis Busck 23

funerana Sepp 43

funicularis Meyr. 9

furcata Walshm. 23

fusigera $\mathrm{M}$ eyr. 12

fusistrigella Walk. 43

futura Meyr. 43

galeomorpha Meyr. 9

geinellata Meyr. 43

gemina Zell. 9

genotta Fold. 43

generatrix Meyr. 23

geranomorpha Meyr. 6

gerda Busck 13

germinans Mejr. 43

glaciata Meyr. 23

glaphyrodes Meyr. 43

glaucescens Meyr. 43

glaucopa Meyr. 43

glyce rostoma Meyr. 23

grandaeva Zell. 16

grandis Perty 16

graphica Busck 43

graphiphorella Walk. 56

graphopterella Walk. 43

gravescens Moyr. 23

griseuna Zell. 23

griseana Zell. 31

griseana F. 23

griseana Sepp 23

griseanomina Busck 23

gubernatrix Meyr. 23

gubernata Meyr. 43

gymnastis Meyr. 43

gymnolopha Meyr. 23

gypsolitha Meyr. 43

gypsotorma Meyr. 43

gunni Busck 22

habilis Meyr. 43

haemitheia Feld. 4 haesituns Walshm. 23

halmas Meyr. 43

hamon Busck 12

haplocentra Meyr. 23

haplodoxa Meyr. 4

haploxyla Meyr. 43

hapsicora Meyr. 23

harpobathia Meyr. 21

harpoceros Meyr. 43

liebes Dogn. 43

hectosea Meyr. 13

helicias Meyr. 24

helicosema Meyr. 16

lielotypa Meyr. 7

liemibathra Meyr. 24

hemichlora Meyr. 11

Lemilampra Mey1. 43

hemiphanta Meyr. 43

hemiscia Walshm. 24

hemitophras Meyr. 24

herbacea Meyr. 43

herifuga Meyr. 43

herilis Feld. 20

hesmarclia Meyr. 9

heleropa Meyr. 26

heterosaris Meyr. 43

lieterosema Meyr. 43

heteroxantha Meyl. 44

hexascia Meyr. 44

himaea Meyr. 24

himerodes Meyr. 44

holarga Meyr. 7

holcadica Meyr. 44

lolophaea Meyi. 7

homala Walshm. 44

homologa Meyr. 24

Hopfferi Zell. 44

hoplitica Meyr. 44 horizontias Meyr. 14 horocharis Meyr. 44

horocyma Meyr. 44

liorometra Meyr. 44

hospitalis Meyr. 44

humerella Walk. 44

humiferella Walk. 29

humilis 7ell. 24

hyacinthitis Meyl. 44

hyalocryptis Meyr. 44

hyalophanta Meyr. 44

hydraena Meyr. 44

hydrelaeas Meyr. 44

hydrophora Mey1. 24

hypocirrha Meyr. 14

ianthina Walshm. 24

iatma Meyr. 44

ichthyodes Meyr. 9

icteropis Meyl. 44

ignobilis Zell. 44 
illepida Meyr. 24

illita Meyr. 9

illucidclle Walk. 38

imnersa Walshm. 44

imminens Meyr. 44

immota Meyr. 24

immunda Zell. 44

impactella Walk. 45

impedita Meyr. 45

impressella Busck 36

impressella IVIk. 12

impurata Meyr. 45

inardescens Meyr. 4j

incisurella Walk. 20

incitatrix Meyr. 45

incompleta Meyr. 24

incongrua Meyr. 24

incrassata Meyr. 24

indecora Zell. 45

indicatella Walk. 45

infamis Meyr. 7

infecta Meyr. 45

inflata Butl. 45

infrenata Meyr. 45

infusa Merr. 45

inga Busck 13

injucunda Meyr. 45

innexa Mioyr. 45

inopina VIalsghm. 14

inquinula Zell. 24

inscita Meyr. 9

inscitum Busck 9

insidiata Meyr. 45

insimulata Meyr. 24

inspectrix Meyir. 9

intersecta Mevr. 40

inturbatella Walk. 45

invigilans Merr. 45

involucralis Meyr. 45

invulgata Meyr. 45

io Busck 6

iocoma Meyr. 45

ioperena Meyr. 45

iopetra Meyx. 24

ioptila Meyr. 45

iostalacta Meyr. 45

iras Meyr. 24

irascens Meyr. 46

irene Barnes \& Busck 24

irenias Meyi. 46

isabella Fold. 35

isarga Meyr. 17

ischioptila Meyr. 46

ischnoscia Meyr. 46

isochyta Meyr. 46

isographa Meyr. 17

isomeris Meyl: 46

isoplintha Meyr. 46

isosticta Meyl. 46 isotona Meyr. 24 isotrocha Meyr. 4 ithytona Meyr. 24

javarica Butl. 46 jucunda Meyr. 46 juvenalis Meyr. 46

klemanniana Stoll 46

lacera Zell. 46

lacertosa Meyr. 26

lactis Busck 9

laeviuscula Zell. 56

laetifica Busck 46

lampyridella Busck 46

languescens Meyr. 12

lapilella Busck 15

lapidea Meyr. 56

lasia Walsghm. 15

lathiptila Meyi. 24

latipennis Zell. 46

latitans Dogn. 46

lativittella Walk. 30

laudata Meyr. 25

lavata Walshm. 46

laxa MLeyr. 46

lebetias Meyr. 25

lecithaula Mieyr. 25

lembifera Merr. 46

leontodes Moyr. 54

lepidocarpa Iॅeyr. 46

lepidota Meyr. 5

lepisma Walsghm. 15

leprosa Feld. 46

leptobelisca Meyr. 9

leptogma Meyr. 46

leptogramma Meyr. 7

leucactis Meyr. 4

leucana Sepp 46

leucaniella Walk. 47

leucillana Meyr. 25

leucocapna Meyr. 17

leucocryptis Meyr. 47

leucodelta Meyr. 7

leucogramma Meyr. 22

leucomias Meyr. 4

leuconympha Meyr. 4

leucophaella Meyr. 47

leucoplasta Meyr. 9

loucoptila Meyr. 10

leucorectis Meyr. 17

leucosaris Meyr. 47

leucothea Busck 47

lianthes Meyr. 47

libertina Meyr. 47

lichenias Meyr. 10

licmaea Meyr. 47

lignicolor Zell. 25

Lindseyi Barnes \& Busck 25 
liniella Busck 18

linteata Meyr. 14

liquescens Meyr. 6

lithochroma Meyr. 4

lithographa Meyr. 10

lithogypsa Meyr. 47

lithosina Zell. 30

7ithoxesta Mey.1. 49

litura Zell. 47

liturella W1k. 5

lobitarsis Zoll. 8

lophoptycha Meyr. 47

lophosaris Meyr. 47

loxogrammos Zell. 47

loxotoma Meyr. 17

lucidiorolla Walk. 47

lucrosa Meyr. 47

luctifica Zull. 47

lunimaculata Dogn. 25

luscina Zoll. 47

lutulenta Zell. 47

lysalges Walsghm. 13

lysimeris Meyr. 25

machetes Walshm. 25

machinatrix Meyr. 48

macraulax Meyr. 48

macroleuca Meyr. 17

macronota Meyr. 48

macroptycha Meyr. 48

major Busck 17

malachita Meyr. 25

malacoxesta Meyr. 48

manceps Meyr. 48

marcida Butl. 48

marginata Busck 51

marginella Busck 4

marmorea. Feld. 25

maroni Busck 13

mastodos Meyr. 7

maturescens Meyr. 17

megaleuca Meyr. 17

megaspilella Walk. 42

melanarma Mcyr. 25

molanclla Murtf. 5

melanesia Meyr. 48

melanixa Meyr. 48

melanocrypta Meyr. 37

melanometra Meyr. 10

inelanonca Meyr. 10

melanopis Meyr. 48

melema Walsghm. 14

melema Walshm. 38

meligrapta Meyr. 48

melinopa Meyi. 48

melixesta Meyr. 48

mendax Zell. 48

mendoron Busck 10

menestella Walshm. 48 mentigera Meyr. 25

meridiana Meyr. 48

meridogramma Meyr. 48

mesosaris Meyr. 48

mesostrota Meyr. 25

metacymba Meyr. 10

metacystis Meyr. 10

metamochla Meyr. 10

methystica Meyr. 48

metroleuca Meyr. 48

meyeriana Cram. 48

microtypa Meyr. 48

milichodes Meyr. 48

milictis Meyr. 25

minna Busck 12

minor Busck 48

miseta Walshm. 49

mistrella Busck 49

mitratella Busck 25

mniodora Meyr. 49

mochlopa Meyr. 10

modulata Meyr. 49

monastra Meyr. 10

monoclona Meyr. 25

monosaris Meyr. 49

monotonia Strand 17

morbida Zell. 10

mundelka Walk. 49

mundula Meyr. 49

murinella Walk. 49

muscula Zell. 49

mistela Walshm. 49

myopina Zell. 49

myrochroa Meyr. 49

myrodora Meyr. 49

myrrhinopa M̌eyr. 49. mysticopis Meyr. 10

navicularis Meyr. 49

neanica Walshm. 47

neastra Meyr. 49

nebrita Walshm. 49

negotiosa Meyr. 49

neocrossa Meyr. 49

neopercnia Meyr. 49

neoptila Meyr. 49

nephelocyma Meyr. 49

nepheloleuca Meyr. 50

nerteropa Meyr. 25

nestes Busck 10

neurocentra Meyr. 50

neurographa Meyr. 25

neurotona Meyr. 25

nictitans Zell. 25

nigricans Busck 50

nimbata Meyr. 26

nimbosa Zell. 12

niphacma Meyr. 50

niphochlaena Meyr. 10 
nitens Butl. 50

nitescens Meyr. 26

nitidorella Butl. 50

nitrota Meyr. 26

niviliturella Walk. 50

nonagriella Walk. 50

notifera Mcyr. 50

notogramma Meyr. 50

notosaris Meyr. 50

notosomia Zell. 50

novorca Meyr. 10

nubeculosa Zell. 24

nubilella Möschl. 18

nuclearis Möschl. 26

nuntia Meyr. 50

nycteropa Meyr. 50

nymphas Moyr. 50

nymphotima Meyr. 50

obclodes Meyr. 32

oblita Butl. 50

oblongata Walsghm. 4

obnubila Busck 15

obnupta Meyr. 10

obmutescens Meyr. 50

obovata Meyr. 50

obsordescens Meyr. 14

obtusa Meyr. 50

obydella Fcld. 50

oceanitis Mfeyr. 50

ocollata Busck 15

ocellea Forbos 50

ocellifer Walshm. 26

ochlodes Walshm. 51

ochricollis Zell. 51

ochricostata Zell. 5

ochrocrossa Meyr. 7

ochropa Walshm. 51

ochrosaris Meyr. 51

ochrothicata Meyr. 51

octacentra Meyr. 51

oenodes Moyr. 14

ogmolopha Meyr. 51

ogmosaris MLyr. 51

ommatopa Moyr. 10

omphacopa Meyr. 51

ophiopa Meyr. 10

ophrysta Moyr. 51

orgadopa Meyr. 51

orion Busck 10

orlloopis Meyr. 51

orthocapna Meyr. 51

orthographa Meyr. 51

ortholampra Meyr. 51

orthopa Meyr. 51

orthophaea Meyr. 26

orthotona Meyr. 26

orthozona Meyr. 7

orthridia Meyr. 12 orthriopa Meyr. 26

osseolla Walshm. 26

ostodes Walslim. 51

ovatella Walk. 26

ovulifera Meyr. 51

oxycentra Meyr. 26

oxydecta Meyr. 26

oxyplaca Meyr. 10

oxyschista Meyr. 51

oxyscia Meyr. 51

pacatun Walsghm. 14

pactota Meyr. 26

palaestrias Meyr. 26

palliata Meyr. 12

palliata Walsghm. 12

pallicosta Feld. 51

pallullella Busck 26

palpalis Zell. 17

pantogenes Meyr. 51

paracapna Meyr. 51

paracrypta Meyr. 26

paracta MLeyr. 51

paradromis Meyr. 10

paramochla Meyr. 46

paraplecta Moyr. 51

parastis Klunder 26

pardalodes Meyı. 52

paropta Meyr. 51

particularis Zell. 52

parvella F. 14

patellifera Meyr. 52

patens Meyr. 52

patula Meyr. 52

pauperatella Wlk. 11

paurocentra Meyr. 52

pauroconis Meyr. 52

peccans Butl. 52

pelinitis Meyr. 52

pelodes Walshm. 61

pellocoma Meyr. 26

percnocarpa Meyr. 52

percnogona Meyr. 26

perducta Meyr. 10

perfusa Meyl. 26

poriapta Walsghm. 15

periaula Meyr. 52

poridesma Meyr. 52

periphrictis Meys. 52

perirrhoa Meyr. 52

periscelta Meyr. 52

perjccta Meyr. 52

perjura Meyr. 52

peronia Busck 52

perophora Meyr. 52

persita Meyr. 52

pertinax Meyr. 52

petrina Walshm. 38

phaeomystis Meyr. 52 
phaeoneura Meyr. 52

phaeophanes Meyr. 52 phaeoplintha Meyr. 52 phaeosaris Meyr. 26 phalacropa Meyr. 52 phaseolodes Méyr. 52 phaula Talshm. 53 philomela Meyr. 17 phocbe Busck 27 phoenissa Butl. 53 pliollicodes Meyr. 53 phortax Meyr. 53 phryactis Meyr. 26 phyllocosma Meyr. 53 phylloxantha Meyr. 53 physotricha Meyr. 53 phytoptera Busck 10 picrantis Meyr. 53 picta Zell. 53 plagosa Zell. 26 planicoma Moyr. 53 platycolpa Meyr. 53 platydesma Meyr. 27 platyphylla Moyr. 53 platyspora Meyr. 10 platyterma Meyr. 53 plebicola Meyr. 53 pleonastos Meyr. 53 plerotis Meyr. 27 plesistia Meyr. 53 pleurotricha Meyr. 53 pleximorpha Meyr. 53 plocogramma Meyr. 11 plumosa Busck 27 plurima Walshm. 53 poliopa Meyr. 11 polyglypta Meyr. 53 pompeiana Meyr. 17 ponderata Mcyr. 11 porinodes Meyr. 53 porphyrastis Meyr. 53 portentosa Busck 15 praecauta Meyr. 50 praeceps Meyr. 32 praecisa Meyr, 27 praenubila Meyr. 11 praorupta Meyr. 22 prasoleuca Meyr. 12 prasoleuea Meyr. 11 pratifora Meyl. 53 procritica Meyr. 53 projecta Meyr. 53 promotella Zell. 16 promotella Zell. 54 prosora Walshm. 54 protosaris Meyr. 27 prudentula Meyr. 11 psalmographa Meyr. 54 pseudacma Meyr. 13 pseudochyta Meyr. 27 psilomorpha Meyr. 54 ptilallactis Meyr. 54 ptilocrates Meyr. 27 ptilopa Meyr. 11 ptilosema Meyr. 12 ptychobathra Meyr. 54 ptychocentra Meyr. 54 ptychophthalma Meyr. 54 phycta Walshm. 27 pumilis Busck 27 punicea Meyr. 54 purulenta Zell. 27 pustulatella Walk. 54 py ramidea Walshm. 54 pyrenodes Meyr. 54 pyrgota Meyr. 54 pyrobathra Meyr. 54 pyrrhias Meyr. 54 pyrrhonota Meyr. 54 pythonaea Meyr. 23 quadratella Wralshm. 43 quadratella Walk. 54 quatiens Meyr. 27 querciella Busek 27 quiescens Meyr. 54 radicalis Zell. 27 radicicola Meyr. 27 raricilia Meyr. 27 receptella Walk. 54 reciprocella Walk. 27 recondita Meyr. 54 rectificata Meyr. 54 recurrens Meyr. 54 recurvella Wik. 13 redintegrata Meyr. 54 reductella Walk. 27 refractrix Meyr. 27 regesta Meyr. 54 relata Meyr. 54 remorsa Meyr. 55 renselariana Stoll 27 reprehensa Meyr. 28 residuella Zell. 55 resiliens Meyr. 28 rhipidaula Meyr. 55 rhodanthes Meyr. 18 rhodocolpa Meyr. 55 rhomaeopa Meyr. 11 rhothiodes Meyr. 55 Ribbei Zell. 28 rita Busck 36 robiginosa Meyr. 55 rosa Busck 55 rosacea Butler 55 rostriformis Meyr. 55 rubiginosella Walk. 55 rufispinis Meyr. 11 
sacra Meyr. 60 sagax Busck 55 salome Busck 55 salubris Meyr. 55 salutaris Butl. 13 sana Meyr. 28 sarcinata Meyr. 28 sardania Meyr. 28 satelles Meyr. 55 satyropa Meyr. 55 scapularis Meyr. 55 sceptrifera Meyr. 55 Schlaegeri Zell. 28 sciaphilina Zell. 55 sciocnesta Meyr. 55 sciogama Meyr. 55 sciophthalma Meyr, 56 sciospila Meyr. 56 scitiorella Walk. 56 scoliandra Moyr. 56 scolopacina Walshm. 56 scoriodes Meyr. 56 scortea Meyr. 56 scutellata Meyr. 11 secundata Meyr. 56 seducta Meyr. 56 segmentata Meyr. 56 sellifera Meyr. 28 sematopa Meyr. 56 semicinerea Zell. 28 seminigrescens Meyr. 18 semiovata Meyr. 28 semisiquella Walk. 56 semocrossa Meyr. 8 seppiana Cram. 56 sequestra Meyr. 56 serangodes Meyr. 28 serarcha Meyr. 28 sericata Butl. 56 sesquitertia Zell. 56 sexmaculata Dogn. 17 similis Busck 28 simplex Busck 56 sinuata F. 57 siraphora Meyi. 57 smileuta Meyr. 28 smodicopa Meyr. 11 sommorella Zell. 57 sororia Zell. 61 sortifera Meyr. 28 sparganota Meyr. 28 spectrophthalma Meyr. 57 sperata Busck 32 spermidias Meyr. 57 spermolitha Meyr. 28 sphragidopis Meyr. 57 spodinopis Meyr. 57 spurca Zell. 29 squamosa Walshm. 18

stabilis Butl. 57

stagnicolor Moyr. 11

staudingerana Maassen 17

staurota Meyr. 29

stella Busck 14

steloglypta Meyr. 11

stenobathra Meyr. 29

stenota Walsghm. 15

stephanodes Meyr. 57

sterrhomitra Meyr. 57

stigmatias Walshin. 57

stomatocosma Moyr. 17

strabonia Meyr. 11

straminella Walk. 57

strenuella Walk. 57

striatella Busck 57

strigivenata Butl. 57

stringens Meyr. 29

striolata Meyr. 57

strophalodes Meyr. 57

stupefucta Meyr. 57

stygeropa Meyr. 57 stylonota Meyr. 57 suavis Meyr. 7

subdulcis Meyr. 57

subita Meyr. 57

sublimbata Zell. 57

sublunaris Meyr. 58

submersa Meyr. 58

subnotatella Walk. tis

subovalis Meyr. 58

substricta Mcyr. 29

subversa Walsghm. 14

suffumigata IValshm. 58

superciliosa Meyr. 29

suppressella Walk. 24

surinamella Möschl. 38

sustentata Meyr. 58

symmictu Walshm. 58

symphonica Meyr. 58

symposias Meyr. 14

syndicastis Meyr. 58

synedra Meyr. 11

synercta Meyr. 29

syngraphopis Meyr. 58

tabida Butl. 58

tanysta Meyr. 29

tectellu Walk. 45

tectoria Meyr. 58

teleosema Meyr. 29

tempestiva Meyr. 58

tenera Zell. 47

tephrodesma Meyr. 58

tetrabola Meyr. 58

tetragonella Walk. 35

tetrapetra Meyr. 58

thalamobathra Meyr. 29 
tialeropa Meyr. 58

Thammi Zell. 29

thapsinopa Meyr. 29

theobromae Busck 15

theoretica Meyr. 29

thesmophora Meyr. 29

thespia Meyr. 58

tholodes Meyr. 58

thologramma Meyr. 55

Thomasi Barnes \& Busck 29

thoristes Busck 58

thylncandra Meyr. 45

thylacosaris Meyr. 58

thymiola Meyr. 51

thysanodes Meyr. 58

tibialis Zell. 29

tinactis Meyr. 58

tinctipennis Butl. 59

tolmeta Walshm. 59

tornogramma Meyr..29

torophragma Meyr. 55

tortricella Chamb. 30

tortricella Wlk. 13

tortriciformellu Clem. is

tractrix Meyr. 29

trastices Buscli 11

tremulella Walk. 59

triacmopa Meyr. 59

tribomias Meyr. 59

tricapsis Meyr. 59

tricharacta Meyr. 59

trichocolpa Meyr. 59

trichoneura Meyr. 59

triclonota Meyr. 29

trichorda Meyr. 59

tridesma Meyi. 13

trilineata Butl. 59

triplectra Meyr. 59

triplintha Meyr. 29

tripustulata Zoll. 59

tripustulella Walk. 59

trirecta Meyr. 59

trisecta Wralshm. 29

trisinuata Meyr. 29

tristrigata Zell. 17

tritogramma Meyr. 30

tritypa Meyr. 11

trivallata Meyr. 30

trizeucta Meyr. 11

trochilosticta Walshm. 59

trochistis Meyr. 3S

trochoscia Meyr. 30

truncatula Meyr. 11

trymalopa Meyr. 59

tryphon Busck 59

tumens Meyr. 59

tumulata Meyr. 59

tyrocrossa Meyr. 59

tyroxesta Meyr. 59 ulosema Meyr. 59

umbratella Meyr. 30

umbriferella Walk. 59

umbrinervis Meyr. 59

uncticoma Meyr. 59

unguentata Meyr. 59

ungulifera Meyr. 11

unipunctella Clem. 30

unisecta Meyr. 59

unisignis Meyr. 60

u ranophanes Meyr. 60

urbana Busck 60

uruguayensis Berg 60

vacans Meyr. 60

vacata Meys: 30

vaccula Walshm. 60

vaga Butl. 60

vanis Busck 12

vannifera Meyr. 60

vapidla Butl. 60

vasifera Meyr. 60

venatum Busck 60

venosella Walk. 60

ventilatrix Meyr. 60

vestalis Zell. 30

vexata Meyr. 60

vinifera Meyr. 60

virens $\mathrm{M}$ Tevr. 30

virginalis Butl. 47

viridis Busck 30

vita Busck 60

vita Meyr. 36

vitrea Meyr. 7

vitreola Meyr. 60

vivax Busck 60

vividella Busck 11

volitans Meyr. 60

walchiana Stoll 30

walchiana Zell. 23

walchiana Zell. 30

xanthobasis Zell. 4

xanthobyrsa Meyr. 60

xanthopetala Meyr. 60

xanthophaeella Walk. 60

xanthoptila MLeyr. 30

xanthosoma Dogn. 60

xuthosaris Meyr. 30

xylinaspis Meyr. 11

xylinopa Meyr. 60

xylocosma Meyr. 30

:ylograpta Meyr. 60

xylurga Meyr. 61

zanclogramma Meyr. 61

Zelleri Walshm. \& Durr. 30

zelotes Walshm. 31

zephyritis Meyr. 61

zobeida Meyr. 61 



\section{W. JUNK, Verlag und Antiquariat für Entomologie 's-Gravenhage}

P'ars 35, 37, 39: F. Bryk, Papilionidae. 1929-1930. 675 p.

36: H. Yenstetter, Heliconiidae. 1929. 136 p.

38, 40, 41. 44: H. Stichel, Riodinidae 1930-1931. $795 \mathrm{p}$.

42: F. Bryk, Dioptidae. 1930. 65 p.

43, 46, 48: M. fanede, Satyridac. 1931. $759 \mathrm{p}$.

47, 64: I. H. Shepmrd, Hesperidae: Subfam. Pyrginae I-II.

1931- -1934. $272 \mathrm{p}$

19: M. finede, Drepanidac. 1981. $60 \mathrm{p}$.

50: H. Faedp, Mimallonitae. 1931. $21 \mathrm{p}$.

51: H. Stiehel, Brassolidae. 19:32. $115 \mathrm{p}$.

52: M. finede, Aganaidac. 1932. $39 \mathrm{p}$.

53, 60: G. 'Tallot, Pieridae I, II. 1932-1934. 384 p.

54: H. Stichel, Amathusiidae [incl. Discophoridac et Hyantidae]. 1933. $171 \mathrm{p}$.

55, 56, 58, 65: II. Schiissler, Satu1nuidne. 1932 -1934. 769 p.

57: H. H. Shepard, Hesperidac: Subfan. Ismeninate 1933. $55 \mathrm{p}$.

59: М. Ficde, Notodontilae. 1934. $351 \mathrm{p}$.

61, 63: L. B. P'rout, Geometridae:Subfam. Sterrhinae [-11.1934.432 p.

62: F. Bryk, Lymantriidae. 1934. 441 p.

64: H. H. Shepard, Hesperidae: Subfam. Pyrginae II.

Im Druck:

66: f. Tabot, Pieridae III (ultima pars).

68: L. B. Prout, Geometridae: Subfam. Sterrhinae III (ultima pars).

69: H. H. Shepard, Hesperidre: Subfam. Pyrginae III.

70: H. Schiissler, Srssphingidae, Oxỵtenidae, Cercophanidae.

71: F. Bryk, Zygnenidae (excl. Zyganena species palacaret.).

In Vorberertung:

F. Bryk, Danaididae.

W. A. Collier, Lasiocampidae.

J. Drneseke, Lycaenidae.

M. Gaede, Pyralididae, ,Timeoidea":
1. Incurvariidac
5. Opostegidae
9. Momphidae
2. Tischeriidae
6. Tineidac
10. Elachistidae
3. Heliozelidae
7. Gelechiidae
11. Cosmopterygidae
4. Nepticulidae
8. Coleophoridae
12. Lyonetiidae
13. Cemiostomidae.

H. Schiissler, Eupterotidac, Thaunetopoeidue, Bombycidae, Endromiidae, Norplidae.

H. H. Shepari, Hesperidae [Continnation].

H. Stichel, Nymphalinae, Apaturinae.

E. Strand, Noetuidae. 
Soeben erschien Lieferung 3 von

\section{Animalium CavernarumCaralogus}

Cafalog der

Höhlen-Fauna
Cafalogue of the

fauna of the caves
Cafalogue de la

faune cavernicole

Herausgegeben von der

\section{Gesellschaft für Höhlenforschung und Höhlenkunde zu Berlin.}

Bearbeitet ron

\section{Dr. Benno Wolf}

Vorstand des Haupt-Verbandes Deutseher Höhlenforscher.

Dicse Arbeit enthält die Aufstellung der gesamten lebenden Tierwelt in Höhlen, deren Größe dem Mensehen den Zutritt ermöglicht. - Die Fauna der Miero-Cavernen (wie Maulwurfsnester ete.) und die der Erdspalten, sowie die Quellenfauna sind also nicht mitberüeksichtigt. - Das Werk behandelt nicht nur die Tierwelt, die nur i، Höhlen vorkommt und sich dem Höhlenleben besonders angepaßt hat, sondern die Gesamtheit derjenigen in Höhlen vorkommenden Tiere, von denen naehgewiesen ist, daß sie in einer irgendwie gearteten biologischen Beziehung zu den Höhlen stehen. Ausgeschlossen sind nur solehe Tiere, von denen ganz offenbar ist, $\mathrm{daß}$ es an soleher biologischen Beziehung fehlt.

Die Einteilung des Werkes ist so übersichtlieh getroffen, daß der Benutzer des Wérkes stets sofort die von ihm gewünsehte Literatur über die Höhlen und deren Fauna findet:

1. Hinweis auf die Herkunft der Höhlentierwelt, ihre Lebensbedingungen und ihre Anpassung an das Höhlenleben.

2. Dic gesante Höhlenfauna-Literatur (in Werken und Zeitsehriften).

3. Die Höhlen geographiseh geordnet (also nach Erdteilen, Ländern ete.) soweit ein Vorkommen lebender Tiere in der Literatur bekannt ist. - Angabe der auf jede einzelne Höhle sieh beziehenden Literatur in faunistiseh-geordneter Übersicht.

4. Die Tierwelt systematisch und geographisch naeh Fundorten (Höhlen) geordnet.

5. Register der Tiernamen (Synonyme besonders gekennzeiehnet).

Der Umfang des $\mathbb{W e r k e s}$ ist auf etwa $70-80$ Bogen zu je 16 Seiten geschätzt. Es erscheint in Lieferungen zu je 8 Druckbogen und soll auf den Zeit-Raum von 3-4 Jahren verteilt werden.

Der Subscriptions-Preis für Bezieher des ganzen Werkes ist pro Bogen etwa M. 1,65 $(=$ holländ. Fl. 1.-) bezw. für jeden Teil (statt M. 18. - = holländ. FI. 10.60) M. 13,50 = holländ. F1. 8.-.

Bitte ausführlichen Prospekt umgehend zu verlangen.

W. Junk, 's-Gravenhage, Scheveningsche Weg 74 .

Druck von Gustav Feller, Neubrandenburg. 